2. To: (Receiving Organization)

Distribution

5. Proj./Prog./Dept./Div.:

8. Originator Remarks:

For Approval/Release

11. Receiver Remarks:
3. From: (Originating Organization)

RPP Vadose Zone Project

6. Design Authority/Design Agent/Cog. Engr.
4. Related EDT No:

$\mathrm{N} / \mathrm{A}$

7. Purchase Order No:

$\mathrm{N} / \mathrm{A}$

9. Equip./Component No.:

$\mathrm{N} / \mathrm{A}$

10. System/Bldg./Facility:

200E/BY Tank Farm

12. Major Assm. Dwg. No.:

$\mathrm{N} / \mathrm{A}$

13. Permit/Permit Application No.:

$\mathrm{N} / \mathrm{A}$

14. Required Response Date:

$$
\mathrm{N} / \mathrm{A}
$$

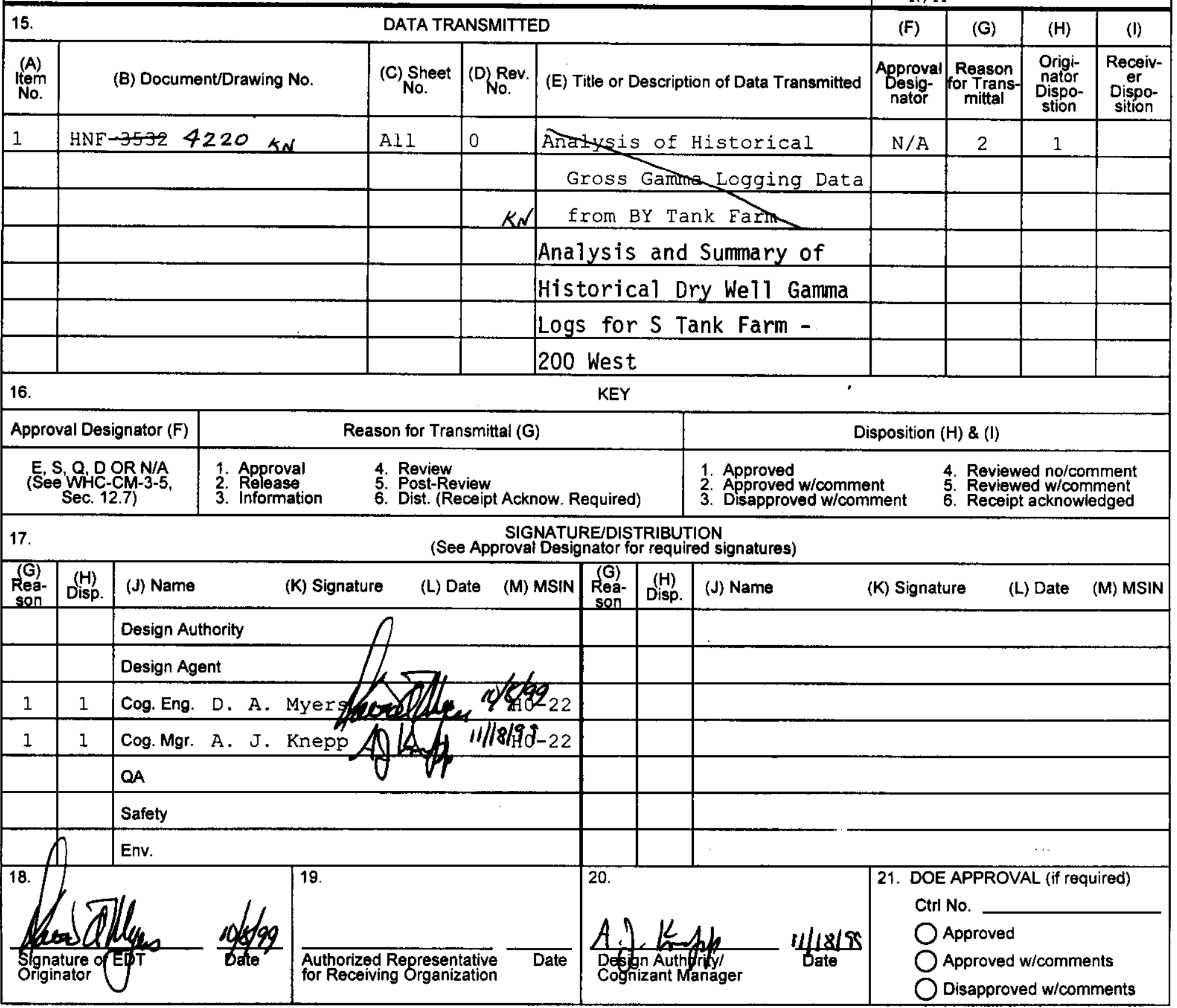


HNF-4220, Rev. 0

\subsection{Data Analysis Description}

Data from the dry well logs are compiled through a number of iterations generating a data set that reveals any trend present. This process does not add or delete data, but merely compiles them into a useful, uncompromised data set. This data set is used to create a depth vs. time plot, or stack plot, to identify trends and zones of contamination. All historical log surveys for one dry well (borehole) are analyzed as a whole for each radioactive zone above background in a well, thus allowing statements to be made about the apparent condition or rate of change of any given radioactive interval. For darity of presentation, all logs are not plotted, but a specific frequency selection (i.e., quarterty) is used to render the stack plot readable without affecting the integrity of the data.

Review of the historical gross gamma ray data revealed that limits in the system design for collecting data prior to 1983 created a situation where the zero point for the start of data collecting was inconsistent, as discussed in the Analysis Techniques report (Randall and Price, 1998). This difference in zero point makes evaluating trends in the data difficult. Several methods can be employed to overcome varying zero points and to essentially create a common starting point from which to view the data, making trend identification easier. One method applies a depth shift to the data, which is simply adjusting data up or down so that certain identifiable features in the logs can be aligned and evaluated. No depth shifting was applied to the data for the S farm.

A second method utilizes a calculation called the grade thickness product (GIP) which can be applied over a depth interval wide enough to indude all variances in depth so as not to require depth shifting. It is a summation of the values of logging instrument readings over the depth interval of interest minus background activity and times the distance between sample point depths, yielding a constant that is independent of the specific starting point. When the calculation is applied over the entire interval, the result is a more acourate representation of the condition of the zone over time.

Gross gamma ray log surveys were recorded over the length of the borehole at sampling intervals of one foot. Differences in the zero-depth reference point cause variations in the maximum count rate for thin radioactive zones. The GIP calculation is used to eliminate this variable sampling effect on the overall net change for a given zone. The average background activity of naturally occurring potassium, uranium, and thorium is obtained from review of the data for each survey and provides a level of confidence that the instrumentation worked consistently and that the gross gamma ray data are valid. The percentage of data values for each survey that are considered as representing a natural background formation response is calaulated; and this parameter is defined as "frequency dean". The average background activity value is caloulated for all survey depth samples between a lower and upper count rate limit. The lower count rate limit is generally set at zero (0) c/s; a value defined as indicating a data gap. The upper count rate limit is generally set at $50 \mathrm{c} / \mathrm{s}$ for probe type 04 (NaI), a conservative value near what is considered background activity, yet one fourth of the count rate considered reportable by the leak detection program.

\footnotetext{
Note: Gross gamma ray dato were collected using a variety of probe types. The values generated by these probe types do not directly correlate, as discassed in the Analysis Techniques report (Randall and Price, 1998). Caution must therefore be used when relating GIP values in zones recorded with different probe types (e.g., the NaI probe type 04 does not record values that relate to those recorded with the Green or Red GM probe types 01 and 02). Scaling factors between the different probe types are presented in "Dry Well Probe Calibrations" (Randall, 1999).
}

Zones where contamination is identified are examined using the GTP calculation. The average background activity is subtracted so that only the contaminated levels above background are induded in the analysis. A graph is generated with GTP plotted against time for each depth interval analyzed. One or more decay lines are then overlaid on the graph based on isotopes identified by the SGLS data, knowledge of tank constituents, and the known presence of isotopes in other boreholes. Sometimes decay lines can be fit through the data a number of ways with none of them fitting perfectly. When two 
or more isotopes are identified, a least squares fit analysis for a multi-component decay is performed. A detailed discussion for how this is accomplished is in the Appendix to the Data Analysis Results for the BX Single Shell Tank Farm Dry Well Gross Gamma Ray Surveillance Log Surveys (WMNW, 1998). Garmmaemitting isotopes that are known to exist in the inventory of the tank farm, or are identified in nearby wells, may not be identified by the SGLS due to being at or below detection levels. Such isotopes are typothesized to have been present and are induded in the least squares fit analysis. The decay rates for each of the components are held fixed in the fitting process and the relative intensities of the components are calculated and reported in the data analysis when appropriate. The relative contribution of gross gamma rays from one component to another depends on the nature of the isotopes and the detector design.

Note: Sparious data were generated during normal data collecting adivities. Spurious zero values are called data gaps and are considered as unrealistically low natural background activity when reconded with the sodium-iodide probes. Between 1975 and 1982, the equipment would cocasionally record a spurious data value of minus one $(-1)$ or zero (0). A value of minus one represents an invalid count rate. Data gaps occur at various locations in the surveys, induding in the background or in the middle of a high contamination zone within a borehole. Data gaps are not inchuded in the calcusation of average background, grade thickesss product, or frequency dean values.

Comparing the GTP data and the decay line(s) reveals information about the rate of change of contamination within a zone over the period that data were collected. When appropriate, multiple plots are generated to show the results for different zones within a borehole. The details for the use of GIP are covered in the Analysis Tectniques report (Randall and Price, 1998).

The objective of the analysis is to assure that a consistent and thorough examination of dry well surveillance logs is performed, and that contamination did not abruptly enter the borehole survey region and quickly migrate out. Al surveys within the time interval analyzed are examined so that no unusual problems or conditions remain as undetected. Table 1 contains a list of the dry wells located in the $S$ Tank Fam as well as information concerning the identity, level, and depth of contamination. In order to demonstrate a spatial relationship to the subsurface contamination, several maps depicting tank and data point locations are provided, (figures $2,4,5, \& 6$ ).

Certain limitations in the data available for analysis make evaluation less complete. Some of the limitations are as follows:

- Inability to identify when down-hole contamination is a result of vadose zone transport or drag down during casing installation

- Insufficient gross gamma ray data to establish a statistical trend or rigorous statistical analysis

- Lack of HPGe data

- Incomplete time interval over which data are available

- Inability to observe below borehole bottom

- Inability to identify isotopes that have decayed to levels below the detection limits of the SGLS. 
HNF-4220, Rev. 0

Table 1. S Tank Farm Zones

\begin{tabular}{|c|c|c|c|c|c|c|c|c|}
\hline $\begin{array}{l}\text { Borehole } \\
\text { Number }\end{array}$ & $\begin{array}{c}\text { Survey } \\
\text { Depth } \\
\text { (feet) }\end{array}$ & \begin{tabular}{c|c|} 
Number \\
of Surveys
\end{tabular} & $\begin{array}{l}\text { Probe } \\
\text { Type }\end{array}$ & Categor & $\begin{array}{l}\text { Zone } \\
\text { Depth } \\
\text { (feet) }\end{array}$ & $\underset{\mathbf{G I P}}{\operatorname{Max}}$ & $\begin{array}{l}\text { Year } \\
\text { Max GTP }\end{array}$ & $\begin{array}{l}\text { Isotopes } \\
\text { Present }\end{array}$ \\
\hline $40-00-02$ & 140 & 121 & 4 & Dean & - & & & - \\
\hline $40-00-04$ & 140 & 274 & 4 & "TF Activity & $0-8$ & 200 & 1987 & ${ }^{4} \mathrm{Cs}^{137}$ \\
\hline $40-00-06$ & 150 & 435 & 4 & Clean & - & -1 & & - \\
\hline $40-01-01$ & 130 & 869 & 4 & dean & - & & & - \\
\hline $40-01-04$ & 100 & 872 & 4 & TF Activity & $0-8$ & 50 & 1986 & $\mathrm{CS}^{137}$ \\
\hline $40-01-06$ & 100 & 889 & 4 & TF Activity & $0-8$ & 75 & 1986 & $\mathrm{Cs}^{137}$ \\
\hline $40-01-08$ & 105 & 825 & 4 & Tf Activity & $0-12$ & 70,000 & 1985 & $\mathrm{CS}^{137} ; \mathrm{CO}^{60} ; \mathrm{Eu}^{151}$ \\
\hline $40-01-10$ & 100 & 605 & 4 & TF Activity & $0-8$ & 30 & 1986 & $\mathrm{Cs}^{137}$ \\
\hline $40-02-01$ & 132 & 816 & 4 & doan & - & & & - \\
\hline \multirow[t]{2}{*}{$40-02-03$} & 100 & 292 & 2 & Undetermined & $17-32$ & $2,500^{\circ}$ & 1980 & $\mathrm{CS}^{137}$ \\
\hline & & 40 & 4 & Undetermined & $50-60$ & 200 & 1980 & $\mathrm{Cs}^{137}$ \\
\hline $40-02-04$ & 150 & 395 & 4 & If Activity & $0-12$ & 2,500 & 1985 & $\mathrm{Cs}^{13 \%}$ \\
\hline $40-02-05$ & 100 & 891 & 4. & Clean & - & & - & - \\
\hline $40-02-07$ & 100 & 885 & 4 & If Activity & $0-5$ & 50 & 1986 & $\mathrm{Cs}^{137}$ \\
\hline \multirow[t]{3}{*}{$40-02-08$} & 100 & 452 & 4 & TF Activity & $0-7$ & 300 & 1986 & $\mathrm{CS}^{133} ; \mathrm{CO}^{60}$ \\
\hline & & & & "Stable & $10-30$ & 200 & 1975 & $\operatorname{cs}^{13} ; \cos ^{\circ 0}$ \\
\hline & & & & Stable & $49-58$ & 75 & 1975 & $\mathrm{Cs}^{139}$ \\
\hline $40-02-10$ & 100 & 798 & 4 & Clean & - & -1 & 1 & - \\
\hline $40-02-11$ & 100 & 539 & 4 & Clean & - & & $=$ & - \\
\hline $40-03-01$ & 100 & 662 & 4 & Clean & $=$ & & & - \\
\hline $40-03-03$ & 130 & 712 & 4 & clean & - & - & $=$ & - \\
\hline $40-03-05$ & 150 & 451 & 4 & dean & - & - & 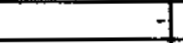 & - \\
\hline $40-03-06$ & 100 & 790 & 4) & Clean & - & & & - \\
\hline $40-03-08$ & 100 & 602 & 4 & Clean & - & & & - \\
\hline \multirow[t]{3}{*}{$40-03-09$} & 132 & 852 & 4 & If Activity & $0-10$ & 600 & 1986 & $\mathrm{Cs}^{137} ; \mathrm{CO}^{\infty}$ \\
\hline & & & & Stable & $15-40$ & 800 & 1975 & $\mathrm{Co}^{60} ; \mathrm{Ru}^{106}$ \\
\hline & & & & "Stable & $125-132$ & 80 & 1985 & $\mathrm{Cs}^{137}$ \\
\hline $40-03-11$ & 100 & 593 & 4 & Clean & - & - & -1 & - \\
\hline $40-04-01$ & 100 & 325 & 4 & Clean & - & & & - \\
\hline $40-04-05$ & 140 & 121 & 2 & Stable & $35-55$ & $500^{\circ}$ & 1980 & $\mathrm{Cs}^{13 \mathrm{~T}}$ \\
\hline $40-04-07$ & 100 & 314 & 4 & Cean & - & & -1 & - \\
\hline \multirow[t]{3}{*}{$40-04-08$} & 100 & 313 & 4 & "Stable & $0-7$ & 200 & 1986 & $\operatorname{cs}^{137}$ \\
\hline & & & & 'stable & $7-11$ & 400 & 1984 & $\mathrm{Cs}^{13 T}$ \\
\hline & & & & "Stable & $11-28$ & 180 & 1985 & $\mathrm{CS}^{137}$ \\
\hline \multirow[t]{2}{*}{$40-05-03$} & 100 & 706 & 4 & IF Activity & $0-10$ & 30 & 1986 & $\mathrm{CS}^{137}$ \\
\hline & & & & Undetermined & $28-41$ & 50 & 1975 & $\mathrm{Sr}^{80}$ \\
\hline $40-05-05$ & 150 & 410 & 4 & dean & - & & & - \\
\hline $40-05-07$ & 100 & 764 & 4 & Clean & - & & & - \\
\hline $40-05-08$ & 100 & 491 & 4 & Clean & - & & & - \\
\hline 40-05-10 & 90 & 754 & 4 & Clean & - & & & - \\
\hline $40-06-02$ & 100 & 881 & 4 & Clean & - & & & - \\
\hline $40-06-04$ & 125 & 707 & 4 & Clean & - & & & - \\
\hline $40-06-05$ & 140 & 293 & 4 & Clean & - & & & - \\
\hline $40-06-06$ & 97 & 879 & 4 & dean & - & & & $=$ \\
\hline $40-0608$ & 97 & 800 & 4 & Cean & - & & & \\
\hline $40-06-09$ & 100 & 858 & 4 & dean & - & & & - \\
\hline $40-07-01$ & 100 & 870 & 4 & Cean & - & & & $=$ \\
\hline $40-07-04$ & 102 & 874 & 4 & Clean & $=$ & & & - \\
\hline $40-07-06$ & 98 & 579 & 4 & Cean & - & & & - \\
\hline $40-07-08$ & 100 & 606 & 4 & TF Activity & $0-10$ & 100 & 1986 & $\mathrm{Cs}^{137}$ \\
\hline $40-07-10$ & 100 & 884 & 4 & TF Activity & $0-12$ & 90 & 1986 & $\mathrm{CS}^{137}$ \\
\hline $40-07-11$ & 98 & 589 & 4 & TF Adtivity & $0-20$ & 210 & 1986 & $\mathrm{CS}^{137}$ \\
\hline $40-08-01$ & 97 & 459 & 4 & Clean & - & 1 & & - \\
\hline $40-08-06$ & 100 & 878 & 4 & TF Activity & $0-7$ & 80 & 1986 & $\mathrm{Cs}^{137}$ \\
\hline
\end{tabular}




\begin{tabular}{|c|c|c|c|c|c|c|c|c|}
\hline $40-08-08$ & 100 & 806 & 4 & Clean & - & 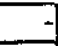 & - & - \\
\hline 40-08-09 & 100 & 872 & 4 & Clean & - & 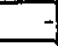 & 7 & - \\
\hline $40-08-12$ & 125 & 430 & 4 & Clean & - & $=$ & - & - \\
\hline 40-09-01 & 97 & 526 & 4 & Clean & - & - & - & - \\
\hline $40-09-02$ & 100 & 872 & 4 & Cean & - & - & 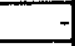 & - \\
\hline 40-09-05 & 145 & 430 & 4 & Cean & - & $=$ & 4 & - \\
\hline $40-09-06$ & 100 & 894 & 4 & Clean & $=$ & - & - & - \\
\hline $40-09-08$ & 100 & 825 & 4 & Cean & - & $=$ & - & - \\
\hline 40-09-09 & 140 & 911 & 4 & Clean & $=$ & - & - & - \\
\hline $40-10-01$ & 150 & 426 & 4 & Stable & $36-54$ & 350 & 1975 & $\mathrm{Cs}^{137}$ \\
\hline $40-10-03$ & 98 & 884 & 4 & Clean & - & - & - & - \\
\hline $40-10-05$ & 100 & 539 & 4 & Clean & $=$ & $=$ & - & $=$ \\
\hline $40-10-06$ & 145 & 892 & 4 & Clean & - & $=$ & 7 & - \\
\hline $40-10-08$ & 100 & 813 & 4 & Clean & - & $=$ & 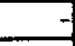 & - \\
\hline $40-10-09$ & 100 & 876 & 4 & Clean & - & $=$ & - & - \\
\hline $40-10-13$ & 125 & 694 & 4 & Cean & - & 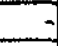 & - & - \\
\hline $40-11-01$ & 145 & 901 & 4 & TF Activity & $0-10$ & 80 & 1985 & $\mathrm{CS}^{137}$ \\
\hline $40-11-05$ & 100 & 543 & 4. & Cean & - & - & - & - \\
\hline $40-11-07$ & 100 & 880 & 4 & Clean & - & $=$ & $=$ & - \\
\hline $40-11-08$ & 100 & 532 & 4 & Clean & - & 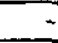 & - & - \\
\hline $40-11-09$ & 100 & 902 & 4 & Cean & - & 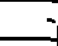 & - & - \\
\hline $40-12-02$ & 100 & 884 & 4 & Clean & - & $=$ & - & - \\
\hline $40-12-04$ & 126 & 735 & 4 & Gean & - & $=$ & - & - \\
\hline $40-12-06$ & 145 & 914 & 4 & Clean & - & $=$ & - & - \\
\hline $40-12-07$ & 100 & 545 & 4 & Clean & - & $=$ & - & - \\
\hline $40-12-09$ & 100 & 887 & 4 & Clean & - & $\sim$ & & - \\
\hline
\end{tabular}

Probe type: 2 = Red GM, least sensitive; reads highest level of gamma ray activity. $4=\mathrm{NaI}$, most sersitive, reads lowest level of gamma ray activity.

Caution must be used when relating GTP values in zones recorded with different probe types.

bNo systematic trend above the detection threshold for the gross gamma ray logs is indicated by the data.

'An irregular change in the intensity of gross gamma rays between successive surveys at or near the surface suggests that contamination may be the result of tank farm activities or logging procecture changes and not vadose zone transport.

'Stability cannot be determined due to insufficient data, exceeding the system design criteria (both upper and lower limits) for recording gross gamma ray data, or possible effects of depth shift or surface activities.

The decay rate of the isotope(s) identified in the zone matches the change in concentration of the isotope(s) as measured over time, and no noticeable deviation from the match is apparent within the period that gross gamma ray data were collected.

"The data are invalid prior to 1986 due to depth control issues; therefore, downward movement of contaminants carnot be determired.

"Arrently, isotopes cannot be identified from gross gamma ray data alone; therefore, if the period of instability is prior to the collection of SGLS data, isotopes with a rapid rate of decay (e.g., Ru-106), or at levels that decay below detection limits, may not be identified. Also, betaemitting isotopes such as Sr-90 cannot be directly detected by the SGLS. The presence of such isotopes is mypothesized.

"Spectral Gamma log Survey was not performed; therefore, the presence of specific isotopes is typothesized.

Stable vs. unstable is an apparent condition limited by the time interval over which data were collected and the level of contamination, and is not a statement concerning the fixed or mobile nature of a given isotope.

\section{Subsurface Condition Categories}

\subsection{Clean}

A dean well is one that exhibits no observable change in the character of the adivity over the logging history of the well, and does not have any isotopes identified by the SGS greater than the average background levels of naturally occurring gamma ray emitting isotopes. Non-gamma emitting radiomudides or other contaminant species might be present but are not detected by either HPGe or 
HNF-4220, Rev. 0

gross gamma logging. Although spurious surveys (those readings that do not repeat over time) may exist in the frequency dean and the average background plots, the trend of the data is dear. Fifty-three out of 72 wells in the S Tank Farm are considered dean (Figure 2) and are listed in Table 2. The remaining 19 wells are considered contaminated and are further categorized and disassed in the following sections.

\section{Table 2. S Tank Farm Clean Wells}

\begin{tabular}{|c|c|c|}
\hline $\begin{array}{l}\text { Borehole } \\
\text { Number }\end{array}$ & $\begin{array}{l}\text { Survey } \\
\text { Depth }\end{array}$ & Cateror \\
\hline $40-00-02$ & 140 & $\mathrm{Ce}$ \\
\hline $40-00-06$ & 150 & Oe \\
\hline $40-01-01$ & 130 & $\mathrm{Cle}$ \\
\hline $40-02-01$ & 132 & Ces \\
\hline $40-02-05$ & 100 & Cean \\
\hline $40-02-10$ & 100 & Cean \\
\hline $40-02-11$ & 100 & Clean \\
\hline $40-03-01$ & 100 & Gean \\
\hline $40-03-03$ & 130 & Clea \\
\hline $40-03-05$ & 150 & Clea \\
\hline $40-03-06$ & 100 & Cear \\
\hline $40-03-08$ & 100 & Clear \\
\hline $40-03-11$ & 100 & Clean \\
\hline $40-04-01$ & 100 & Gean \\
\hline $40-04-07$ & 100 & $\mathrm{Cle}$ \\
\hline $40-05-05$ & 150 & $\mathrm{Ce}$ \\
\hline $40-05-07$ & 100 & $\mathrm{de}_{\mathrm{e}}$ \\
\hline $40-05-08$ & 100 & \\
\hline $40-05-10$ & 90 & e \\
\hline $40-06-02$ & 100 & \\
\hline $40-06-04$ & 125 & \\
\hline $40-06-05$ & 140 & $\mathrm{Cle}$ \\
\hline $40-06-06$ & 97 & Clear \\
\hline $40-06-08$ & 97 & Coar \\
\hline $40-06-09$ & 100 & Cle \\
\hline $40-07-01$ & 100 & Cles \\
\hline $40-07-04$ & 102 & $\mathrm{Ce}$ \\
\hline $40-07-06$ & 98 & \\
\hline $40-08-01$ & 97 & $c$ \\
\hline $40-08-08$ & 100 & \\
\hline $40-08-09$ & 100 & \\
\hline $40-08-12$ & 125 & \\
\hline $40-09-01$ & 97 & \\
\hline $40-09-02$ & 100 & \\
\hline $40-09-05$ & 145 & \\
\hline $40-09-06$ & 100 & \\
\hline $40-09-08$ & 100 & $\mathrm{c}$ \\
\hline $40-09-09$ & 140 & \\
\hline $40-10-03$ & 98 & \\
\hline $40-10-05$ & 100 & $\mathrm{Cle}$ \\
\hline $40-10-06$ & 145 & $\mathrm{Ce}_{\mathrm{e}}$ \\
\hline $40-10-08$ & 100 & $\mathrm{Cle}$ \\
\hline $40-10-09$ & 100 & $\mathrm{Cle}$ \\
\hline $40-10-13$ & 125 & $\mathrm{Ce}$ \\
\hline & & \\
\hline $40-11-05$ & 100 & \\
\hline $40-11-07$ & 100 & \\
\hline $40-11-08$ & 100 & \\
\hline $40-11-09$ & 100 & $\mathrm{C}$ \\
\hline $40-12-02$ & 100 & \\
\hline $40-12-04$ & 126 & Cean \\
\hline $40-12-06$ & 145 & Clear \\
\hline
\end{tabular}




\begin{tabular}{|r|r|r|}
\hline $40-12-07$ & 100 & Clean \\
\hline $40-12-09$ & 100 & dean \\
\hline
\end{tabular}

\subsection{Contaminated}

Specific gamma emitting isotopes that are in the subsurface are identified from data acquired by the SGLS. Integration of the decay rate of the radionudide species with the gross gamma ray data collected during the dry well surveillance program provides insight as to the rate of change, if any, of radionudides in the subsurface. During the analysis of S Tank Farm data, five gamma-emitting isotopes were identified or hypothesized to have occurred in radioactive zones. They are cesium-137 (Cs-137), cobalt-60 (Co-60), europium-154 (Eu-154), strontium-90 (Sr-90), and ruthenium-106 (Ru-106). Cesium-137 is the most commonly identified isotope and is often not associated with other isotopes, although it is found with one or more of the other isotopes in three wells.

Ruthenium-106 is not currently present above the detection threshold in any of the wells examined by the SGLS. This is due to the very rapid exponential dedine over a short half-life of 1.02 years. Ruthenium-106 is mypothesized to have been present in one well in 1975 on the basis of the gross gamma ray data and the resulting GTP calculations that mimic the decay rate of Ru-106, coupled with the inventory list of radionudides known to be in the tanks during that time period. However, the method of fitting a decay curve to the observed GTP trend identifies only those contaminants that are decaying but not changing. Ruthenium-106 is assumed to be present if the decay curve for Ru-106 matches the GTP plot. If any decay curve does not match, then the contaminants cannot be identified with this method without additional information.

Strontium-90 is indirectly indicated by the SGLS since it emits beta partides and not gamma rays. However, a high gross garmma ray response that is not assodated with an isotope as detected by the SGLS is hypothesized to be due to the presence of Sr-90 in one well in the S Tank Farm (MACTEC-ERS, 1997). Gross gamma ray data provides information about rates of decay for the isotopes present provided subsurface conditions are stable, (i.e no net addition or subtraction, movement, of contaminant). Although, other beta-emitting isotopes can cause an elevated gross gamma ray response, isotopes with half-lives similar to the decay rate of Sr-90 are hypothesized to be present. In this case, the half-life for Sr-90 fits with the gross gamma ray data and the calculated decay rate. In order for instruments to detect an elevated gross gamma ray response due to beta partides, a large amount of source material such as $\mathbf{S r - 9 0}$ needs to be present. An alternative possibility for the cause of elevated gross gamma with no visible photo peaks associated with specific gamma emitting radionudides is the presence of a strong ganma source located remotely from the detection point within the borehole.

The isotopes identified with the SGLS are primarily present under three subsurface conditions: stable, tank farm activity, and undetermined. Dry well locations (centered beneath the borehole name on the map) are labeled with the conditions of subsurface zones and are shown in Figure 2. A different condition can be indicated for each zone within a well with multiple zones. 
HNF-4220, Rev. 0

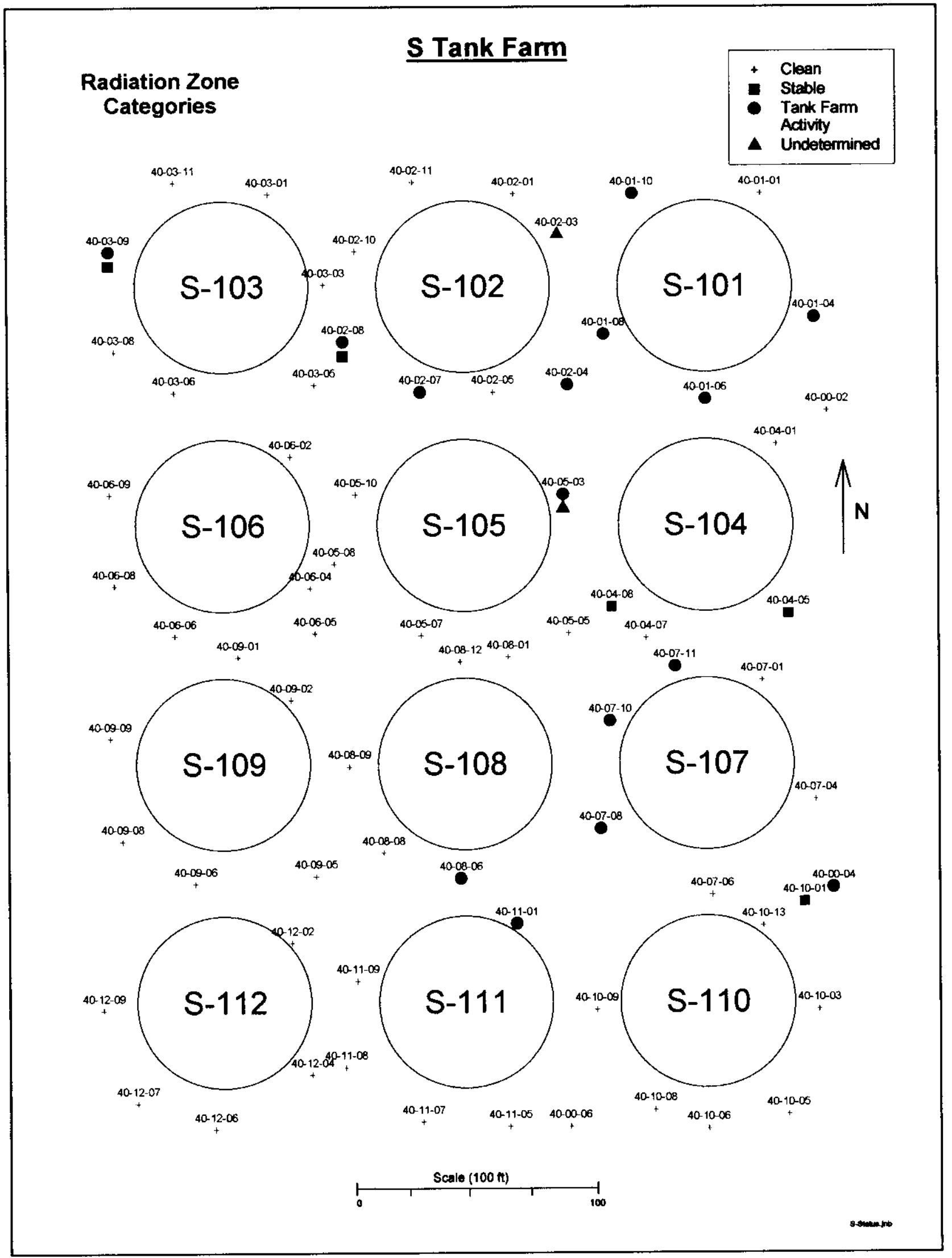

Figure 2. S Tank Farm Radiation Zone Categories 
HNF-4220, Rev. 0

\subsubsection{Tank Farm Attributed}

A sudden or abrupt change in the intensity of gross gamma rays between sets of successive surveys at or near the surface suggest that contamination may be the result of tank farm activities or logging procedure changes and not vadose zone transport. Radioactive contamination occurs near the surface in fourteen wells, apparently as the result of tank farm activities (i.e., logging procedure changes, transfer line operations, valve box and conduit leaks, surface spills, etc.). These wells are listed in Table 3. A notable decrease in background radiation and surface activity occurred in 1985 or 1986 in many of the wells, suggesting that contaminated surface soil was covered with dean material to stabilize the contamination. Maximum GTP values are selected from the period where readings became stable.

Table 3. S Tank Farm Activity Zones

\begin{tabular}{|c|c|c|c|c|c|c|c|}
\hline $\begin{array}{l}\text { Borehole } \\
\text { Number }\end{array}$ & $\begin{array}{c}\text { Survey } \\
\text { Depth } \\
\text { (feet) }\end{array}$ & Category & $\begin{array}{c}\text { Zone } \\
\text { Depth } \\
\text { (feet) }\end{array}$ & $\begin{array}{c}\operatorname{Max} \\
\text { GTP } \\
\left(\mathrm{ft}^{*} \mathrm{c} / \mathrm{s}\right)\end{array}$ & $\begin{array}{c}\text { Year } \\
\text { Max GTP }\end{array}$ & $\begin{array}{l}\text { Isotopes } \\
\text { Present }\end{array}$ & Comment \\
\hline $40-00-04$ & 140 & IF Adivity & $0-8$ & 200 & 1987 & $\Rightarrow>$ & Surf, contamination possibly covered in 1987 \\
\hline $40-01-04$ & 100 & TF Activity & $0-8$ & 50 & 1986 & $\mathrm{Cs}^{137}$ & Surf. contamination possibly covered in 1986 \\
\hline $40-01-06$ & 100 & TF Activity & $0-8$ & 75 & 1986 & $\mathrm{Cs}^{137}$ & Surf. contamination possibly covered in 1986 \\
\hline $40-01-08$ & 105 & IF Adivity & $0-12$ & 70,000 & 1985 & $\mathrm{Cs}^{137} ; \mathrm{Co}^{60} ; \mathrm{Eu}^{154}$ & Surf. contamination possibly covered in 1985 \\
\hline $40-01-10$ & 100 & TF Activity & $0-8$ & 30 & 1986 & $\mathrm{Cs}^{137}$ & Surf. contamination possibly covered in 1986 \\
\hline $40-02-04$ & 150 & TF Activity & $0-12$ & 2,500 & 1985 & $\mathrm{Cs}^{137}$ & Surf. contamination possibly covered in 1985 \\
\hline $40-02-07$ & 100 & TF Activity & $0-5$ & 50 & 1986 & $\mathrm{Cs}^{137}$ & Surf. contamination possibly covered in 1986 \\
\hline $40-02-08$ & 100 & TF Activity & $0-7$ & 300 & 1986 & $\mathrm{Cs}^{137} ; \mathrm{Co}^{60}$ & Surf. contamination possibly covered in 1986 \\
\hline 40-03-09 & 132 & TF Activity & $0-10$ & 800 & 1975 & $\mathrm{CS}^{137}: \mathrm{CO}^{60}$ & \\
\hline $40-05-03$ & 100 & TF Activity & $0-10$ & 50 & 1975 & $\mathrm{CS}^{137}$ & \\
\hline $40-07-08$ & 100 & TF Activity & $0-10$ & 100 & 1986 & $\mathrm{CS}^{137}$ & Surf. contarnination possibly covered in 1986 \\
\hline $40-07-10$ & 100 & IF Activity & $0-12$ & 90 & 1986 & $\mathrm{Cs}^{137}$ & Surf, contamination possibly covered in 1986 \\
\hline 40-07-11 & 98 & TF Activity & $0-20$ & 210 & 1986 & $\mathrm{CS}^{137}$ & Surf, contamination possibly covered in 1986 \\
\hline $40-08-06$ & 100 & Tf Activity & $0-7$ & 80 & 1986 & $\mathrm{Cs}^{137}$ & Surf. contamination possibly covered in 1986 \\
\hline 40-11-01 & 145 & TF Activity & $0-10$ & 80 & 1986 & $\mathrm{Cs}^{137}$ & Surf, contamination possibly covered in 1986 \\
\hline
\end{tabular}

Spectral Gamma Log Survey was not performed; therefore, the presence of specific isotopes is hypothesized.

\subsubsection{Undetermined}

Infrequently, stability cannot be determined due to insufficient data, exceeding the system design criteria (both upper and lower limits) for recording gross gamma ray data, or possible effects of depth shift or surface activities. Three zones out of 28 zones in the 72 wells examined are undetermined (Table 4). The zone from 17 to 32 feet in well $40-02-03$ is conservatively dassified as undetermined because there is a slight decrease in GTP values near the end of data collection that makes a rigorous dassification of stable uncertain. For the zone from 50 to 60 feet in the same well, a peak exists between 1980 and 1981 that is not apparent between 1985 and 1993. This could be due to the contaminant being deaned out of the well between 1980 and 1985 . However, the average background is lower in the surveys that were obtained after 1985, which may indicate that the probe type employed to generate the data was misidentified. A less sensitive detector than the one previously employed would not detect this peak and would account for the lower average background readings. The zone from 28 to 41 feet in well 40-05-03 is undetermined because there is an elevated gross gamma ray response that is unaccounted for. The elevated gross gamma ray response is hypothesized to be due to Sr-90 since there is reasonable agreement between the gross gamma ray data and the calculated decay rate with the half-life of $\mathrm{Sr}-90$, but this cannot be rigorously proven with the data available. 


\section{Borehole 40-03-08}

\section{No Gamma Ray Emitting Contamination was Identified.}

No significant levels of gamma ray contamination are present, based upon gross gamma data, above the survey probe detection threshold between 1975 and 1994 in the vadose zone from 2 to 100 feet. The HPGe logging system detected Cs-137 at $5 \mathrm{pCi} / \mathrm{g}$ at surface, but less than $1 \mathrm{pCi} / \mathrm{g}$ for 2 to 100 feet.

Gross Gamma Survey Information

\begin{tabular}{|r|l|}
\hline Probe Type Processed : & $04: \mathrm{NaI}$ \\
\hline Other Probe Types : & $03:$ Neutron \\
\hline Survey Depth : & $100 \mathrm{ft}$ \\
\hline First Survey Date : & $1 / 13 / 1975$ \\
\hline Last Survey Date : & $10 / 26 / 1993$ \\
\hline Number Surveys Processed : & 602 \\
\hline
\end{tabular}

Analysis Notes

Method Used to Compute Background : $\quad$ Threshold $0<$ val $<50$

Depth(s) where Contamination Identified NONE in Gross Gamma Surveys :

Analyst Name : R.R. Randall

Company Name : Three Rivers Scientific 


\section{Borehole 40-03-08}

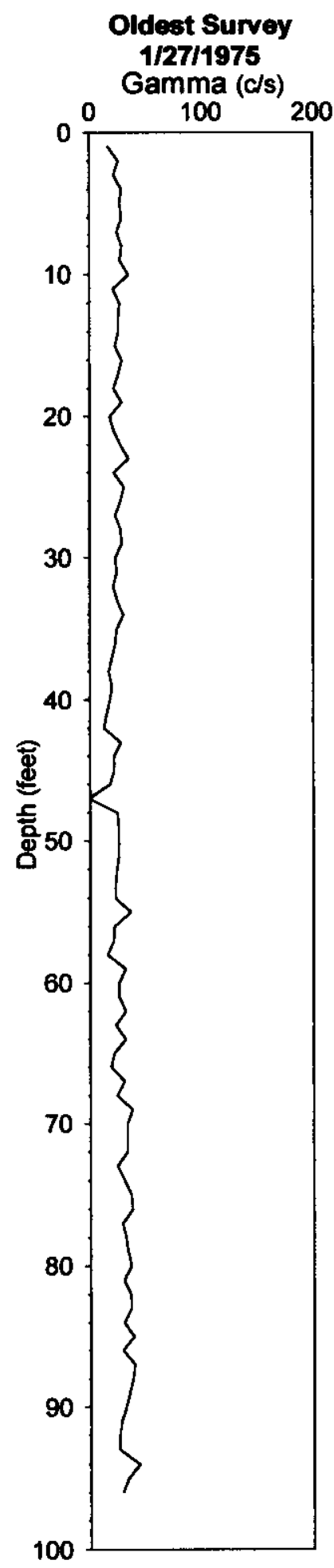
No Gamma-Ray Emitting Contamination Above Survey Detection Threshold
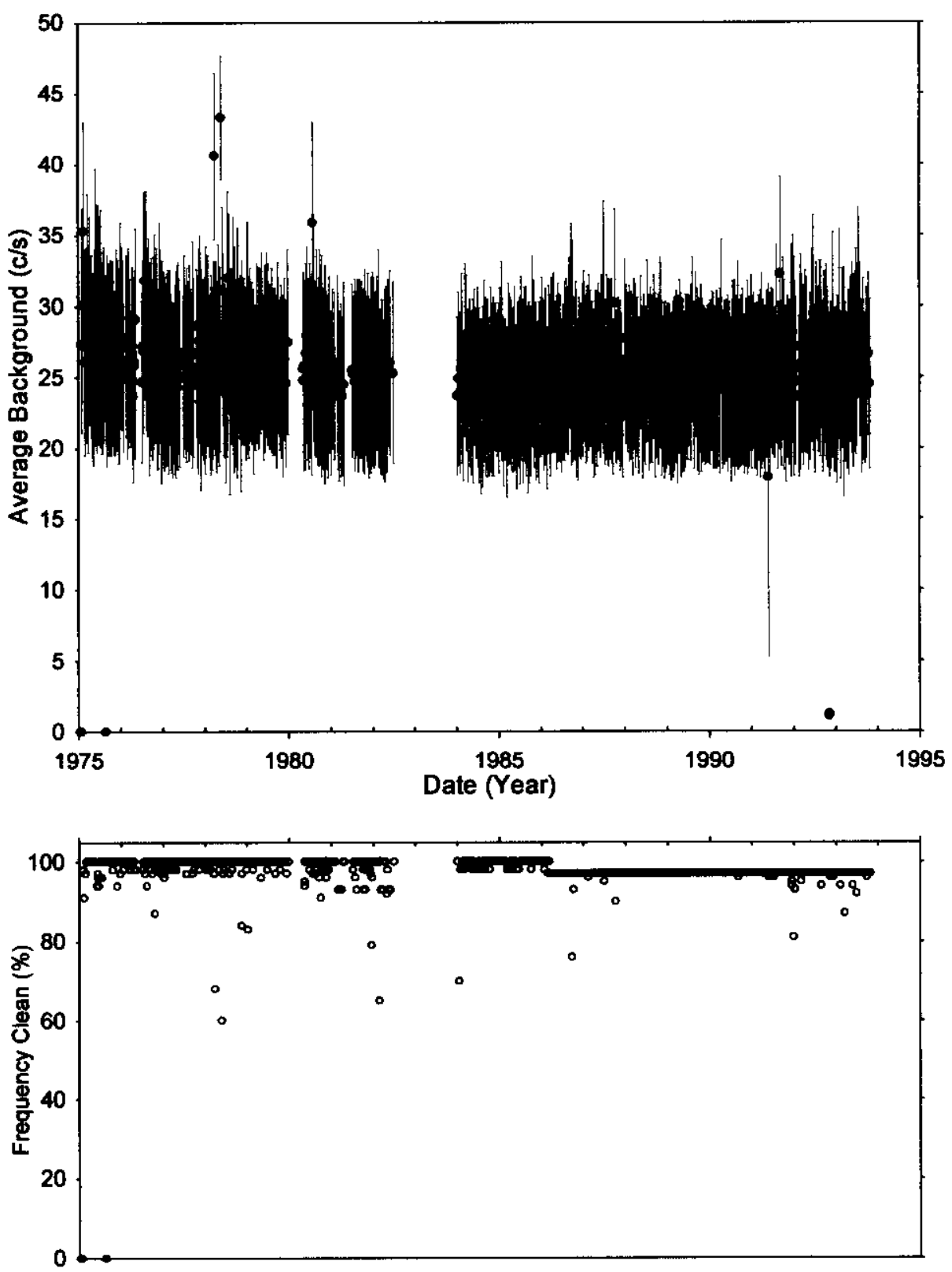

Anatysis by: Three Rivers Scientific 
HNF-4220, Rev. 0

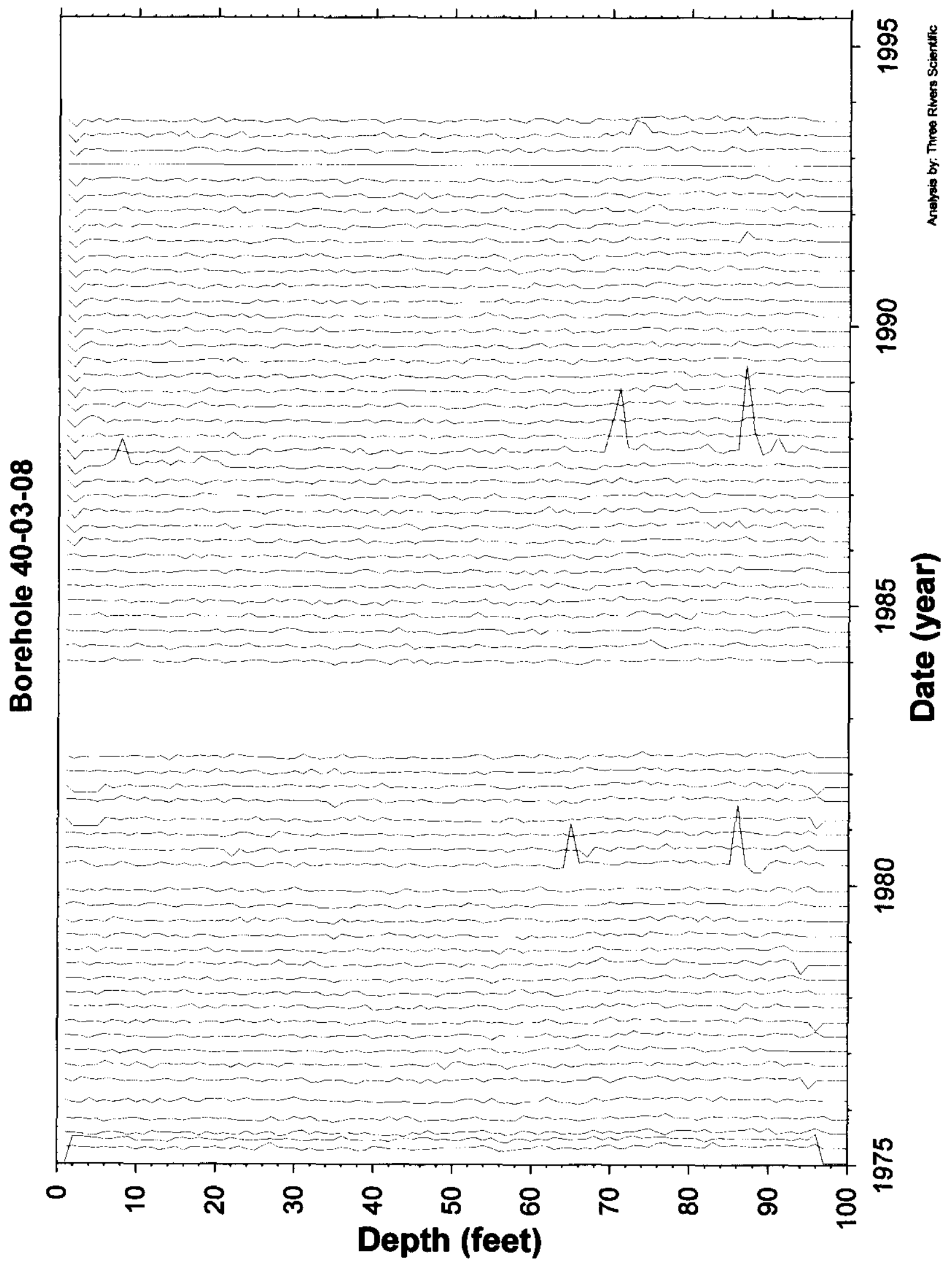

Tank S-103

Page 96 


\section{Borehole 40-03-09}

\section{Contamination (Cs-137\& Co-60) from 0-10 feet is Tank Farm Activity. Contamination ( $\mathrm{Ru}-106$ \& Co-60) from 15-40 feet is Stable. Contamination (Cs-137) from 125-132 feet is Stable*.}

Grade thickness product over 0 to 10 feet is decreasing consistent with a least square fit for Cs137 \& Co-60 (both HPGe identified) from 1986 to 1994. Before 1986, the gross gamma response over time is indicative of tank farm activity, but appears stable since 1986. The ratio of gross from Co-60 to gross from Cs-137 is 1.81 as of 11-1-93.

Grade thickness product over 15 to 40 feet is decreasing consistent with a least square fit for Co60 (HPGe identified) and Ru-106 (hypothesized) from 1975 to 1994. The ratio of gross from Co-60 to gross from Ru-106 is 0.11 as of $1-27-75$. Note, Cs-137 is also HPGe identified in this interval, but at very low levels and would not be possible to match the apparent $\mathrm{Ru}-106$ decay character.

Grade thickness product over 125 to 132 feet is decreasing consistent with Cs-137 (HPGe identified) decay from 1985 to 1994 . Before 1985, the gross gamma logging system could not reliably measure near the bottom of each borehole. Therefore, the data before 1985 cannot be used in an assessment of category.

Gross Gamma Survey Information

\begin{tabular}{|r|l|}
\hline Probe Type : & $04: \mathrm{NaI}$ \\
\hline Other Probe Types : & $03:$ Neutron \\
\hline Survey Depth : & $132 \mathrm{ft}$ \\
\hline First Survey Date : & $1 / 13 / 1975$ \\
\hline Last Survey Date : & $11 / 1 / 1993$ \\
\hline Number Surveys : & 852 \\
\hline
\end{tabular}

Analysis Notes

\begin{tabular}{r|l|} 
Method Used to Compute Background : & $\begin{array}{l}\text { Threshold } 0<\text { val<50 for 0-10, 15-40, 125- } \\
132\end{array}$ \\
$\begin{aligned} \text { Depth(s) where Contamination Identified } \\
\text { in Gross Gamma Surveys : }\end{aligned}$ & $\begin{array}{l}0-10 \mathrm{ft} . \text { Tank Farm Activity, 15-40 ft., and } \\
125-132 \text { feet is Stable* }\end{array}$ \\
\hline Analyst Name : & R.R. Randall \\
\hline Company Name : & Three Rivers Scientific \\
\hline
\end{tabular}


HNF-4220, Rev. 0
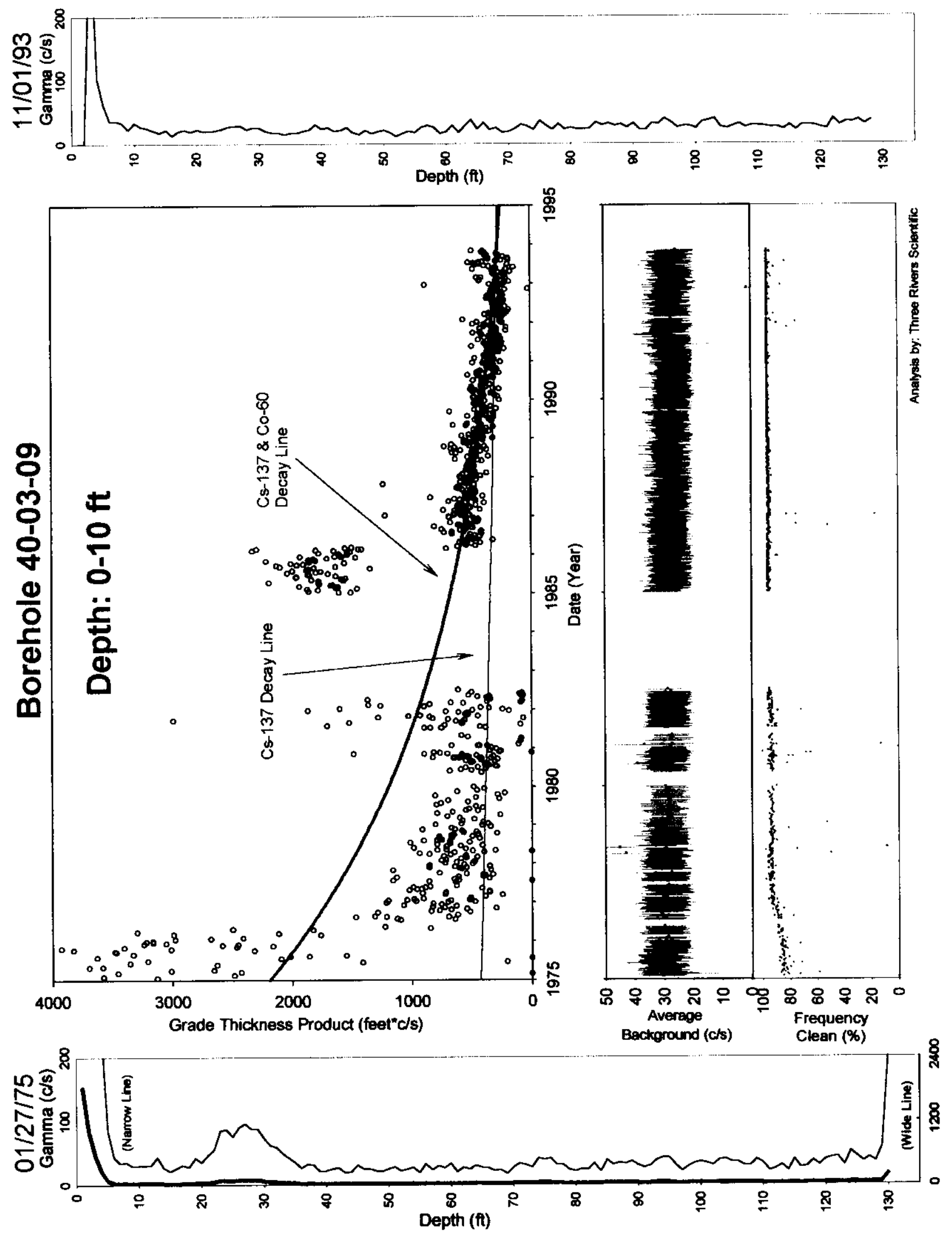
HNF-4220, Rev. 0
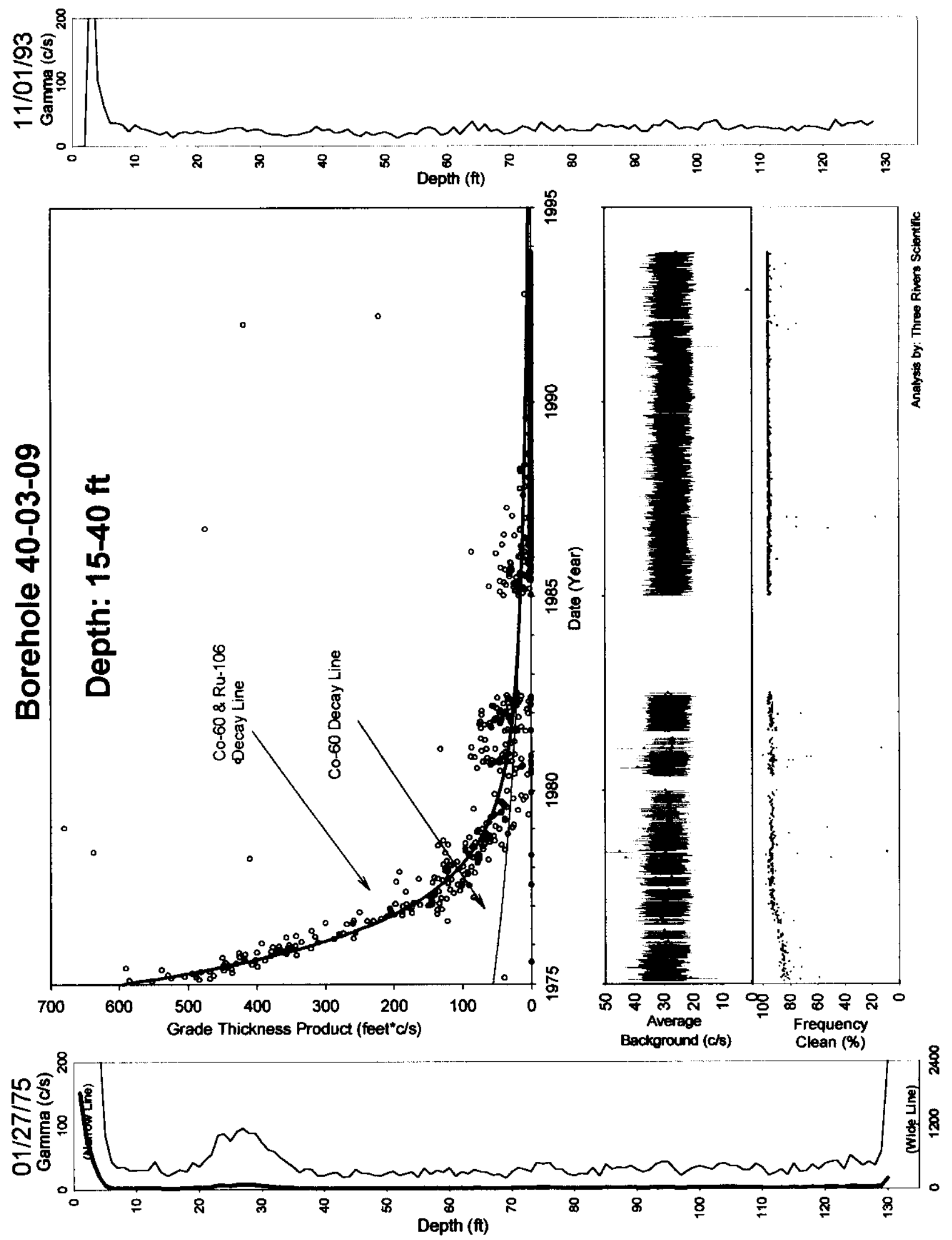

Tank S-103 

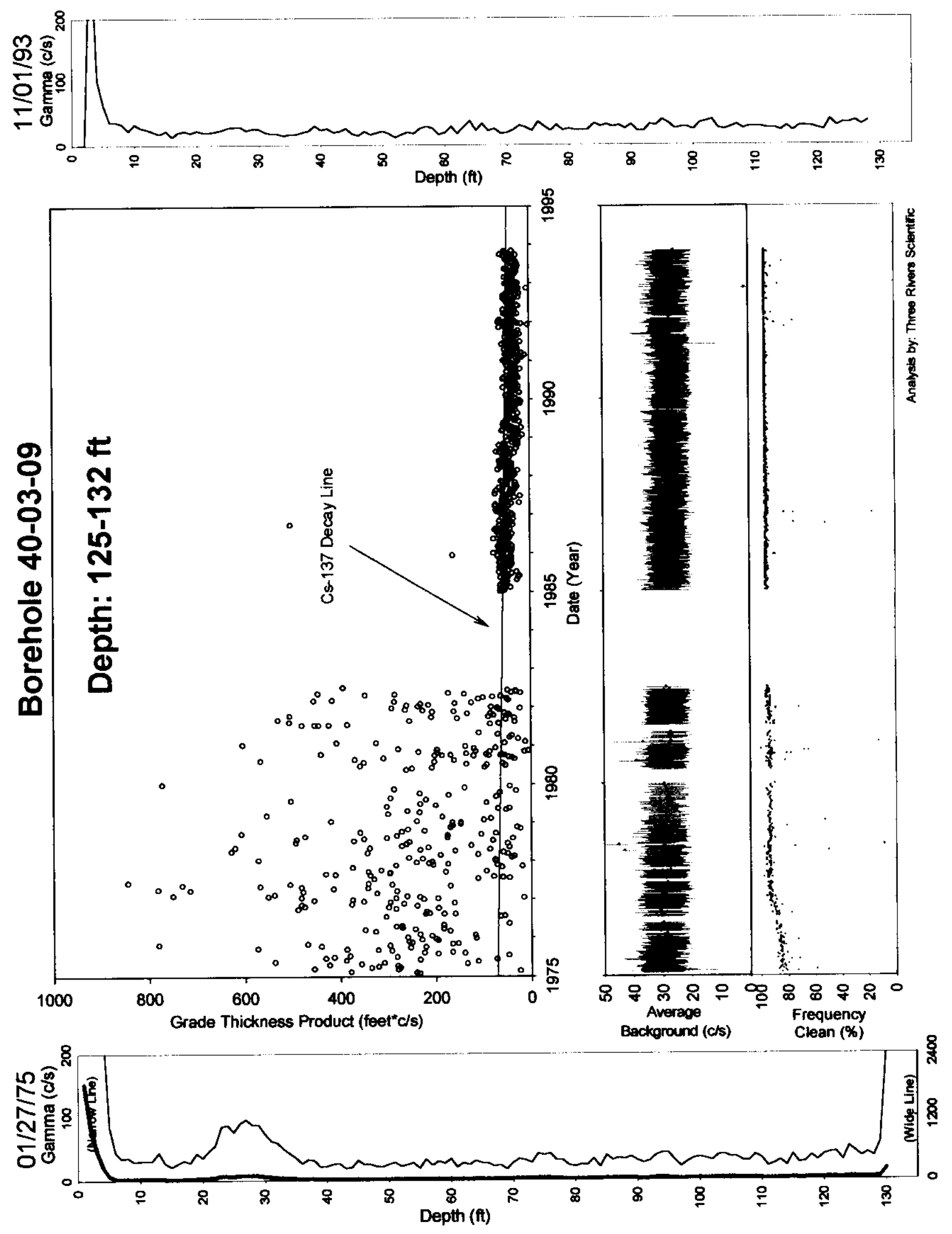
HNF-4220, Rev. 0

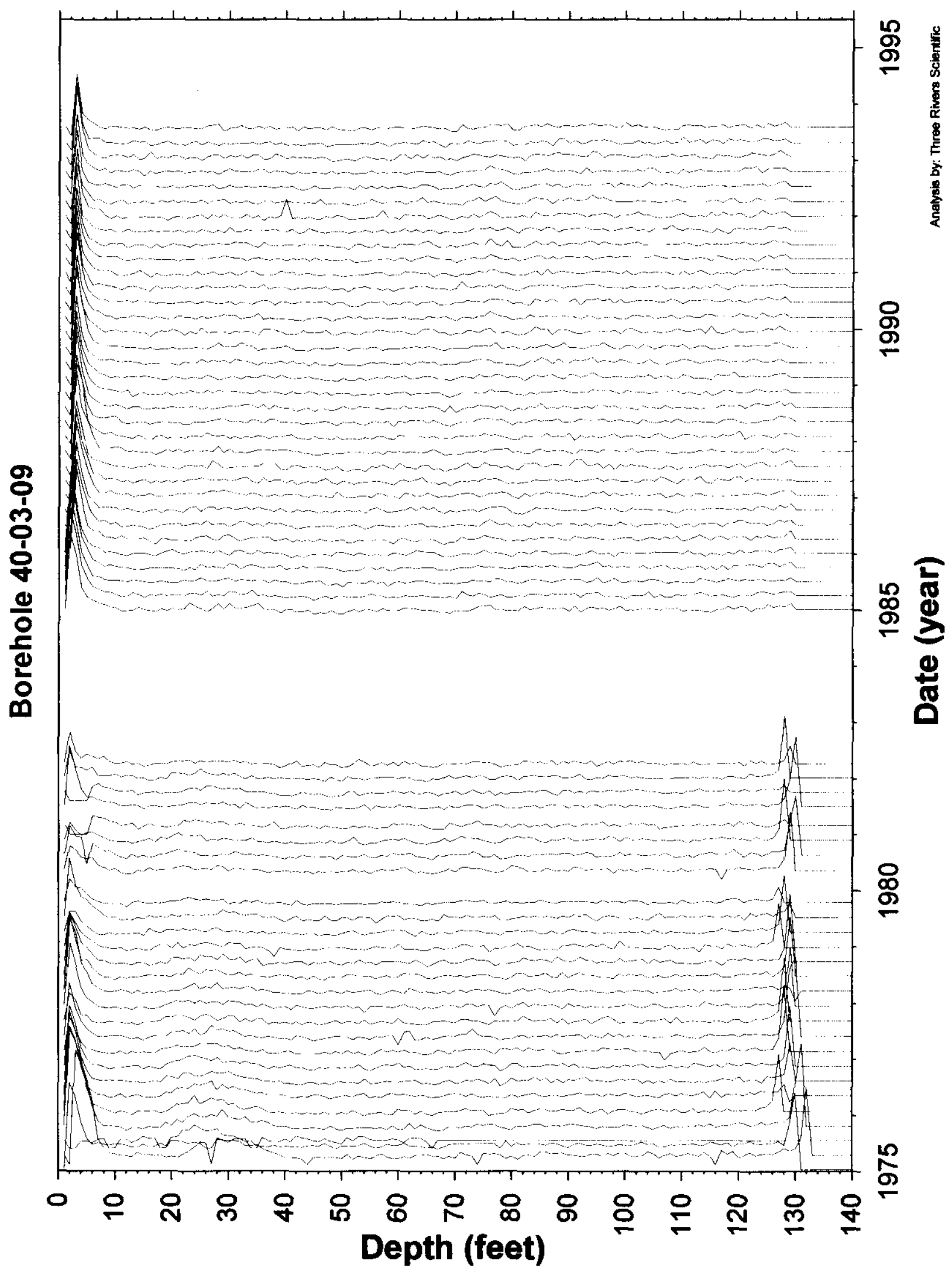

Tank S-103

Page 101 


\section{Borehole 40-03-11}

\section{No Gamma Ray Emitting Contamination was Identified.}

No significant levels of gamma ray contamination are present, based upon gross gamma data, above the survey probe detection threshold between 1975 and 1994 in the vadose zone from 2 to 100 feet. The HPGe logging system detected Cs-137 at $3 \mathrm{pCi} / \mathrm{g}$ at surface, but less than $1 \mathrm{pCi} / \mathrm{g}$ for 2 to 100 feet.

Gross Gamma Survey Information

\begin{tabular}{|r|l|}
\hline Probe Type Processed : & $04:$ Nal \\
\hline Other Probe Types : & $03:$ Neutron \\
\hline Survey Depth : & $100 \mathrm{ft}$ \\
\hline First Survey Date : & $1 / 13 / 1975$ \\
\hline Last Survey Date : & $10 / 26 / 1993$ \\
\hline Number Surveys Processed : & 593 \\
\hline
\end{tabular}

Analysis Notes

Method Used to Compute Background : $\quad$ Threshold $0<$ val $<50$

Depth(s) where Contamination Identified NONE

in Gross Gamma Surveys :

Analyst Name : R.R. Randall

Company Name : Three Rivers Scientific 


\section{Borehole 40-03-11}

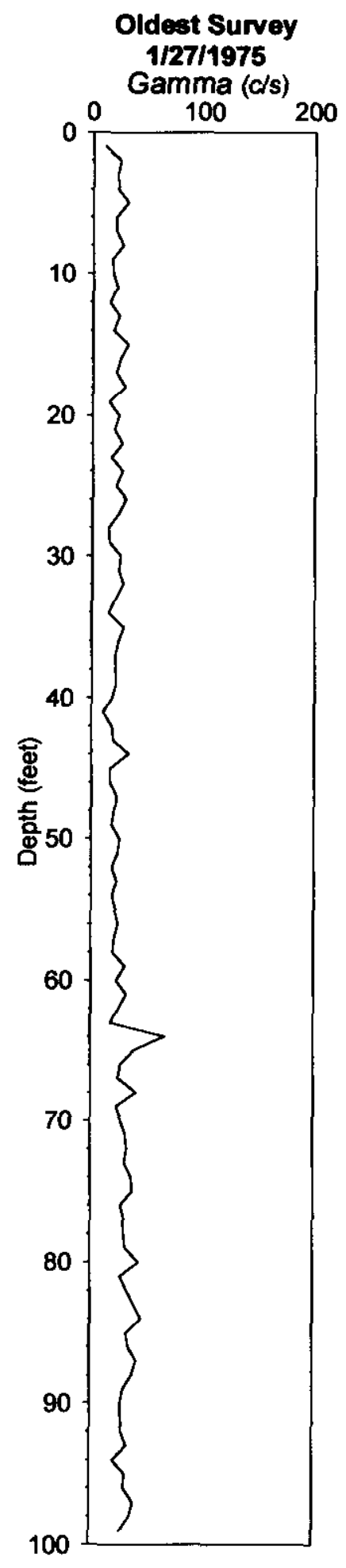

\section{No Gamma-Ray Emitting Contamination Above Survey Detection Threshold}
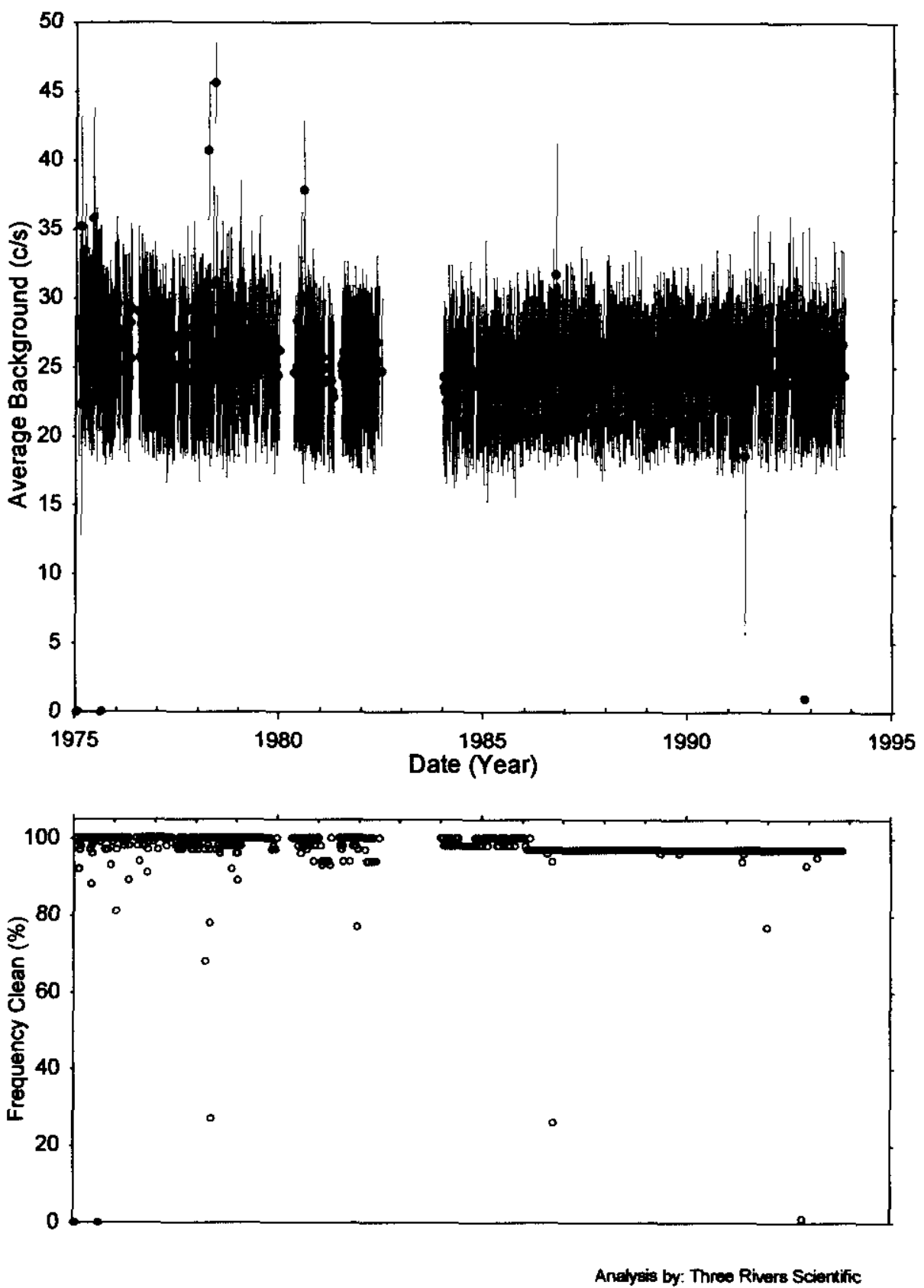
HNF-4220, Rev. 0

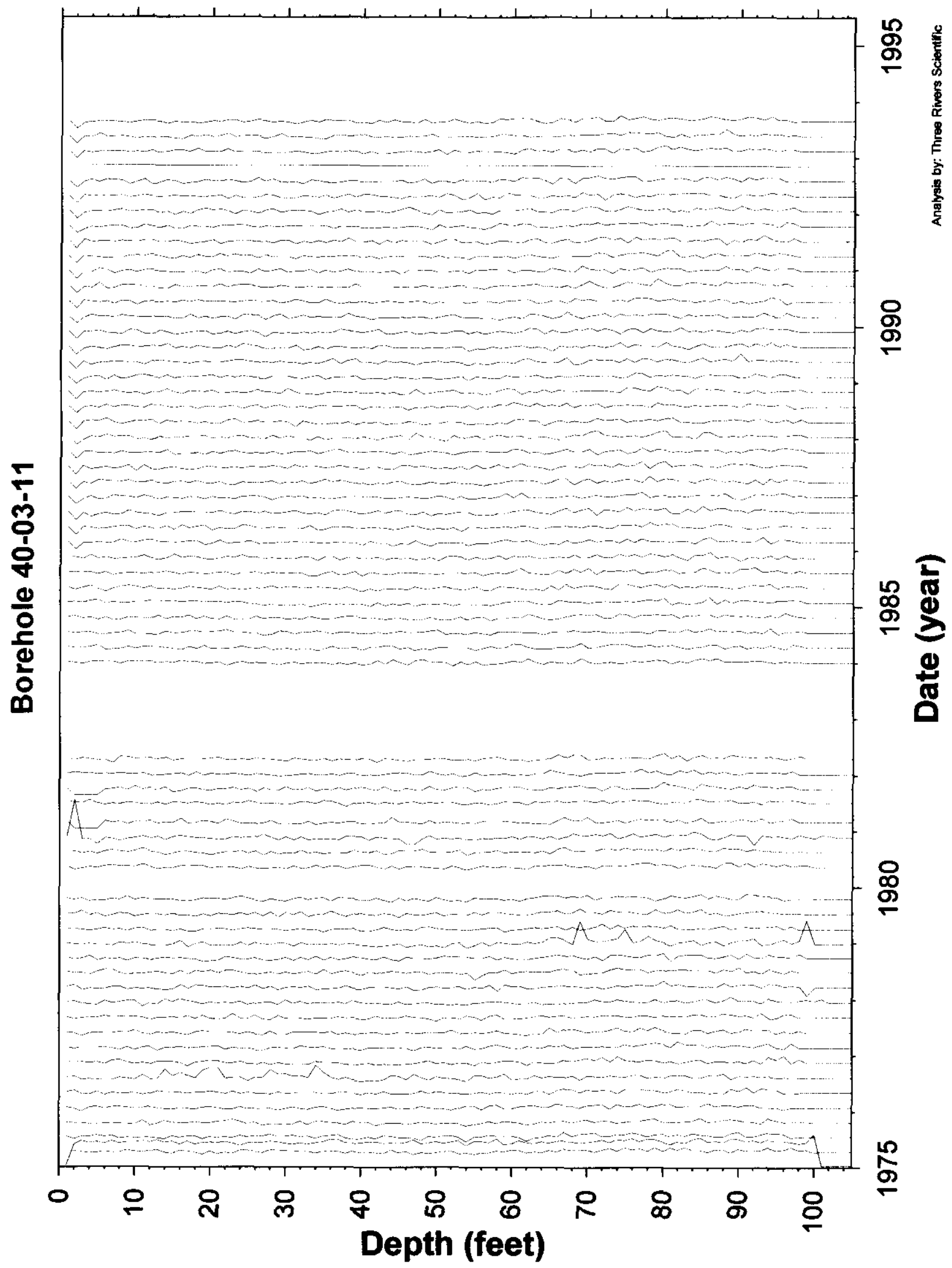

Tank S-103

Page 104 
HNF -4220 , Rev. 0

\section{S Tank 104 Wells}

Table of Contents

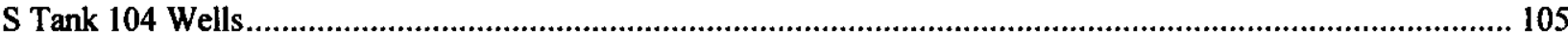

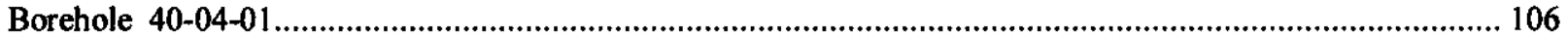

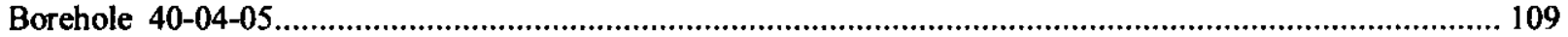

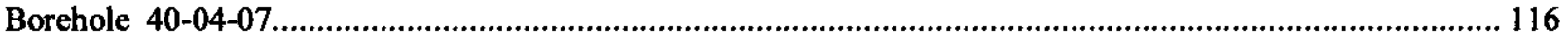

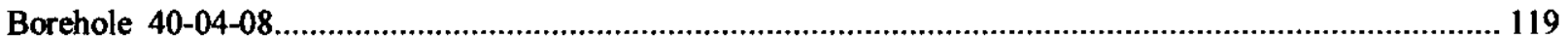

This section contains the analysis results for vadose zone boreholes (dry wells) associated with Tank 104 in the " $S$ " Tank Farm.

Special Note: (none) 


\section{Borehole 40-04-01}

\section{Contamination (Cs-137) from 10-20 feet is Undetermined.}

Grade thickness product over 10 to 20 feet has as much scatter as possible Cs-137 (HPGe identified) decay. Since the scatter does not allow a categorization of stable, the classification is undetermined. The HPGe logging system detected Cs-137 at the surface with $10 \mathrm{pCi} / \mathrm{g}$ and a peak at 17 feet with a maximum of $3 \mathrm{pCi} / \mathrm{g}$, but less than $1 \mathrm{pCi} / \mathrm{g}$ for the rest of the depths.

Gross Gamma Survey Information

\begin{tabular}{|r|l|}
\hline Probe Type Processed : & $04: \mathrm{NaI}$ \\
\hline Other Probe Types : & $03:$ Neutron \\
\hline Survey Depth : & $100 \mathrm{ft}$ \\
\hline First Survey Date : & $1 / 14 / 1975$ \\
\hline Last Survey Date : & $6 / 9 / 1994$ \\
\hline Number Surveys Processed : & 325 \\
\hline
\end{tabular}

Analysis Notes

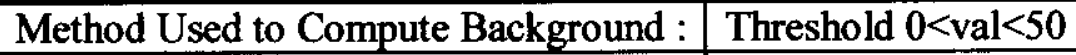

Depth(s) where Contamination Identified $10-20 \mathrm{ft}$. Undetermined in Gross Gamma Surveys :

Analyst Name : R.R. Randall

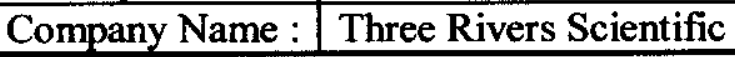



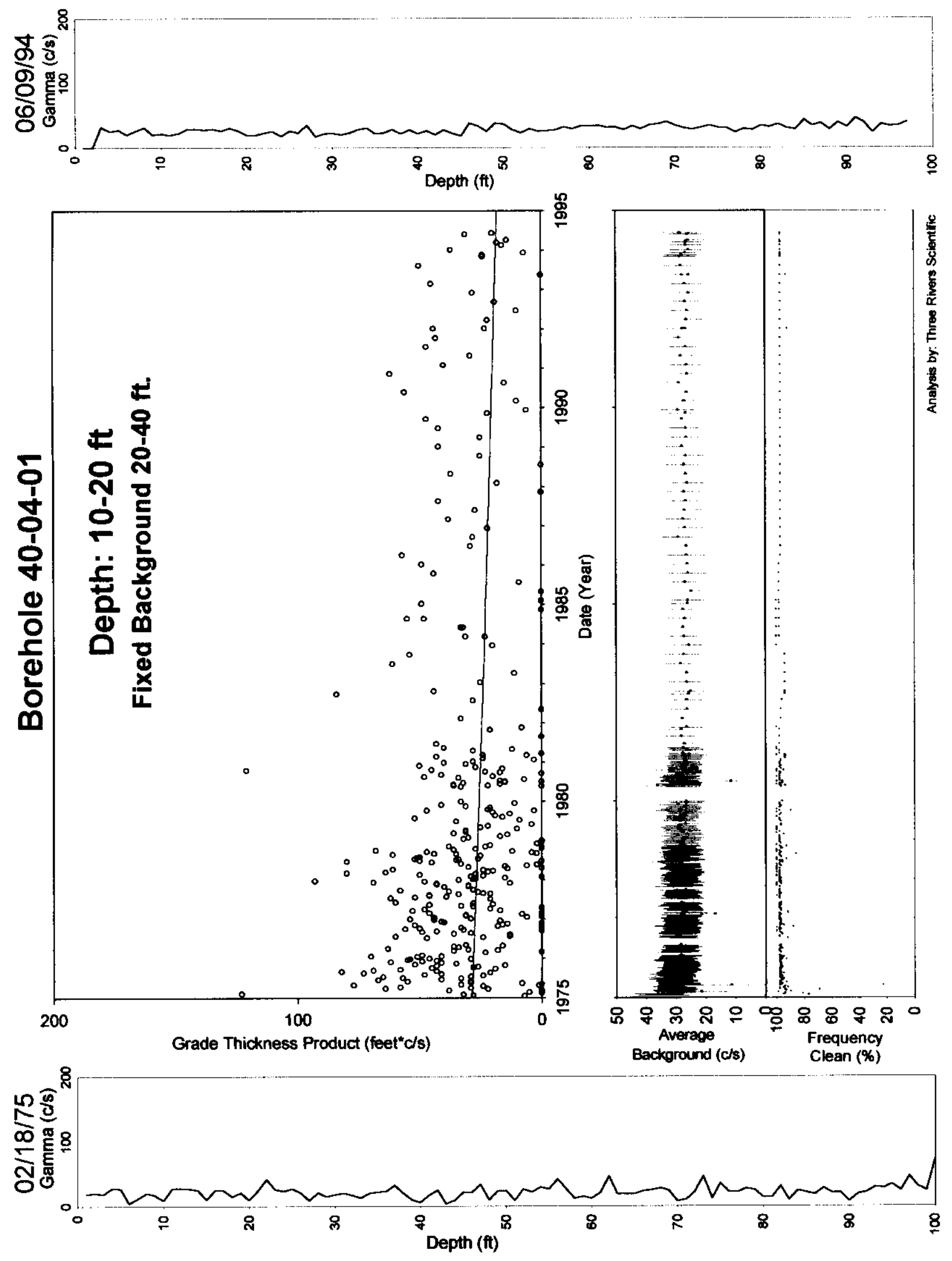

Tank S-104 
HNF-4220, Rev. 0

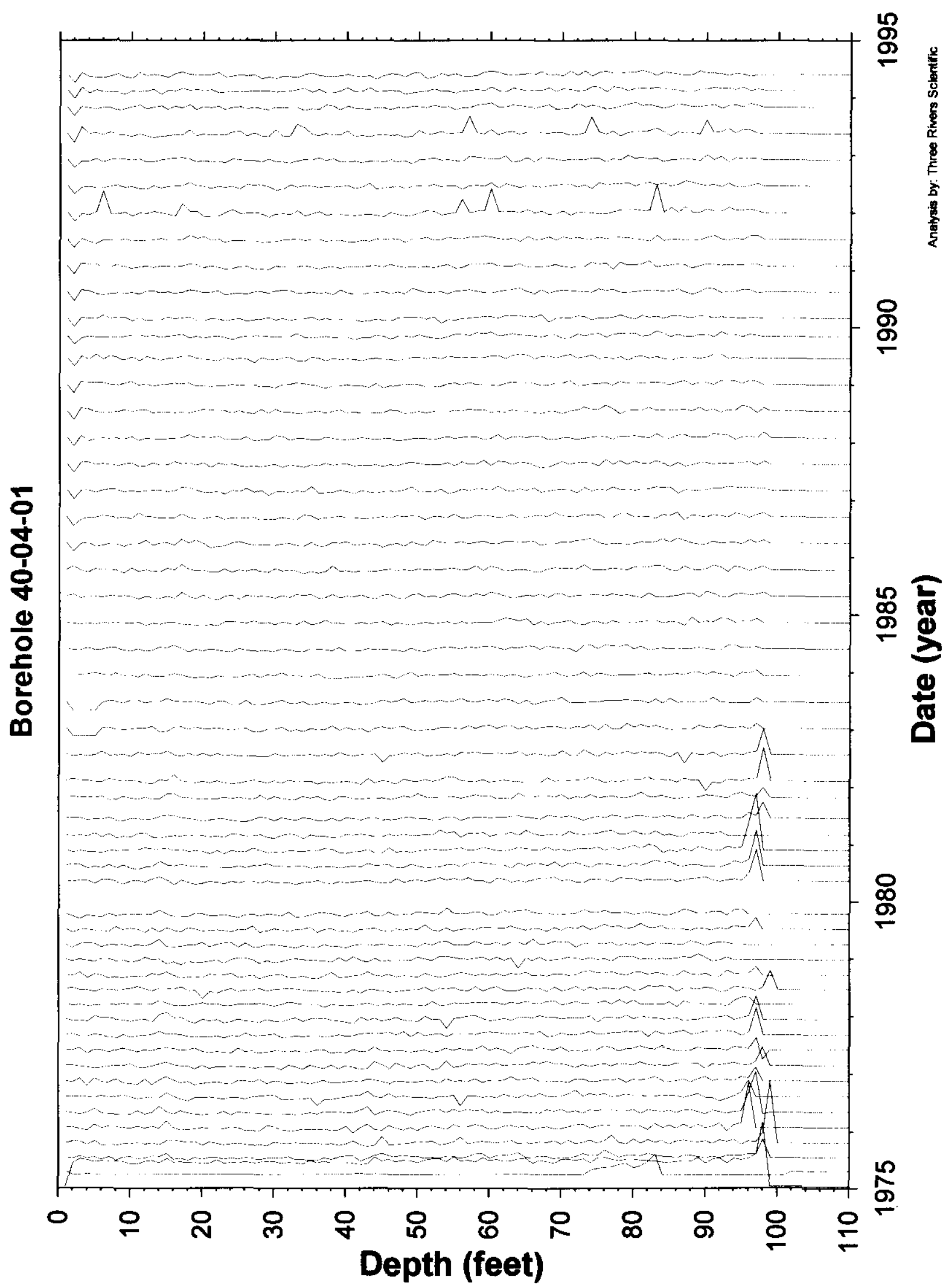

Tank S-104 


\section{Borehole 40-04-05}

\section{Contamination (Cs-137) from 35-55 feet is Stable.}

Grade thickness product over 35 to 55 feet is decreasing consistent with Cs-137 (HPGe identified above and below this interval where high count rate limits exceeded) decay. The probe type 01 (Green GM) grade thickness product is affected by high count rate limitations in this zone, as evidenced by the stable response from the Red GM grade thickness product.

The probe type $04(\mathrm{NaI})$ is not valid in the interval 26 to 60 feet due to high count rate limitations, but is able to detect low levels in the remainder of the borehole that both GM detectors cannot read. There are no indications of lower contaminant zones outside of this interval using the historical gross gamma data.

Gross Gamma Survey Information

\begin{tabular}{|r|l|}
\hline Probe Type Peocessed : & $01:$ Green GM; 02:Red GM; 04:NaI \\
\hline Other Probe Types : & $03:$ Neutron \\
\hline Survey Depth : & $140 \mathrm{ft}$ \\
\hline First Survey Date : & $01: 07 / 25 / 1980$ and 02:05/05/1980 \\
\hline Last Survey Date : & $01: 06 / 10 / 1994$ and 02:06/10/1994 \\
\hline Number Surveys Processed : & $01: 109,02: 121$, and 04:25 \\
\hline
\end{tabular}

Analysis Notes

\begin{tabular}{|r|l|}
\hline Method Used to Compute Background : & $\begin{array}{l}01: \text { Threshold } 0<\text { val }<25 ; 02: \text { Fixed Bkg 50- } \\
130 \mathrm{ft} ; 04: \text { Threshold } 0<\text { val }<50\end{array}$ \\
\hline $\begin{array}{r}\text { Depth(s) where Contamination Identified } \\
\text { in Gross Gamma Surveys : }\end{array}$ & $35-55 \mathrm{ft} \mathrm{Stable}$ \\
\hline Analyst Name : & R.R. Randall \\
\hline Company Name : & Three Rivers Scientific \\
\hline
\end{tabular}


HNF-4220, Rev. 0
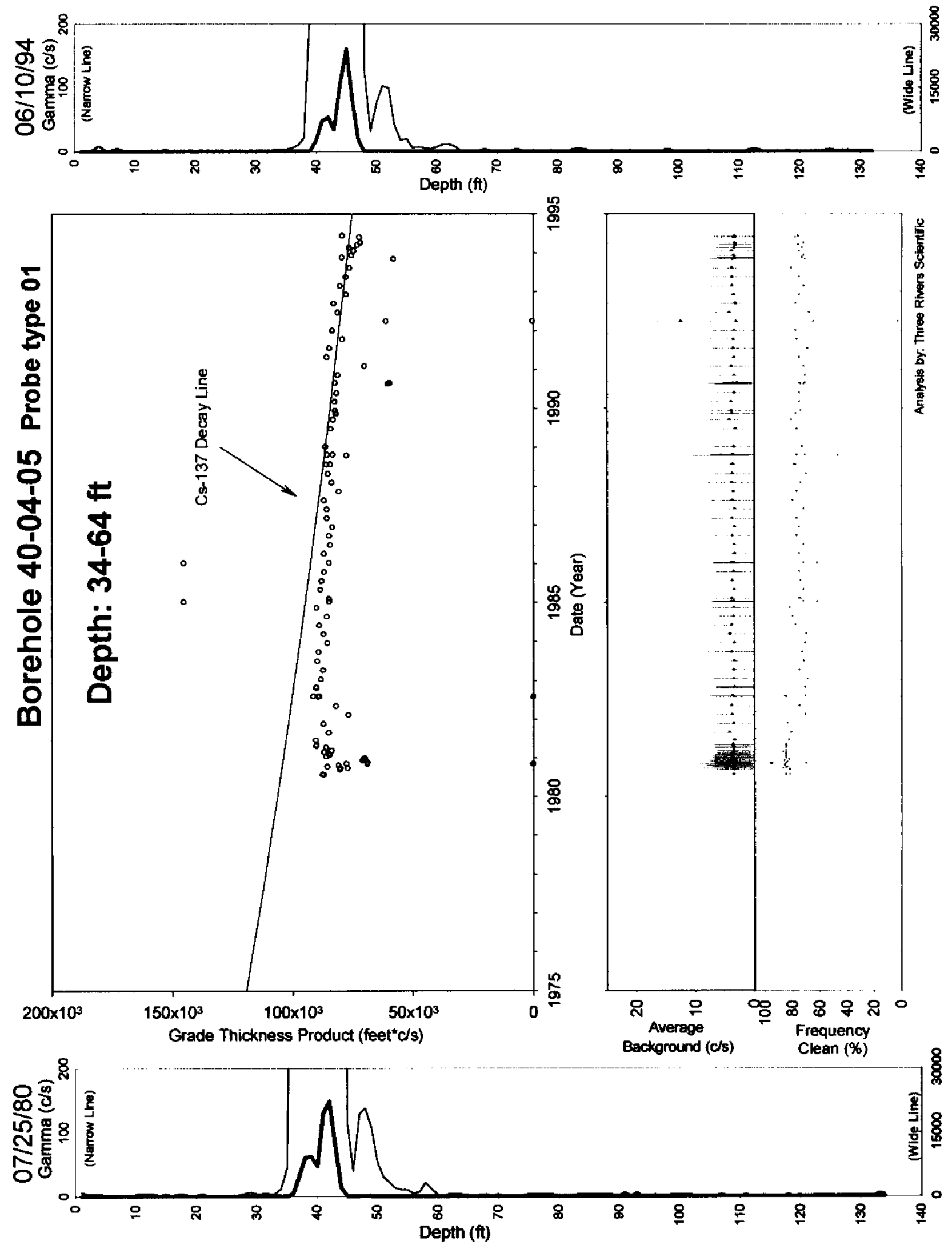
HNF-4220, Rev, 0

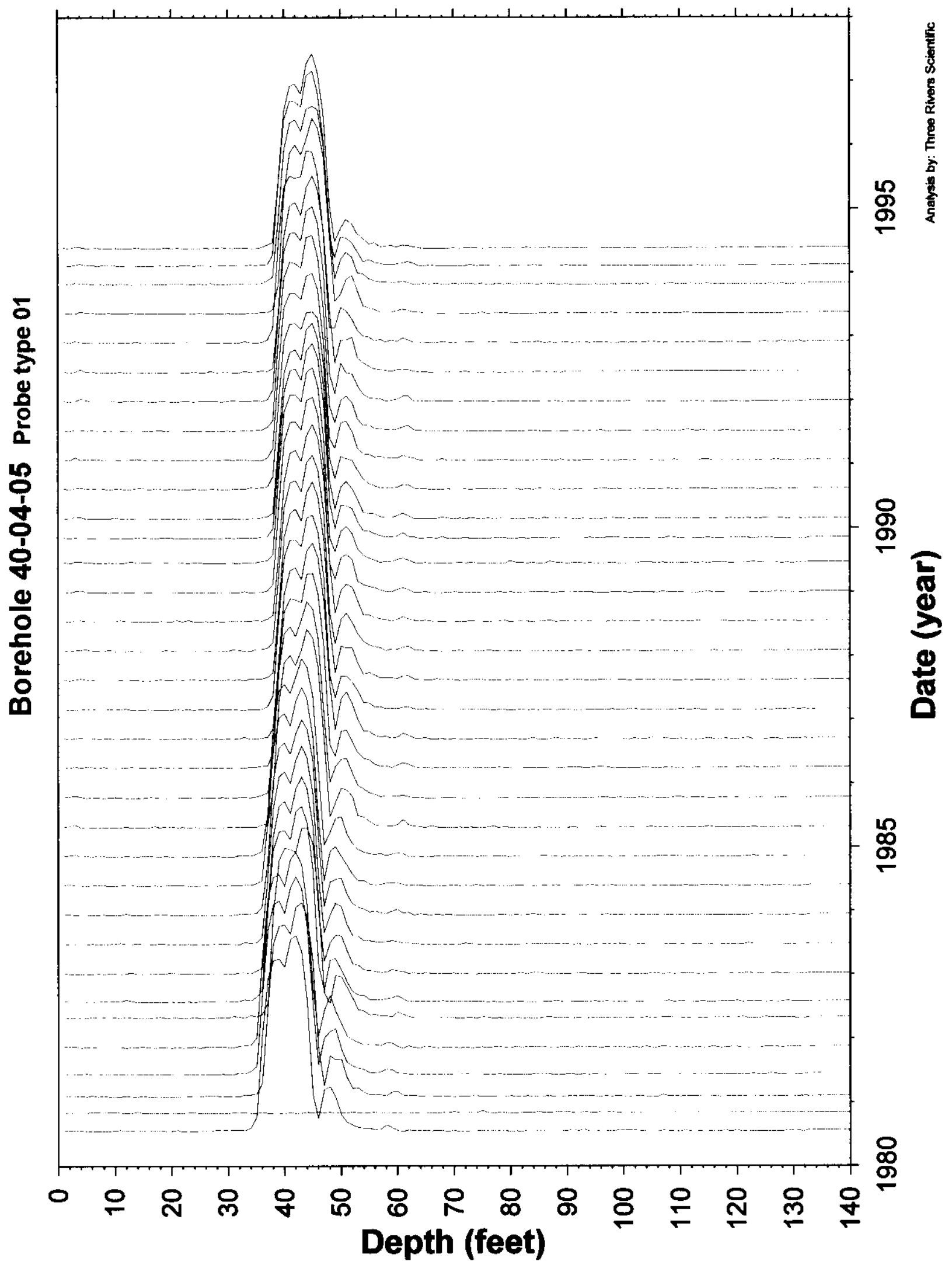

Tank S-104

Page 111 
HNF-4220, Rev. 0
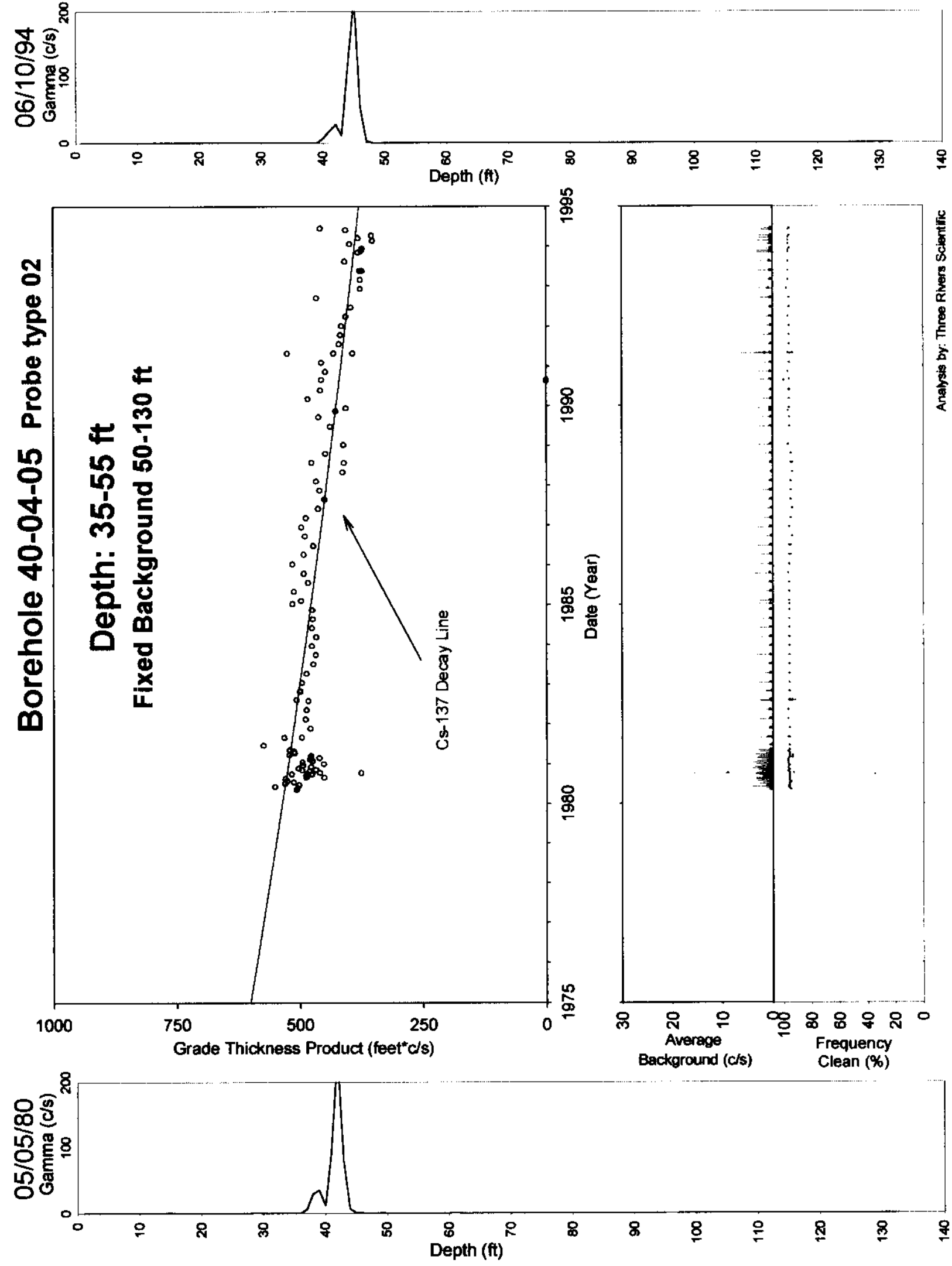

Tank S-104 
HNF-4220, Rev. 0

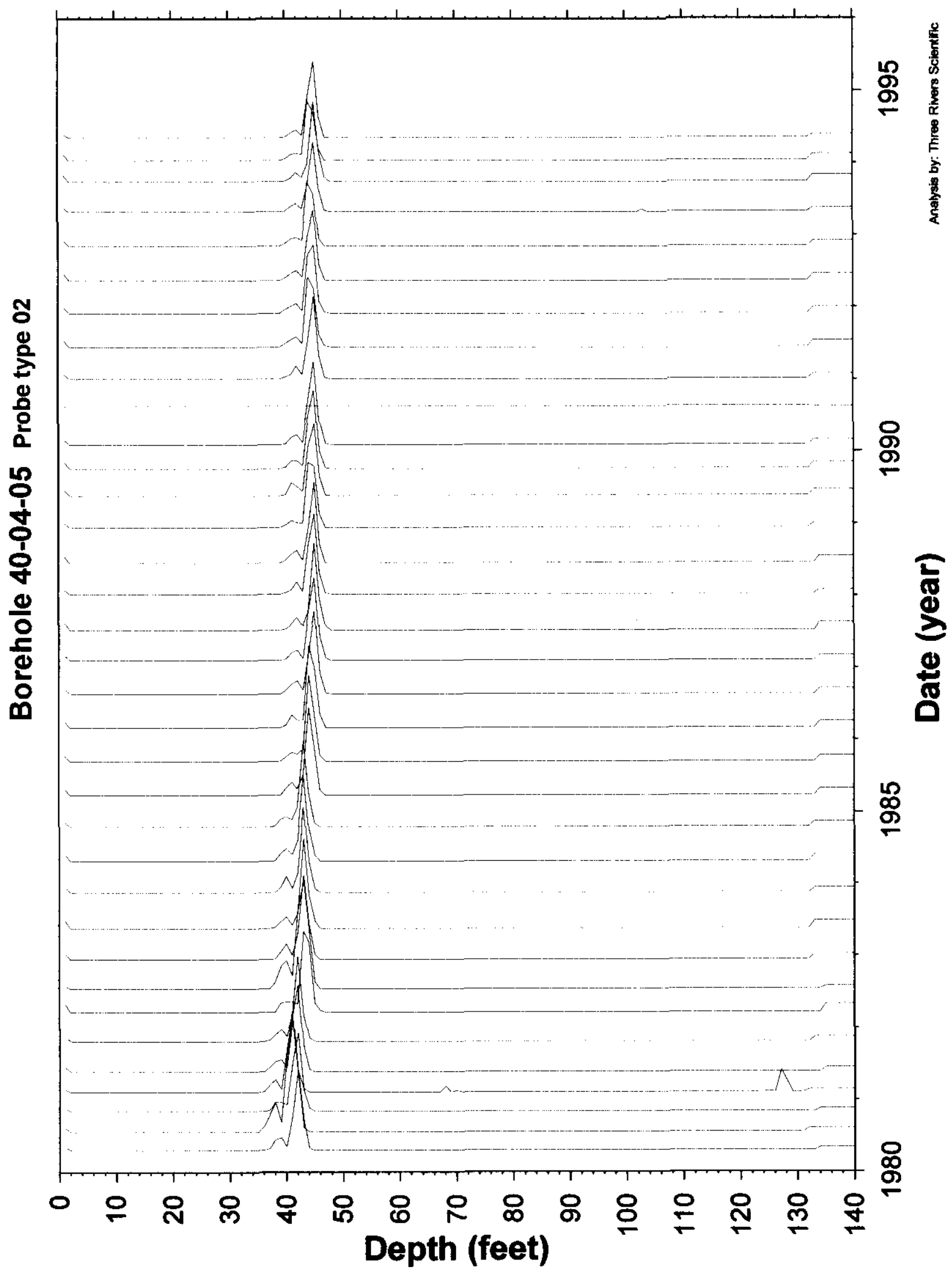

Tank S-104

Page 113 
HNF-4220, Rev. 0
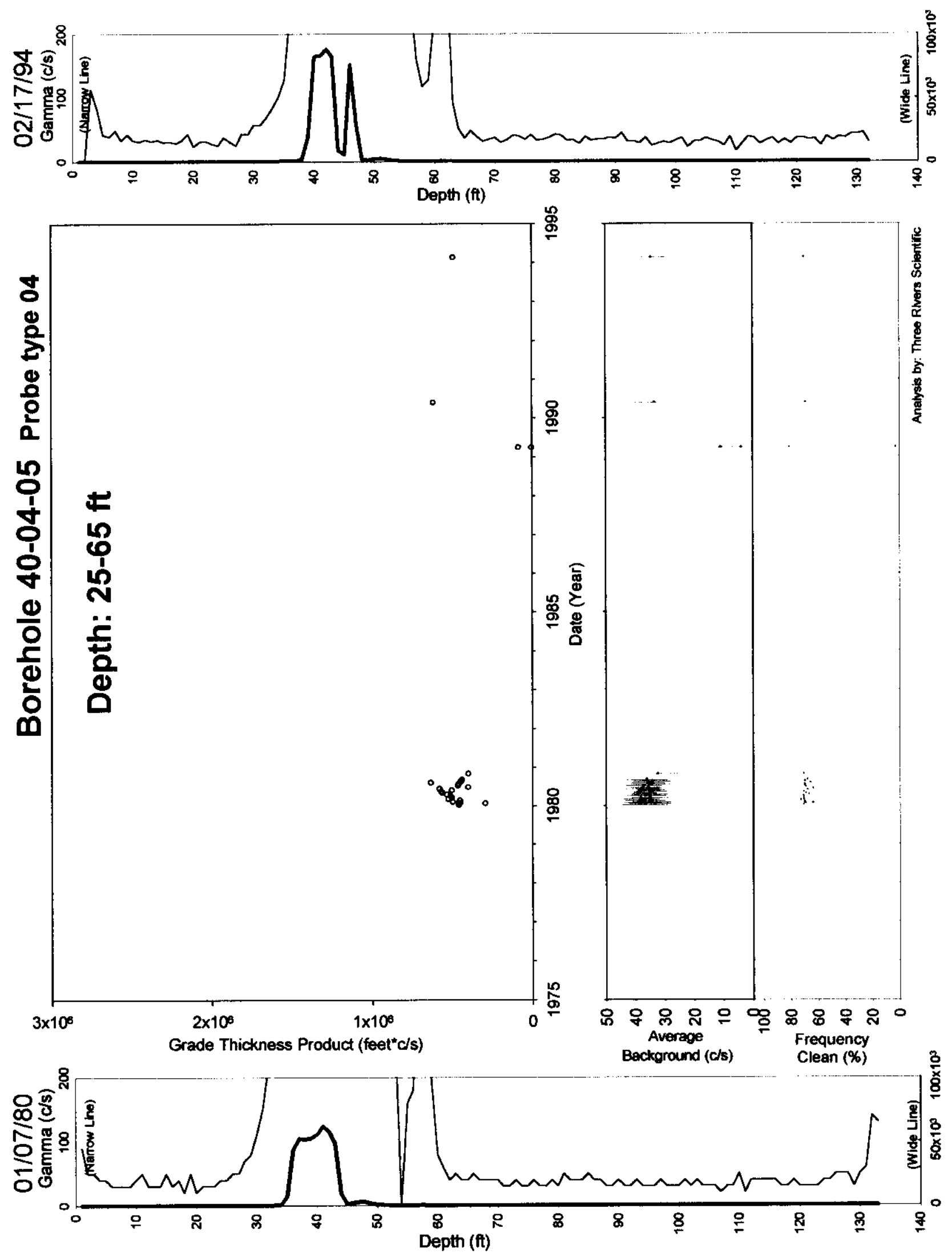

Tank S-104 
HNF-4220, Rev. 0

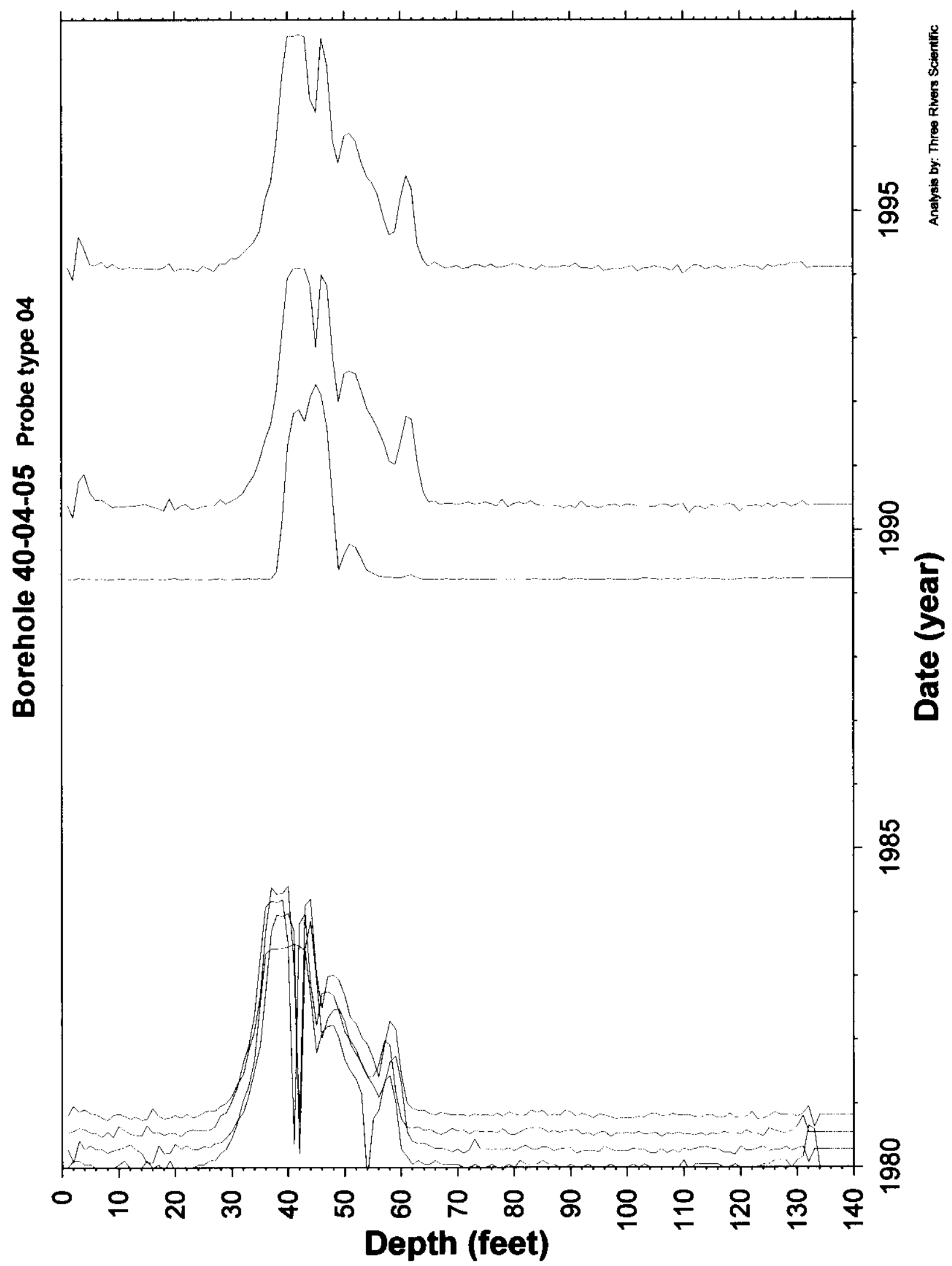

Tank S-104

Page 115 


\section{Borehole 40-04-07}

\section{Contamination (Cs-137) from 5-22 feet is Stable.}

Grade thickness product over 5 to 22 feet is decreasing consistent with Cs-137 (HPGe identified) decay. The levels are at the minimum detectable with the historical gross gamma data. Cs-137 was identified in a peak at 54 feet with a maximum reading of $5 \mathrm{pCi} / \mathrm{g}$ and is not detectable with the historical gross gamma data.

Gross Gamma Survey Information

\begin{tabular}{|r|l|}
\hline Probe Type Processed : & $04:$ NaI \\
\hline Other Probe Types : & $03:$ Neutron (2) 01: Green GM (1) \\
\hline Survey Depth : & $100 \mathrm{ft}$ \\
\hline First Survey Date : & $1 / 14 / 1975$ \\
\hline Last Survey Date : & $6 / 9 / 1994$ \\
\hline Number Surveys Processed : & 314 \\
\hline
\end{tabular}

Analysis Notes

Method Used to Compute Background : $\quad$ Threshold $0<$ val $<50$

Depth(s) where Contamination Identified $0-10 \mathrm{ft}$. Stable in Gross Gamma Surveys :

Analyst Name : R.R. Randall

Company Name : Three Rivers Scientific 
HNF-4220, Rev. 0
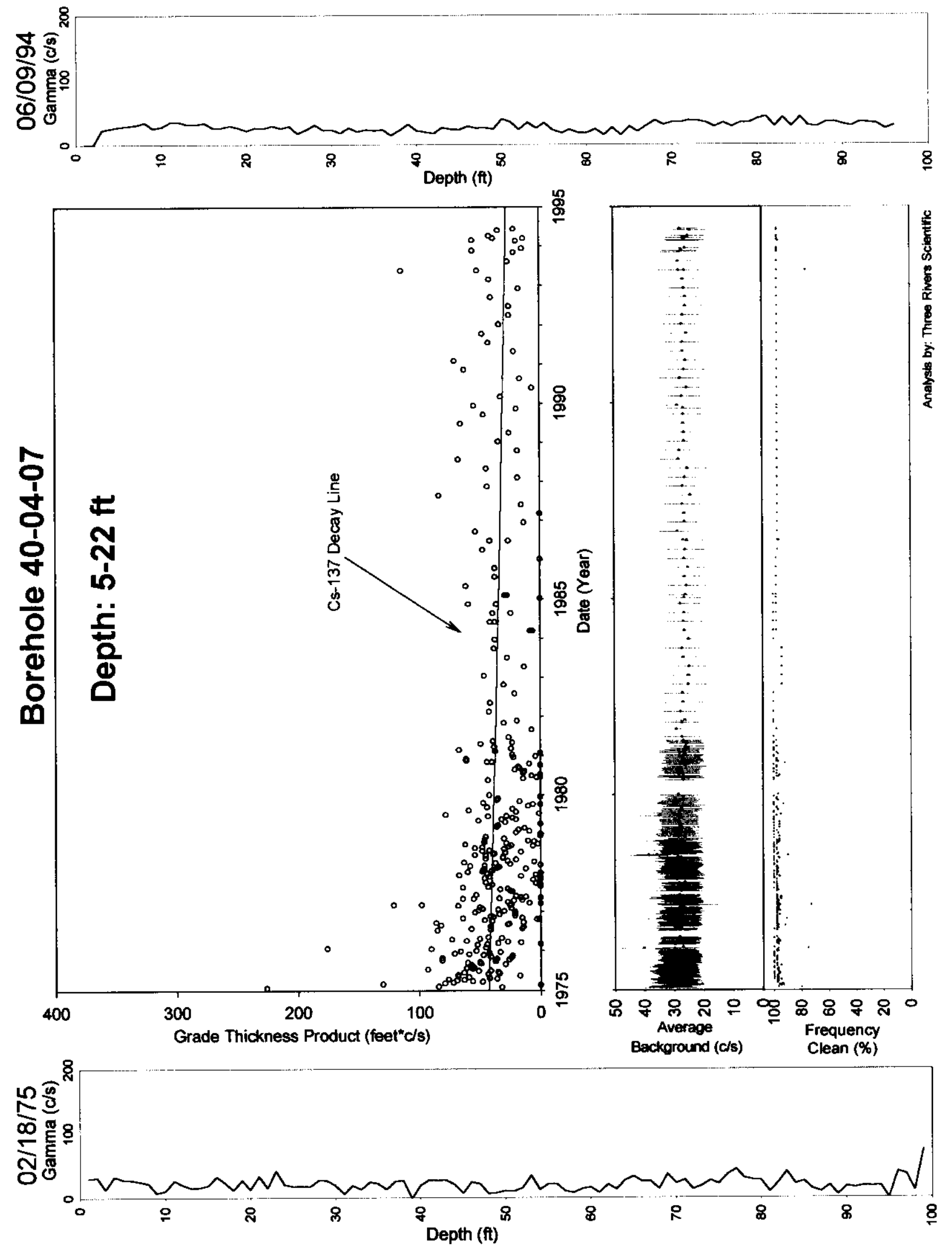

Tank S-104 
HNF-4220, Rev. 0

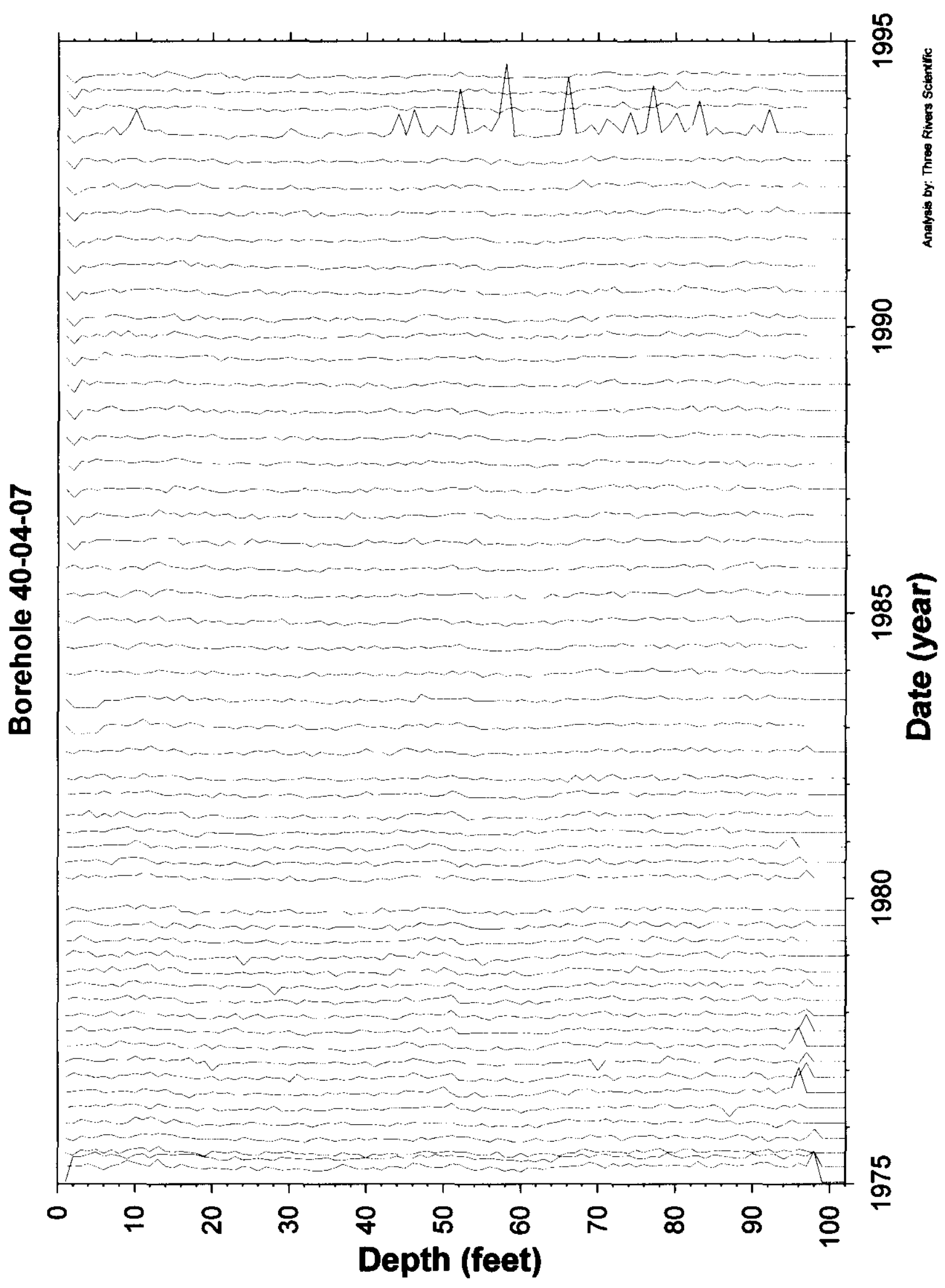

Tank S-104

Page 118 


\title{
Borehole 40-04-08
}

\author{
Contamination (Cs-137) from 0-7 feet is Stable*. \\ Contamination (Cs-137) from 7-11 feet is Stable*. \\ Contamination (Cs-137) from 11-28 feet is Stable*.
}

Grade thickness product over 0-7, 7-11, and 11-28 feet is not decreasing consistent with Cs-137 (HPGe identified) decay prior to 1985 . Depth shifting cannot be rigorously performed due to changes in the near surface data collection in about 1984. Data collection system upgrades eliminated depth control problems after 1986. Since 1986, all three zones exhibit stability, and the data before 1985 is not valid, thus the categorization of Stable*.

A grade thickness product was computed and plot included for the entire range of 0 to 28 feet in order to eliminate depth control errors that are present in each sub-interval. This plot suggest some changes in 1975, but stability from 1976 to 1994 . The result for this inclusive interval indicates that the observed changes in the three sub zones are mostly depth control errors. The possible changes early in the total depth interval may be caused by surface activity, fast decay component, or tank farm activity. The historical gross gamma data alone cannot determine the cause of the observation. It is not possible to speculate on possible downward movement for the early depth control plagued data.

Gross Gamma Survey Information

\begin{tabular}{|r|l|}
\hline Probe Type Processed : & $04:$ NaI \\
\hline Other Probe Types : & $03:$ Neutron (2) 01: Green Gm (1) \\
\hline Survey Depth : & $50 \mathrm{ft}$ \\
\hline First Survey Date : & $3 / 17 / 1975$ \\
\hline Last Survey Date : & $8 / 26 / 1994$ \\
\hline Number Surveys Processed : & 313 \\
\hline &
\end{tabular}

Analysis Notes

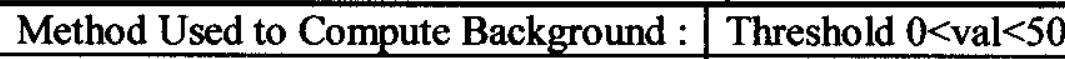

Depth(s) where Contamination Identified $0-7 \mathrm{ft} ., 7-11 \mathrm{ft} ., 11-28 \mathrm{ft}$. Stable* in Gross Gamma Surveys :

Analyst Name: $\quad$ R.R. Randall

Company Name : Three Rivers Scientific 
HNF-4220, Rev. 0
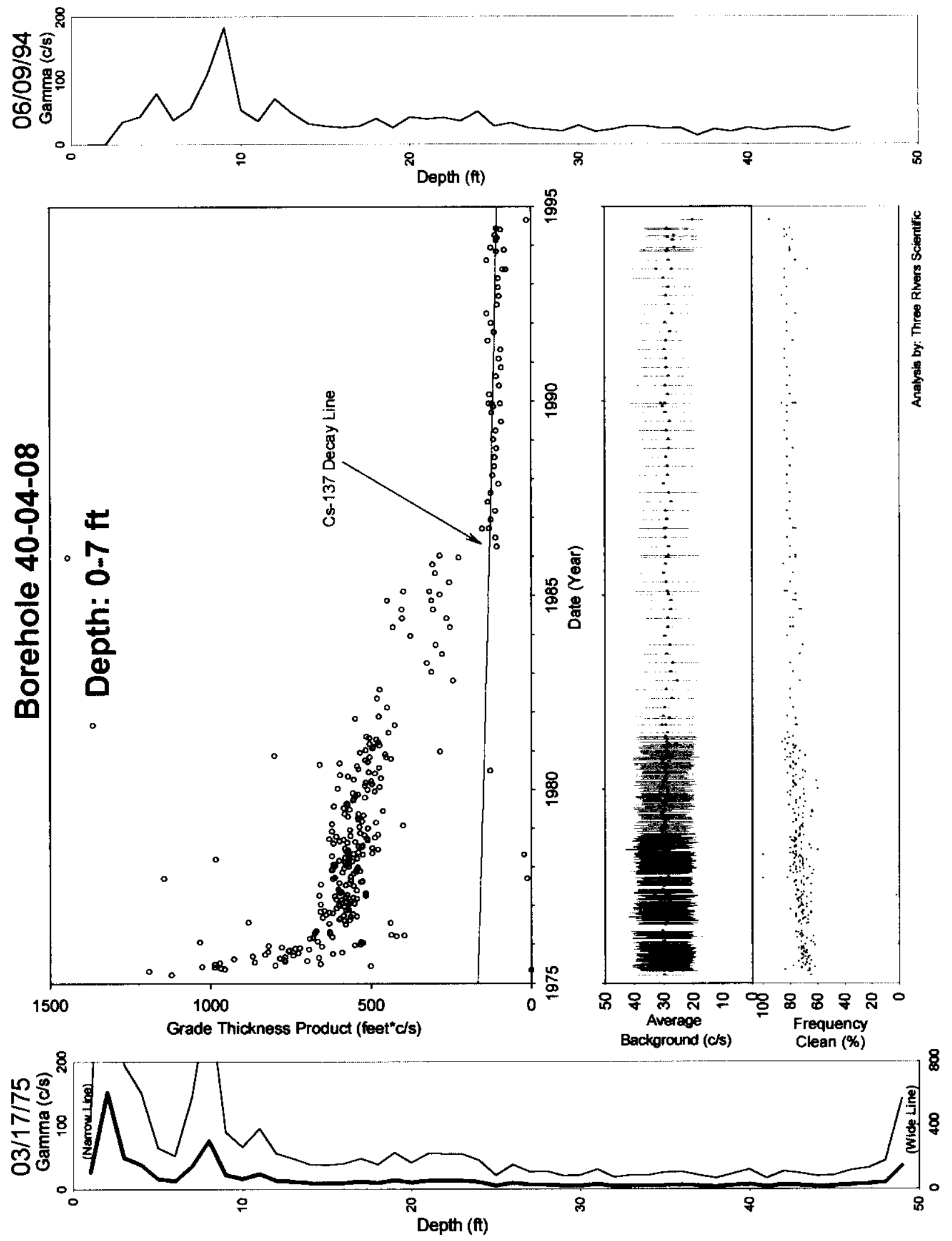
HNF-4220, Rev. 0
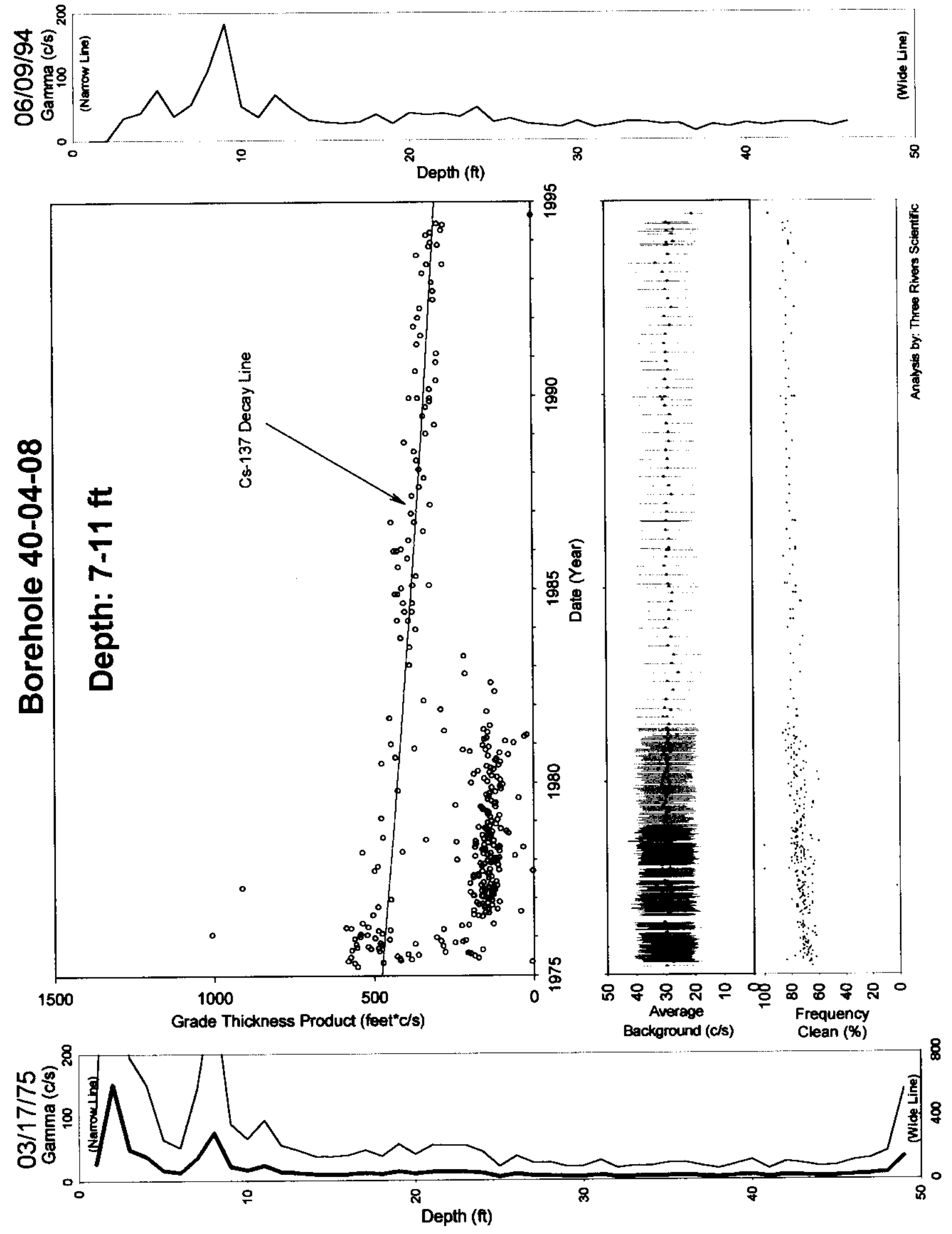

Tank S-104

Page 121 
HNF-4220, Rev. 0
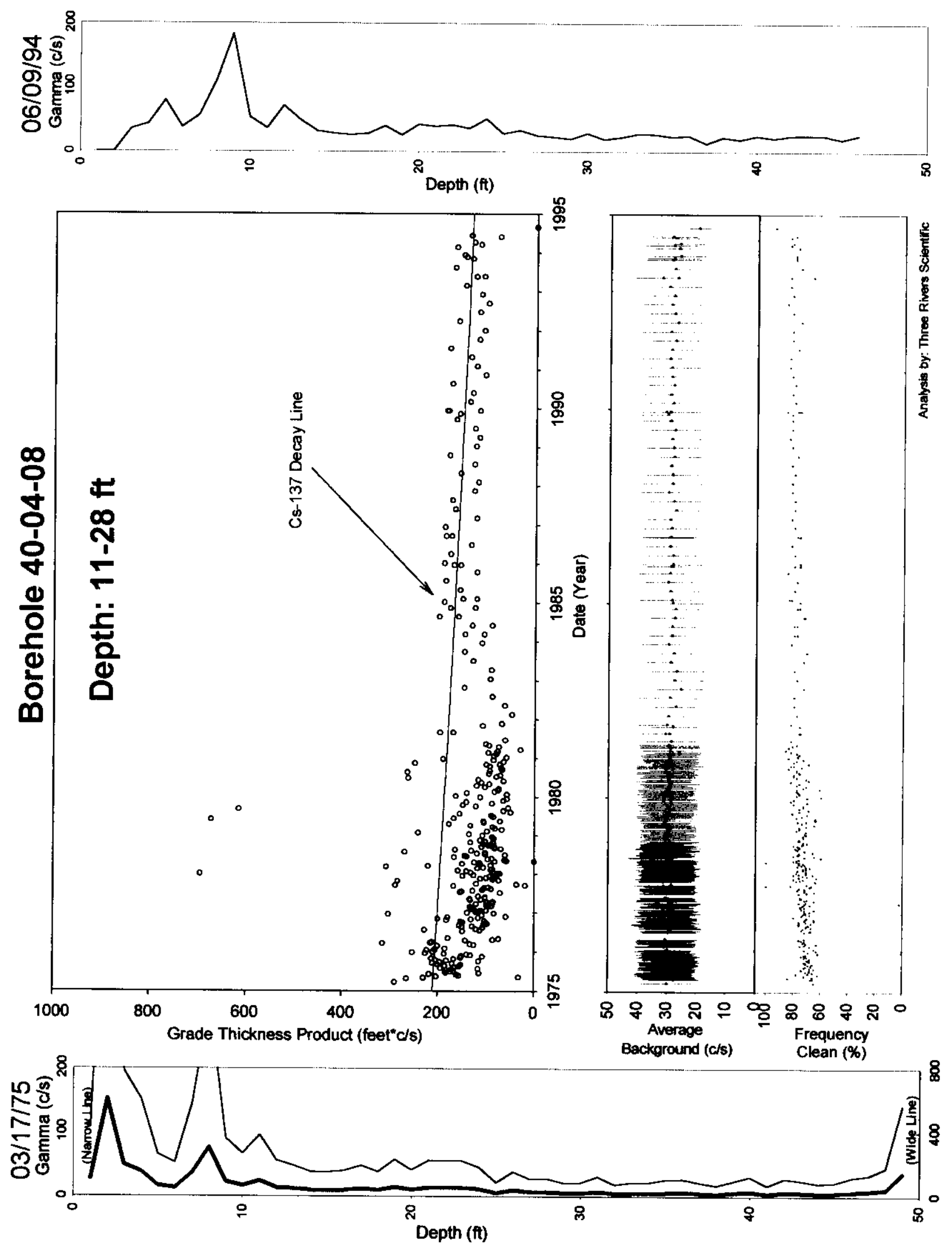

Tank S-104

Page 122 
HNF-4220, Rev. 0
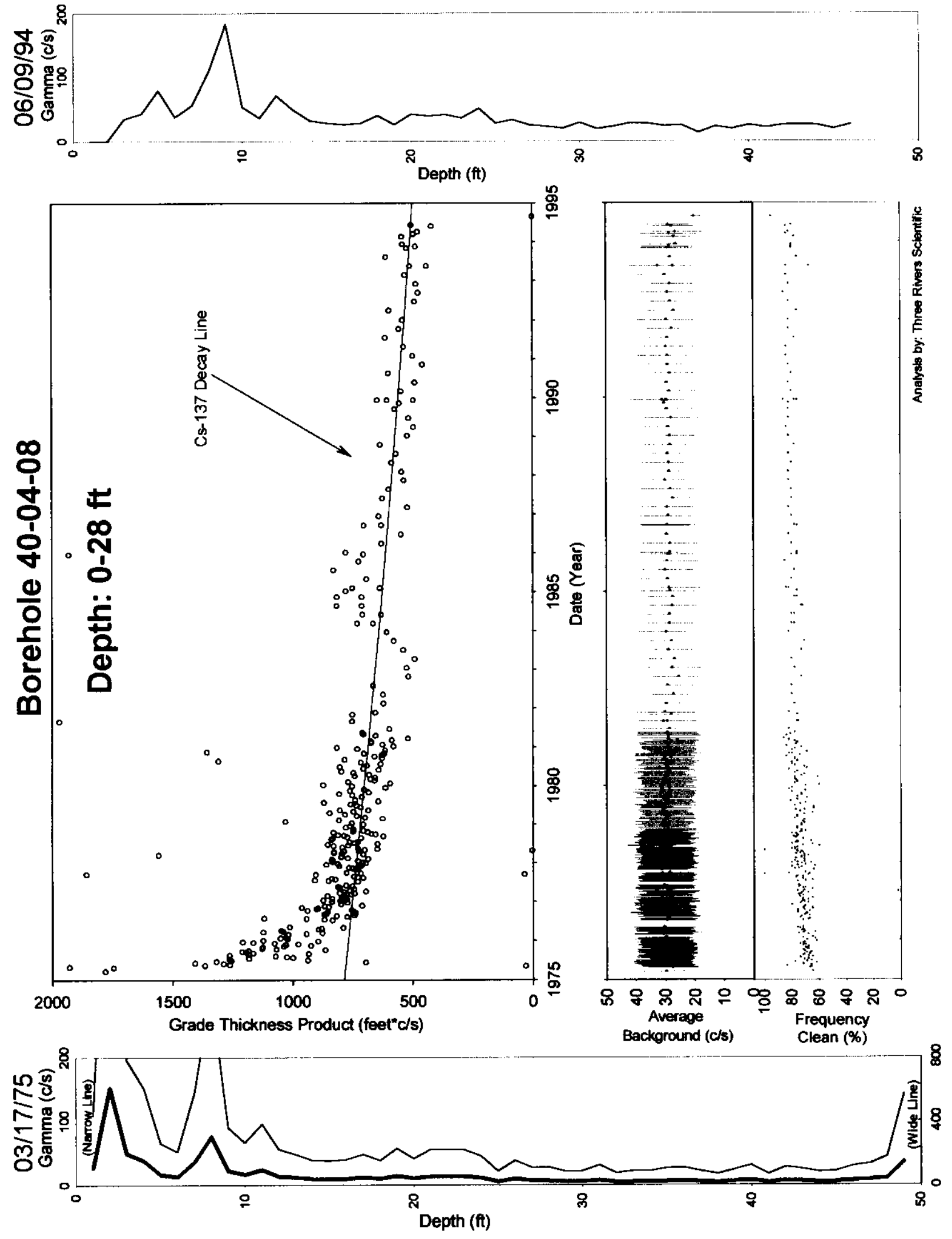

Tank S-104 


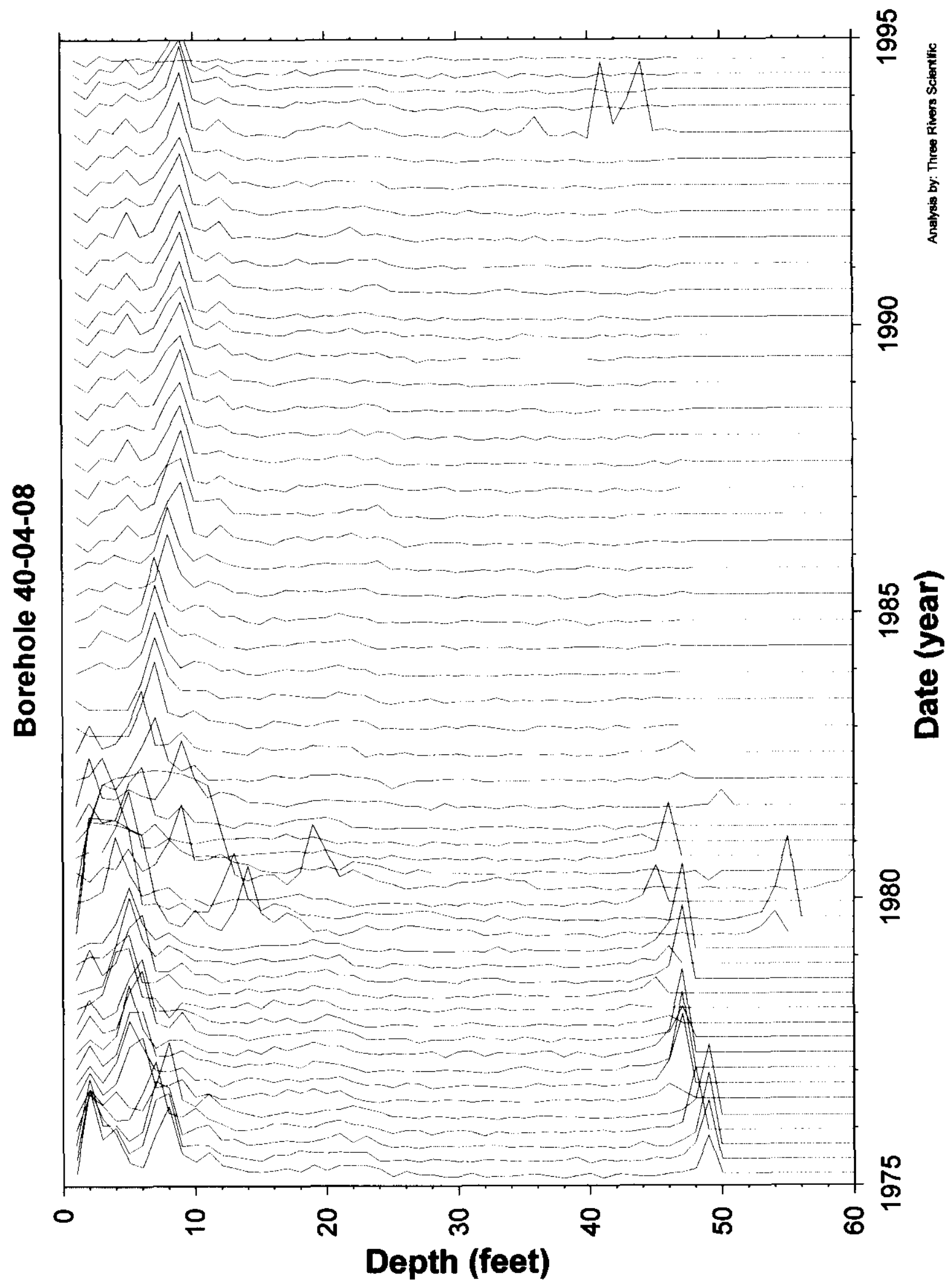

Tank S-104

Page 124 
HNF-4220, Rev. 0

\section{S Tank 105 Wells}

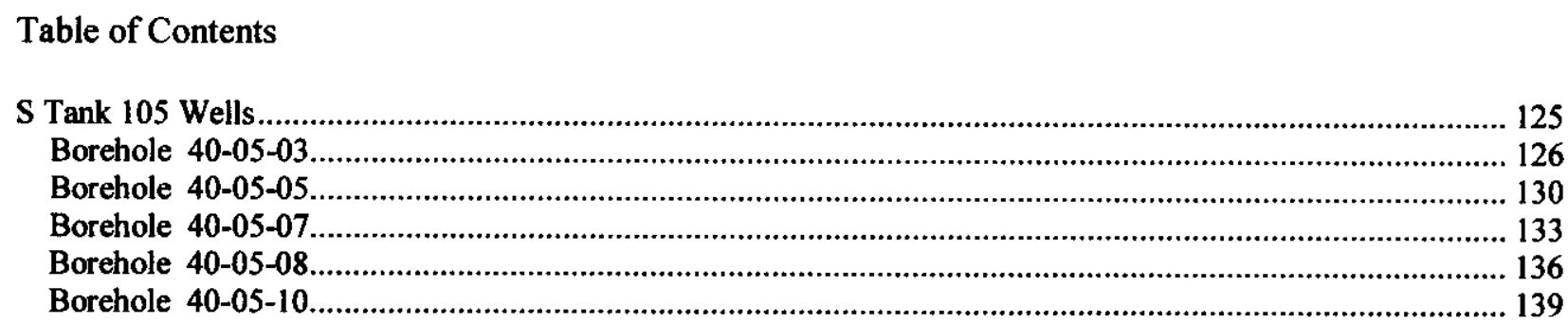

This section contains the analysis results for vadose zone boreholes (dry wells) associated with Tank 105 in the "S" Tank Farm.

Special Note: Borehole 40-05-03 has a gross gamma increase at 38 feet (both historical and HPGe data) that is not explained by the radionuclides detected. The indication is $\mathrm{Sr}-90$ in this interval.

Borehole 40-05-05 does not have HPGe data since the casing was determined as bent and unsafe for the logging instrument. 


\section{Borehole 40-05-03}

\section{Contamination (Cs-137) from 0-10 feet is Tank Farm Activity. Contamination (Sr-90) from 28-41 feet is Undetermined.}

Grade thickness product from 0 to 10 feet changes rapidly in 1984 and is erratic until another rapid change in 1986 and is categorized as tank farm activity. The grade thickness product, while at low levels from 1986 to 1994 , appears stable.

The HPGe logging system detected Cs-137 0 to 1 feet at a reading of $23 \mathrm{pCi} / \mathrm{g}$, but less than 1 $\mathrm{pCi} / \mathrm{g}$ for the remainder of the depths.

There is an elevated gross gamma response in both the historical data and the HPGe data at 32 feet that is not due to changes in KUT or detection of any other gamma emitting isotopes. A split in the casing would show increases in all three KUT values. The stack plot shows the elevated zone from 1975 until 1994. One possibility is the presence of Sr-90, with a half life of 28.5 years. Therefore, a grade thickness product was computed for the interval $28-41$ feet, and Sr-90 (hypothesized) decay line was compared to the historical data. The levels are very low and no clear conclusion can be reached, thus the categorization is undetermined. The levels of Cs137 (HPGe identified) in this interval is not high enough to register on the historical gross gamma data, and was therefore not used.

Gross Gamma Survey Information

\begin{tabular}{|r|l|}
\hline Probe Type Processed : & $04:$ NaI \\
\hline Other Probe Types : & $03:$ Neutron \\
\hline Survey Depth : & $100 \mathrm{ft}$ \\
\hline First Survey Date : & $1 / 13 / 1975$ \\
\hline Last Survey Date : & $11 / 2 / 1993$ \\
\hline Number Surveys Processed : & 706 \\
\hline
\end{tabular}

Analysis Notes

\begin{tabular}{|r|l|}
\hline Method Used to Compute Background : & $\begin{array}{l}0-10 \mathrm{ft}: \text { Threshold } 0<\mathrm{val}<50 \text { 28-41 ft:Fixed } \\
\text { Bkg over 10-28 ft }\end{array}$ \\
\hline Depth(s) where Contamination Identified & $0-10 \mathrm{ft}$ Tank Farm Activity \\
in Gross Gamma Surveys : & $28-41 \mathrm{ft}$ Undetermined \\
\hline Analyst Name : & R.R. Randall \\
\hline Company Name : & Three Rivers Scientific \\
\hline
\end{tabular}


HNF-4220, Rev. 0
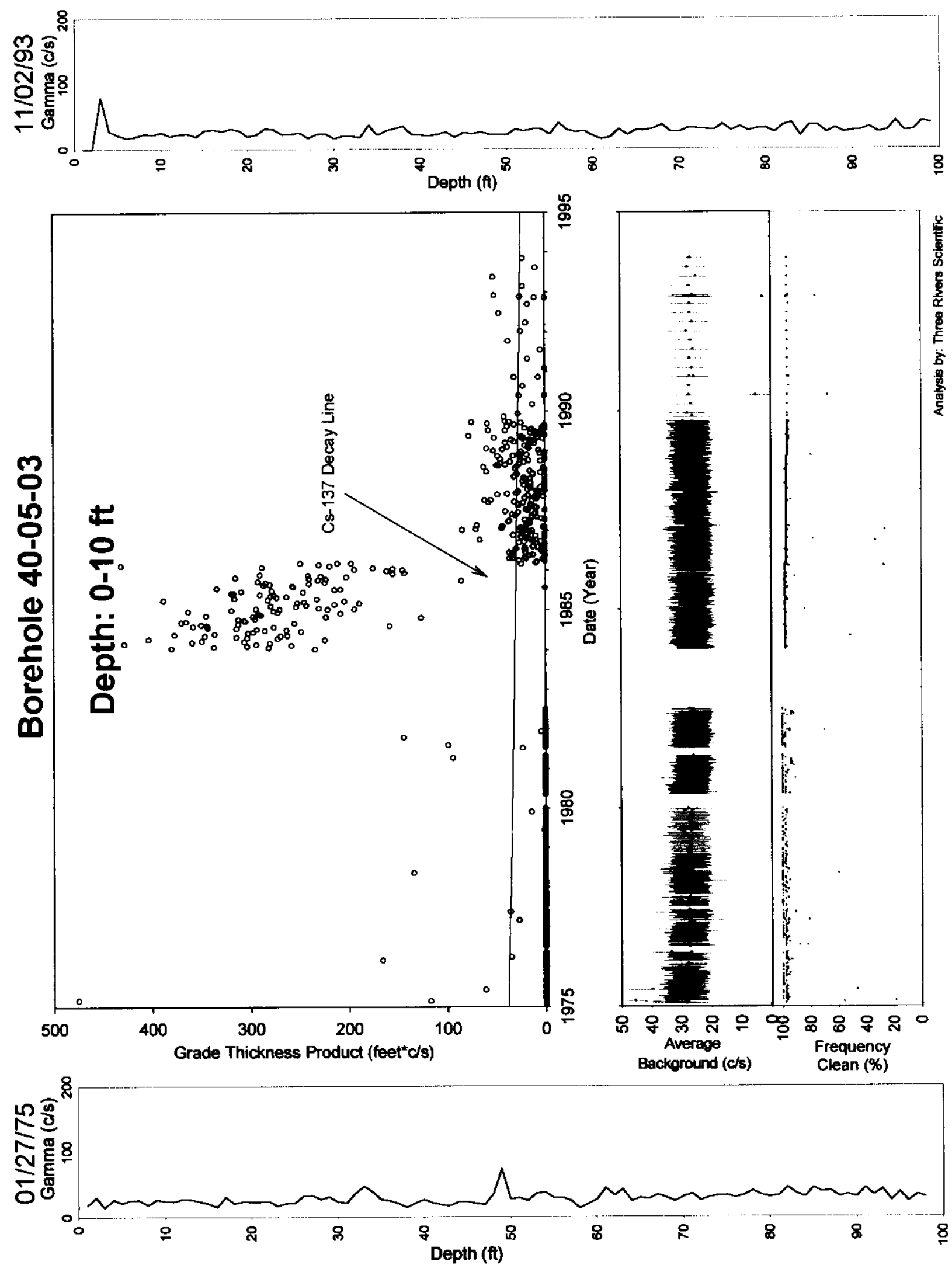

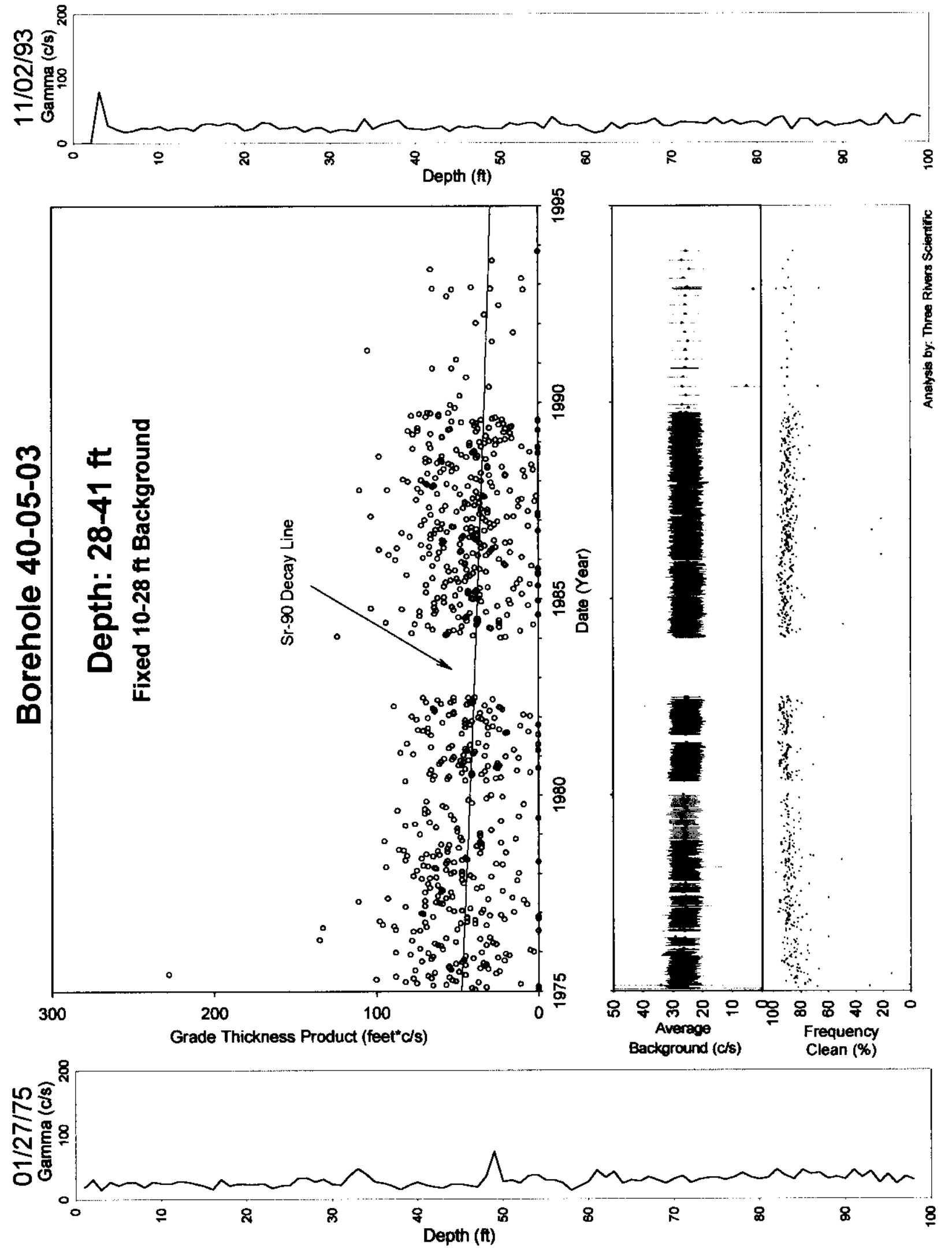
HNF-4220, Rev. 0

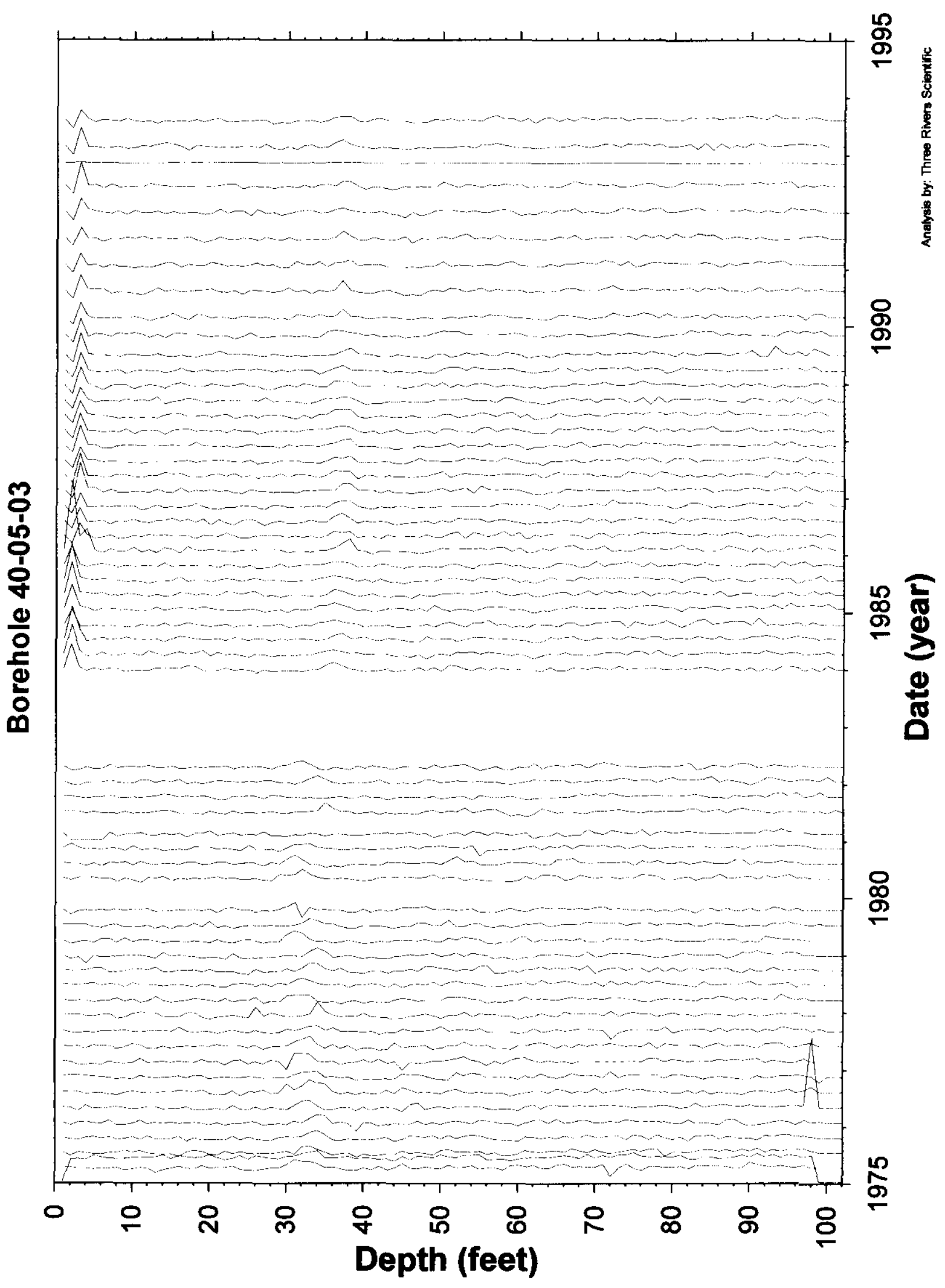

Tank S-105

Page 129 


\section{Borehole 40-05-05}

\section{No Gamma Ray Emitting Contamination was Identified.}

No significant levels of gamma ray contamination are present, based upon gross gamma data, above the survey probe detection threshold between 1975 and 1994 in the vadose zone from 2 to 150 feet. The HPGe logging system was not run in this borehole due to bent casing

Gross Gamma Survey Information

\begin{tabular}{|r|l|}
\hline Probe Type Processed : & $04:$ NaI \\
\hline Other Probe Types : & $03:$ Neutron \\
\hline Survey Depth : & $150 \mathrm{ft}$ \\
\hline First Survey Date : & $1 / 13 / 1975$ \\
\hline Last Survey Date : & $11 / 2 / 1993$ \\
\hline Number Surveys Processed : & 410 \\
\hline
\end{tabular}

Analysis Notes

Method Used to Compute Background : $\quad$ Threshold $0<$ val $<50$

Depth(s) where Contamination Identified NONE in Gross Gamma Surveys :

Analyst Name : $\quad$ R.R. Randall

Company Name : Three Rivers Scientific 


\section{Borehole 40-05-05}

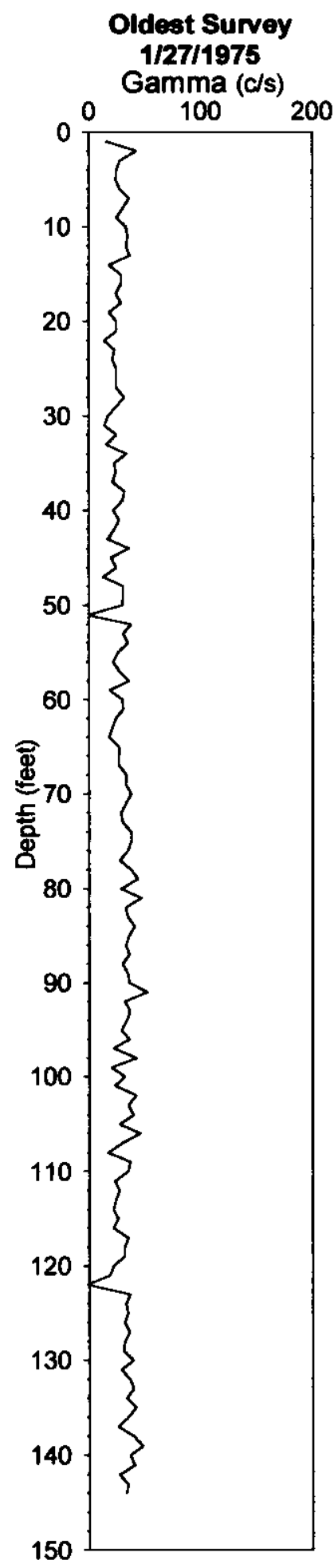
No Gamma-Ray Emitting Contamination Above Survey Detection Threshold
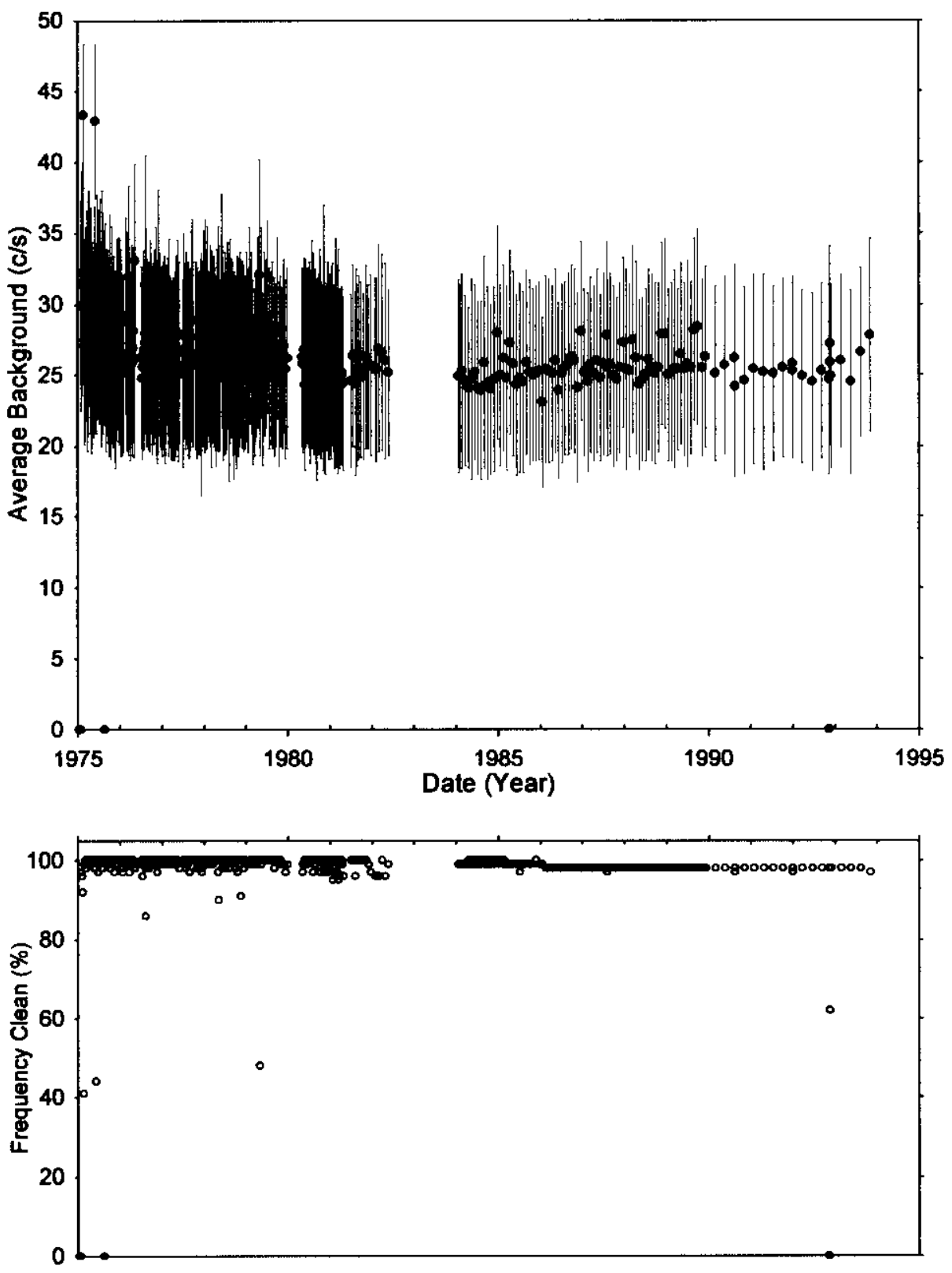

Analysis by: Throe Rivers Scientific 
HNF-4220, Rev. 0

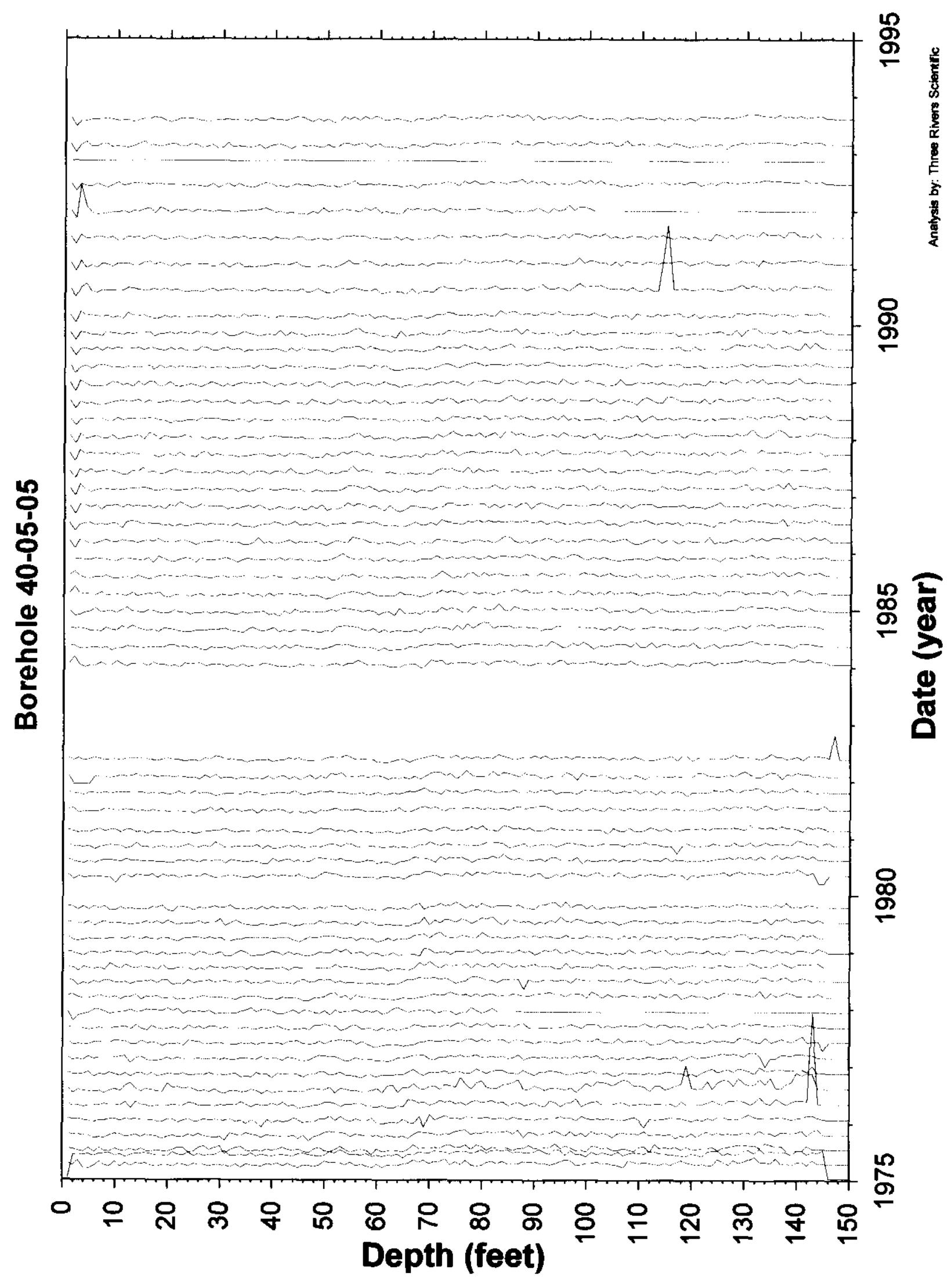

Tank S-105

Page 132 


\section{Borehole 40-05-07}

\section{No Gamma Ray Emitting Contamination was Identified.}

No significant levels of gamma ray contamination are present, based upon gross gamma data, above the survey probe detection threshold between 1975 and 1994 in the vadose zone from 2 to 100 feet. The HPGe logging system detected Cs-137 at $2 \mathrm{pCi} / \mathrm{g}$ from 0 to 2 feet, but less than 1 $\mathrm{pCi} / \mathrm{g}$ for rest of the depths.

Gross Gamma Survey Information

Probe Type Processed : $04: \mathrm{NaI}$

Other Probe Types : $03:$ Neutron

Survey Depth : $100 \mathrm{ft}$

First Survey Date : $1 / 13 / 1975$

Last Survey Date : $10 / 26 / 1993$

Number Surveys Processed : 764

Analysis Notes

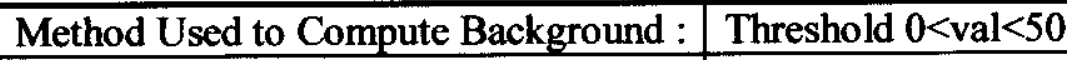

Depth(s) where Contamination Identified NONE

in Gross Gamma Surveys :

Analyst Name : R.R. Randall

Company Name : Three Rivers Scientific 


\section{Borehole 40-05-07}

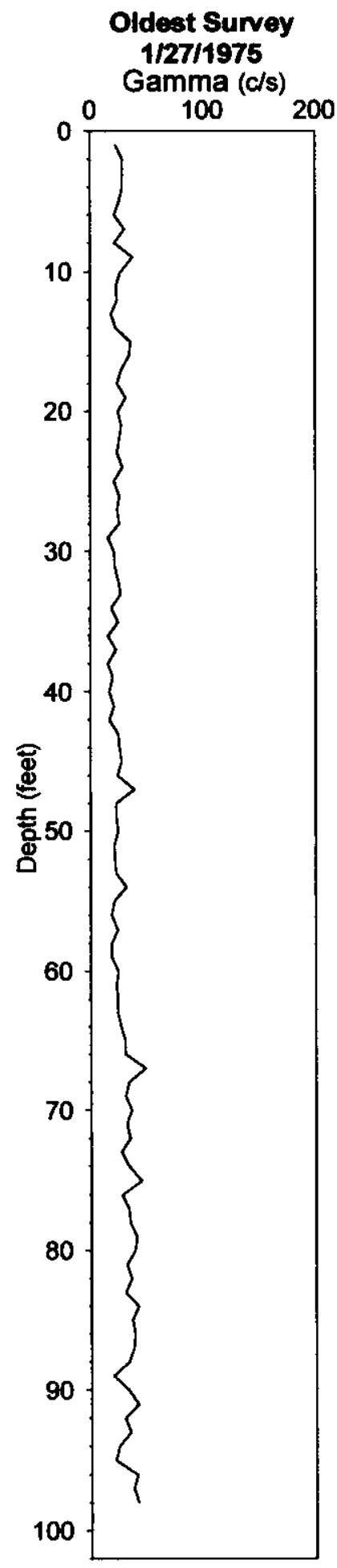
No Gamma-Ray Emitting Contamination
Above Survey Detection Threshold
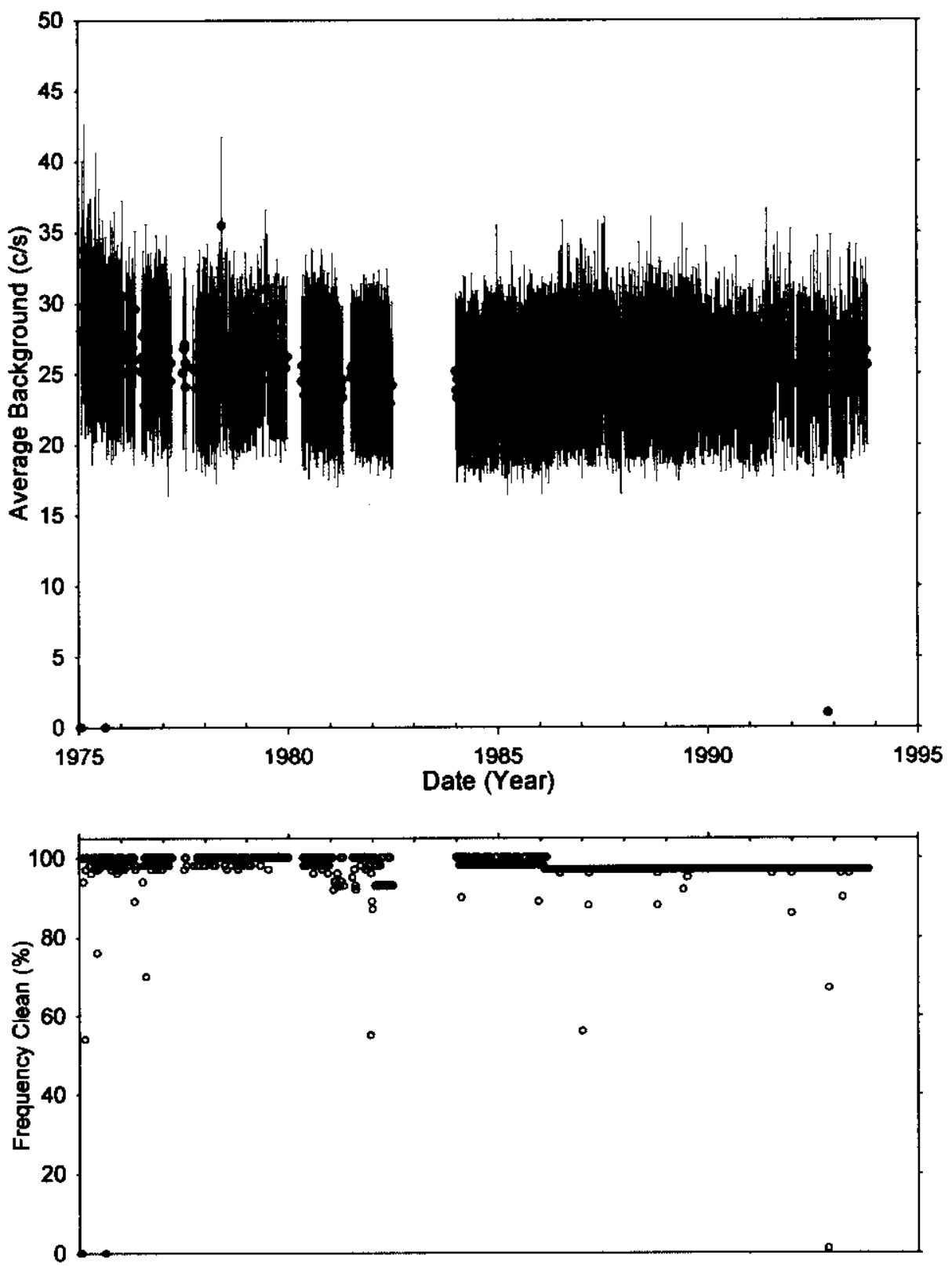

Anatysis by: Three Rivers Scientific 
HNF-4220, Rev. 0

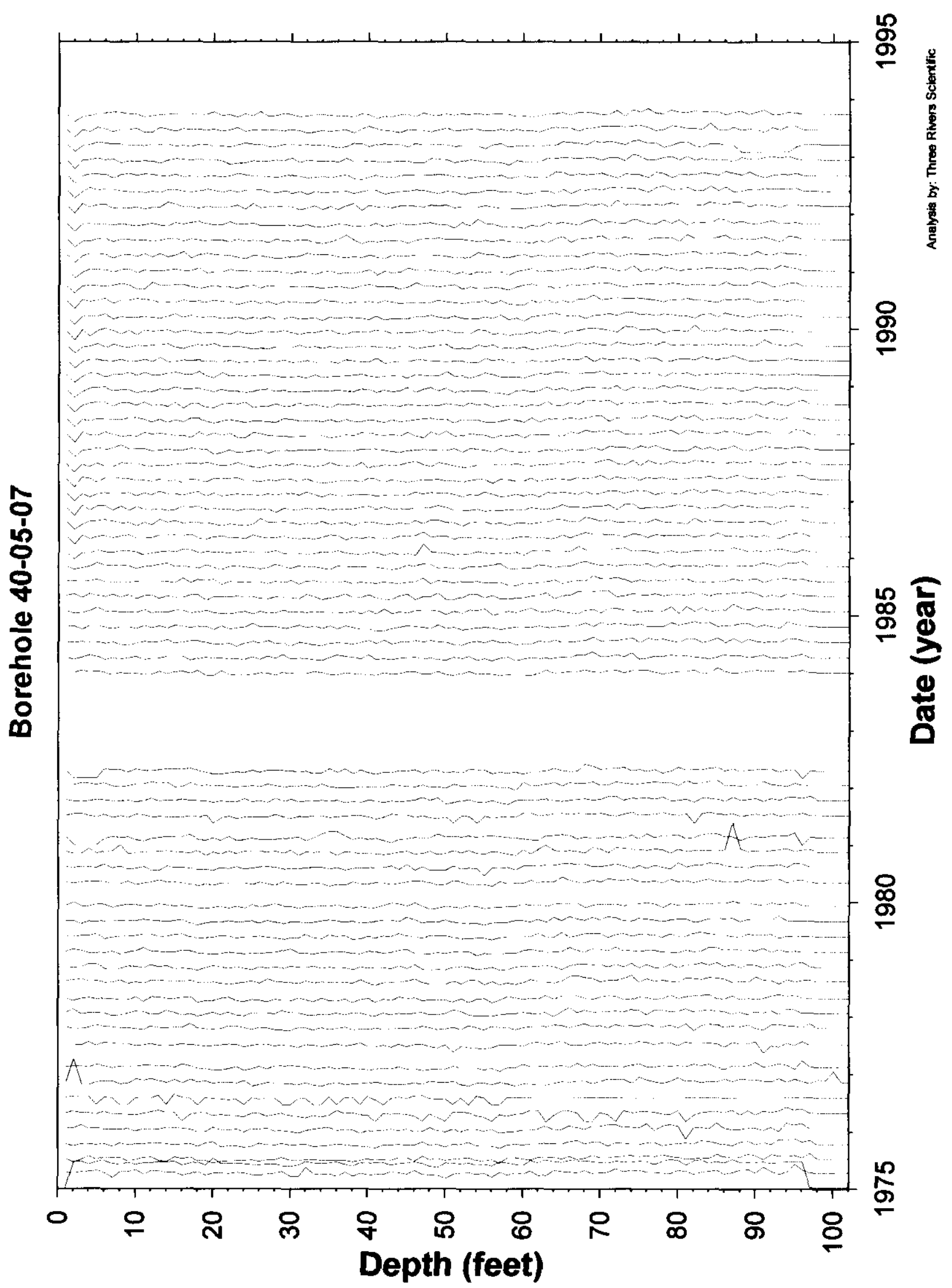

Tank S-105

Page 135 


\section{Borehole 40-05-08}

\section{No Gamma Ray Emitting Contamination was Identified.}

No significant levels of gamma ray contamination are present, based upon gross gamma data, above the survey probe detection threshold between 1976 and 1994 in the vadose zone from 2 to 100 feet. The HPGe logging system detected Cs-137 at $2 \mathrm{pCi} / \mathrm{g}$ at 0 feet, but less than $1 \mathrm{pCi} / \mathrm{g}$ for rest of the depths.

Gross Gamma Survey Information

\begin{tabular}{|r|l|}
\hline Probe Type Processed : & $04:$ NaI \\
\hline Other Probe Types : & $03:$ Neutron \\
\hline Survey Depth : & $100 \mathrm{ft}$ \\
\hline First Survey Date : & $5 / 10 / 1976$ \\
\hline Last Survey Date : & $10 / 26 / 1993$ \\
\hline Number Surveys Processed : & 491 \\
\hline
\end{tabular}

Analysis Notes

Method Used to Compute Background : $\quad$ Threshold $0<$ val $<50$

Depth(s) where Contamination Identified NONE in Gross Gamma Surveys :

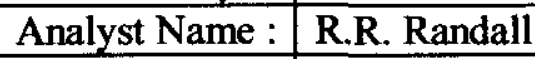

Company Name : Three Rivers Scientific 


\section{Borehole 40-05-08}

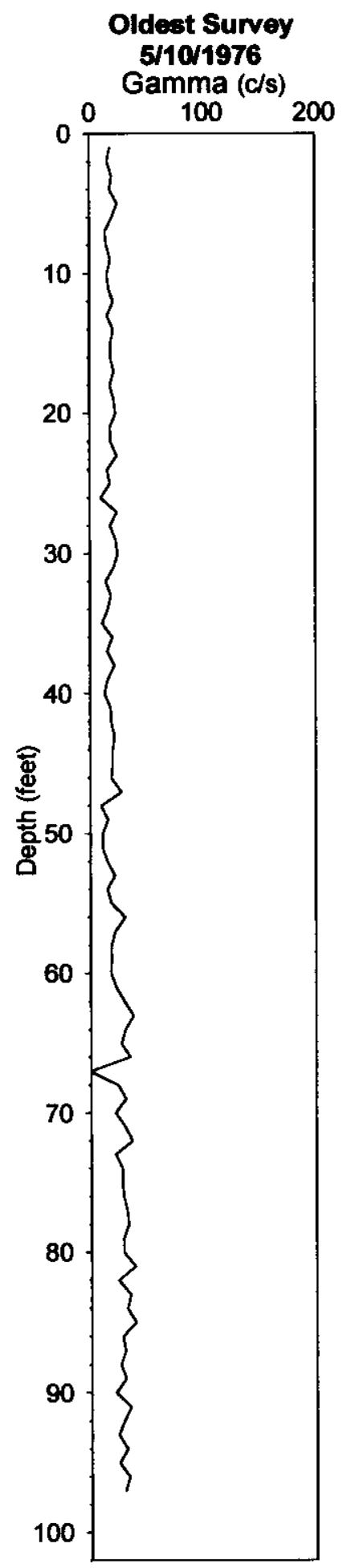

No Gamma-Ray Emitting Contamination Above Survey Detection Threshold
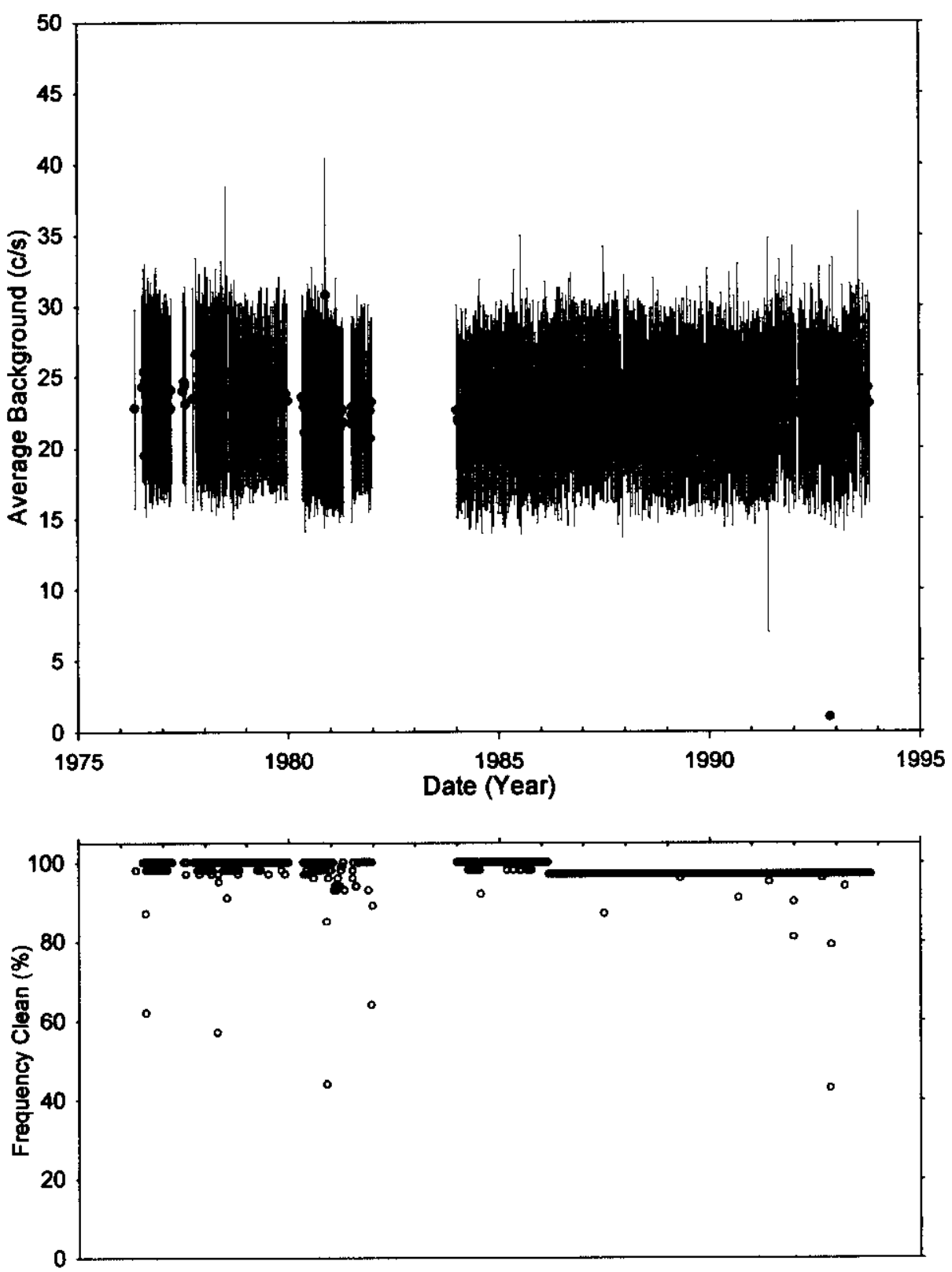

Anslysis by: Three Rivers Scientific 
HNF-4220, Rev. 0

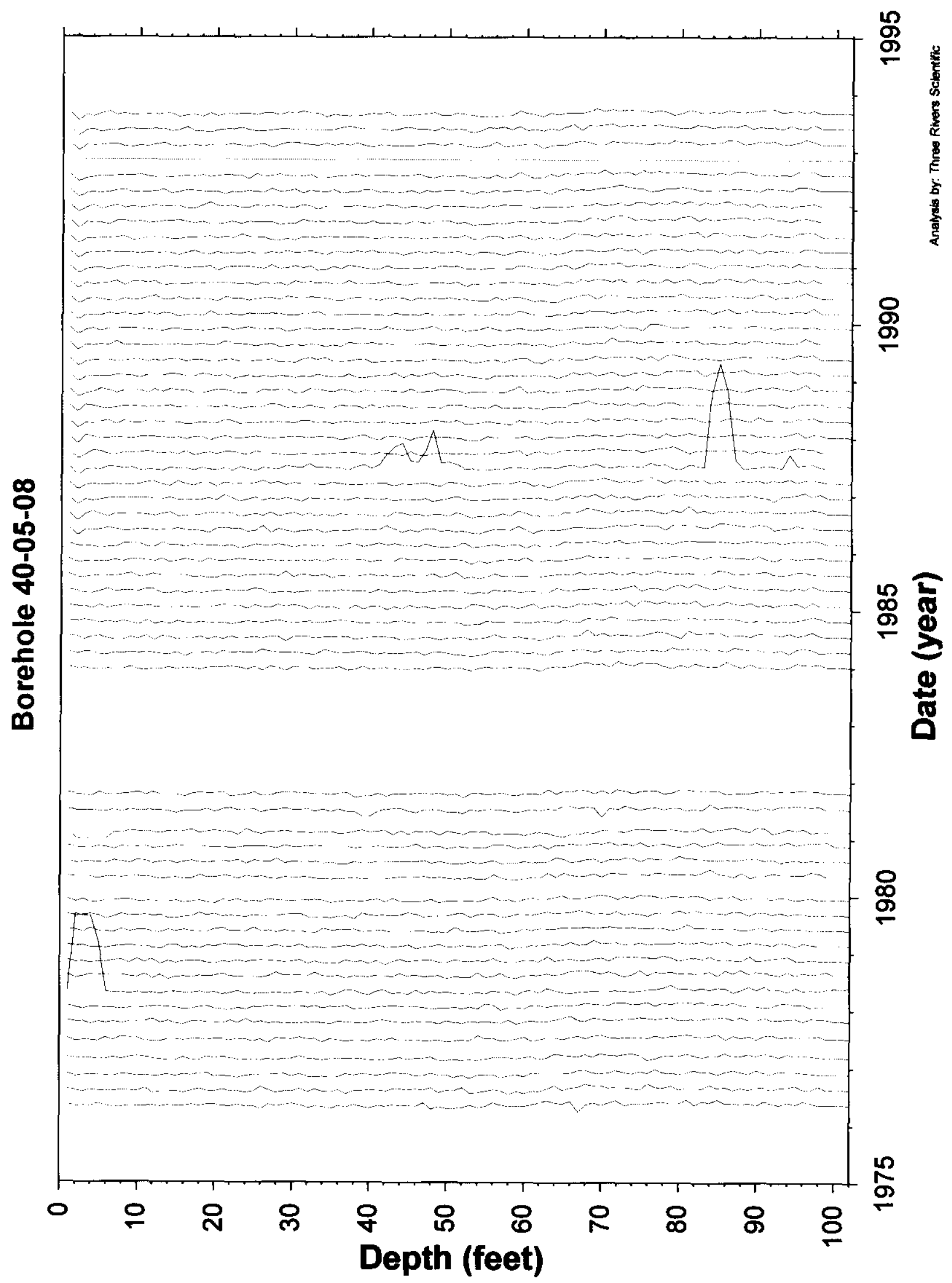

Tank S-105

Page 138 


\section{Borehole 40-05-10}

\section{No Gamma Ray Emitting Contamination was Identified.}

No significant levels of gamma ray contamination are present, based upon gross gamma data, above the survey probe detection threshold between 1975 and 1994 in the vadose zone from 2 to 90 feet. The HPGe logging system detected Cs-137 at $3 \mathrm{pCi} / \mathrm{g}$ at 0 feet, but less than $1 \mathrm{pCi} / \mathrm{g}$ for rest of the depths.

Gross Gamma Survey Information

\begin{tabular}{|r|l|}
\hline Probe Type Processed : & $04:$ NaI \\
\hline Other Probe Types : & $03:$ Neutron \\
\hline Survey Depth : & $90 \mathrm{ft}$ \\
\hline First Survey Date : & $1 / 13 / 1975$ \\
\hline Last Survey Date : & $10 / 26 / 1993$ \\
\hline Number Surveys Processed : & 754 \\
\hline
\end{tabular}

Analysis Notes

Method Used to Compute Background : $\quad$ Threshold $0<$ val $<50$

Depth(s) where Contamination Identified NONE

in Gross Gamma Surveys :

Analyst Name : R.R. Randall

Company Name: Three Rivers Scientific 


\section{Borehole 40-05-10}

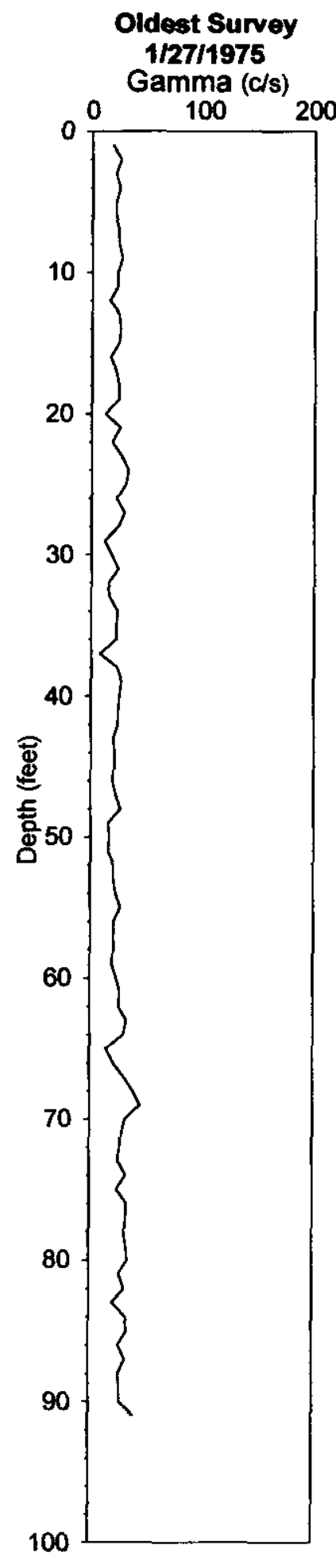
No Gamma-Ray Emitting Contamination Above Survey Detection Threshold
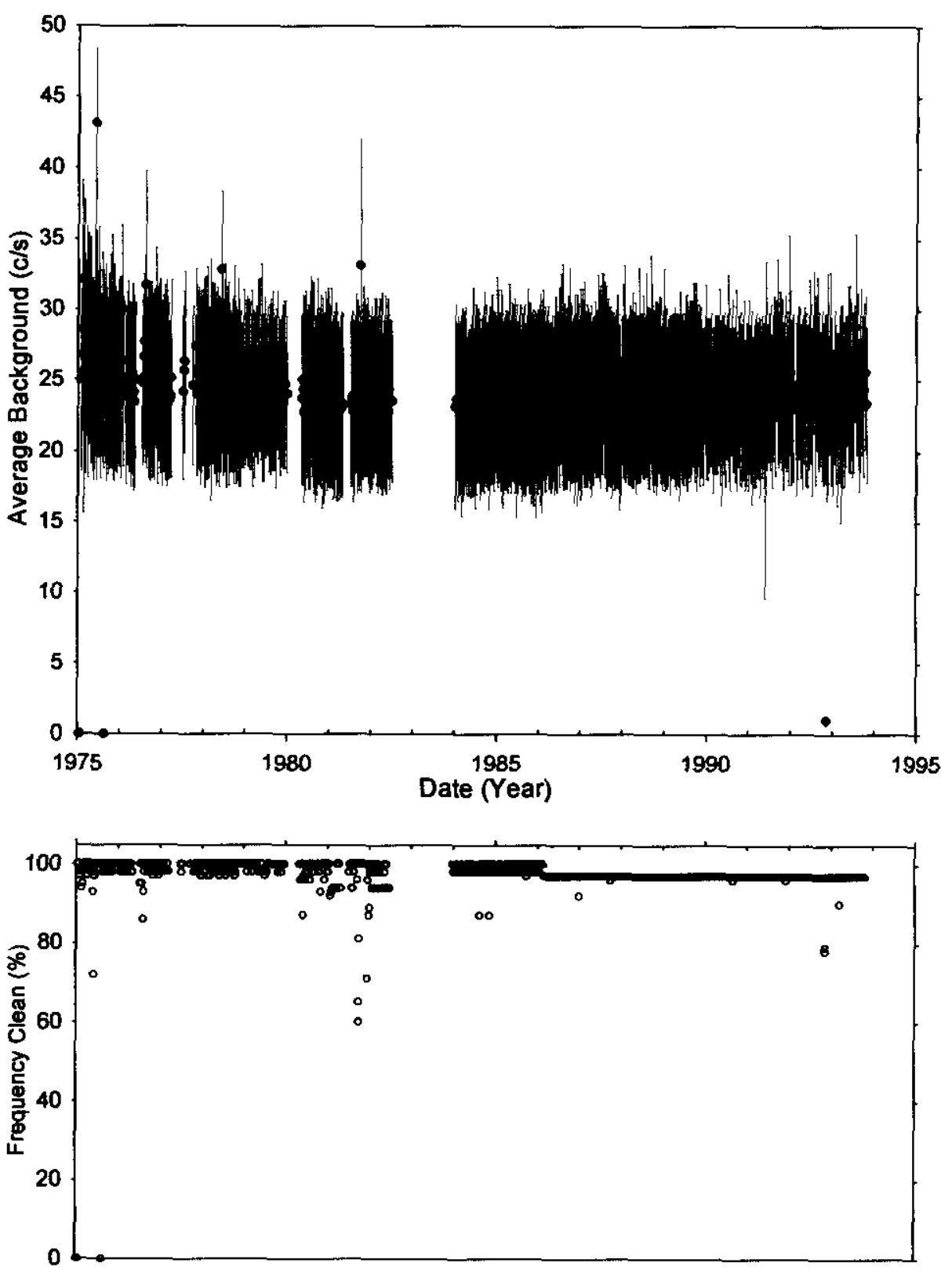

Analysis by: Throe Rivers Scienkific 


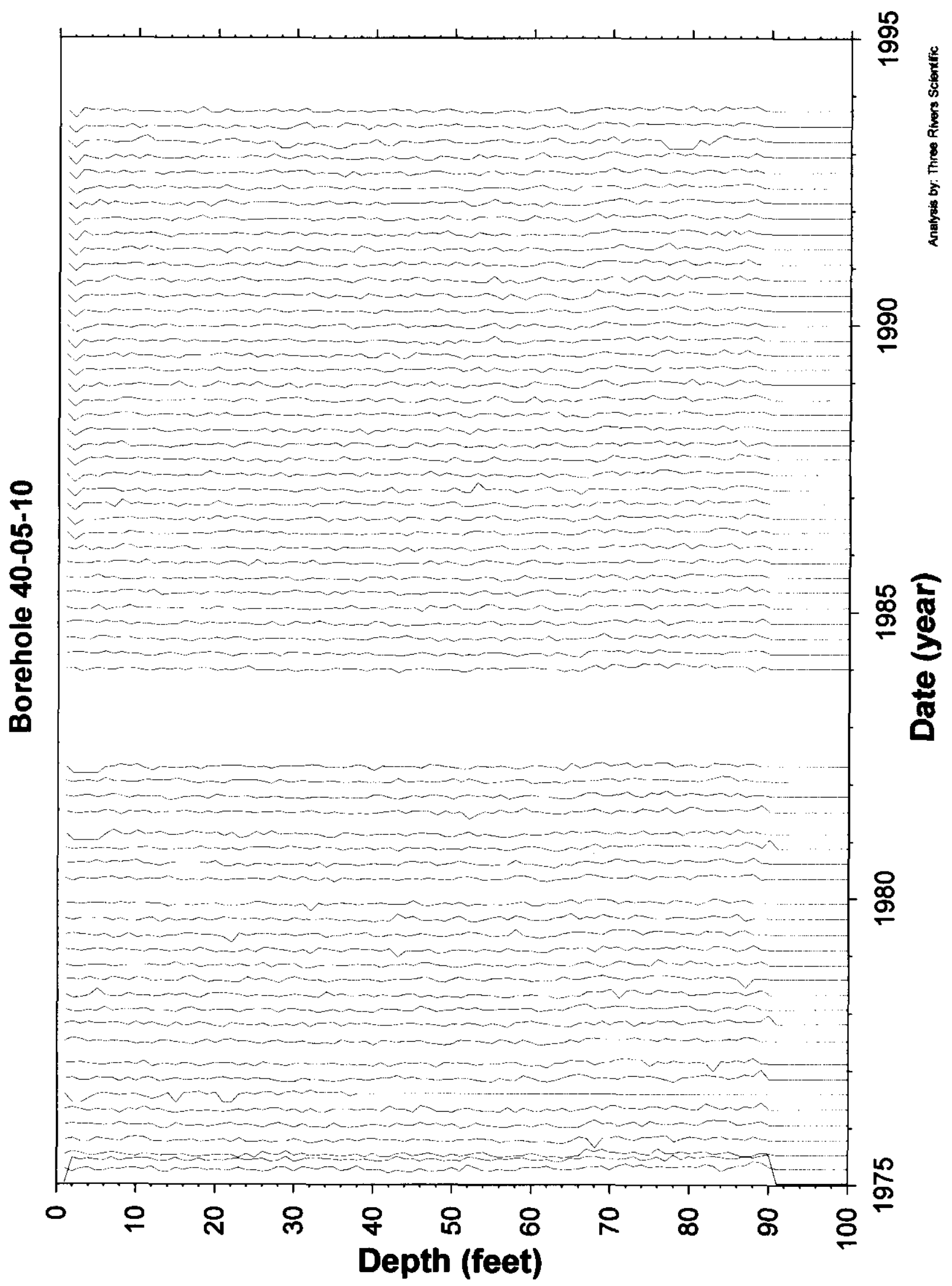

Tank S-105 


\section{S Tank 106 Wells}

Table of Contents

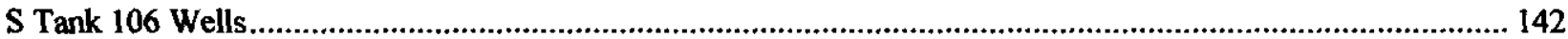

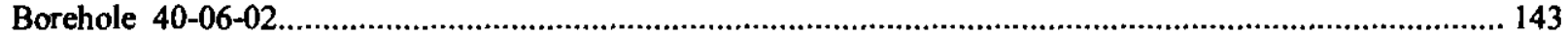

Borehole 40-06-04

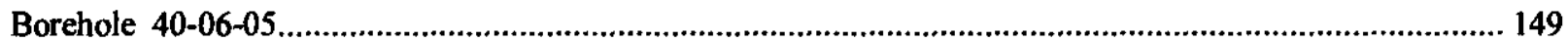

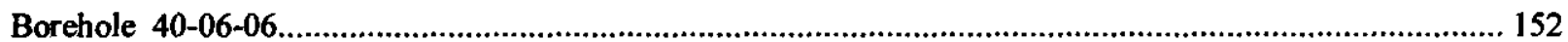

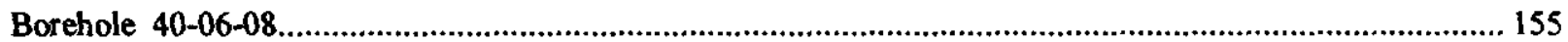

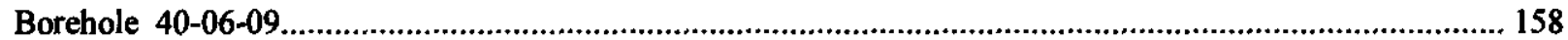

This section contains the analysis results for vadose zone boreholes (dry wells) associated with Tank 106 in the " $\mathrm{S}$ " Tank Farm.

Special Note: (none) 


\section{Borehole 40-06-02}

\section{No Gamma Ray Emitting Contamination was Identified.}

No significant levels of gamma ray contamination are present, based upon gross gamma data, above the survey probe detection threshold between 1975 and 1994 in the vadose zone from 2 to 100 feet. The HPGe logging system detected Cs-137 at less than $1 \mathrm{pCi} / \mathrm{g}$ from 0 to 15 feet.

Gross Gamma Survey Information

Probe Type Processed: $04:$ NaI

Other Probe Types : 03 : Neutron

Survey Depth : $100 \mathrm{ft}$

First Survey Date : $1 / 13 / 1975$

Last Survey Date : $11 / 01 / 1993$

Number Surveys Processed: 881

\section{Analysis Notes}

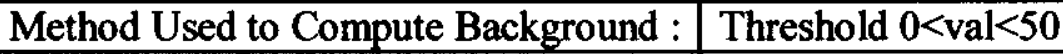

Depth(s) where Contamination was NONE

Identified in Gross Gamma Surveys :

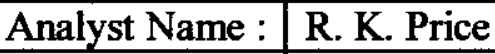

Company Name : Three Rivers Scientific 


\section{Borehole 40-06-02}

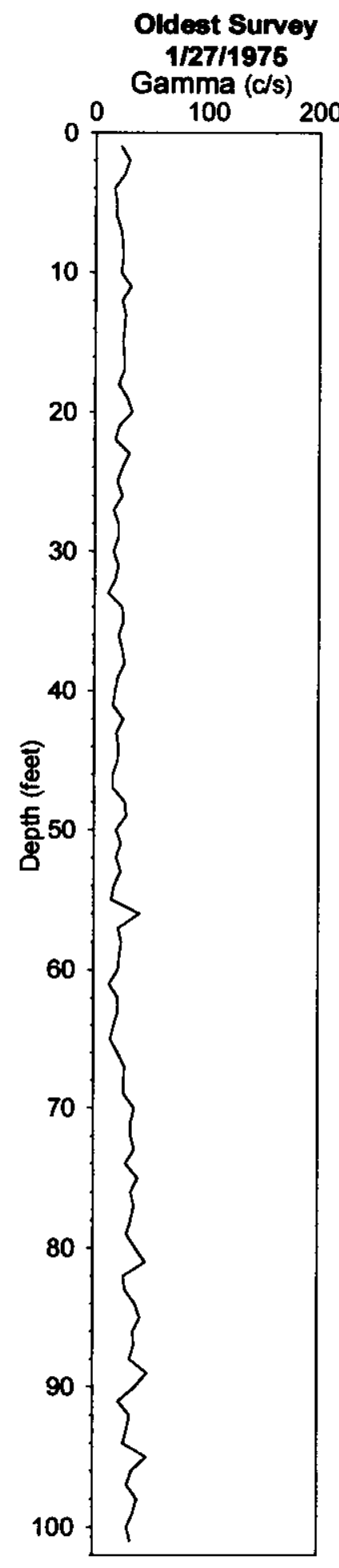
No Gamma-Ray Emitting Contamination
Above Survey Detection Threshold
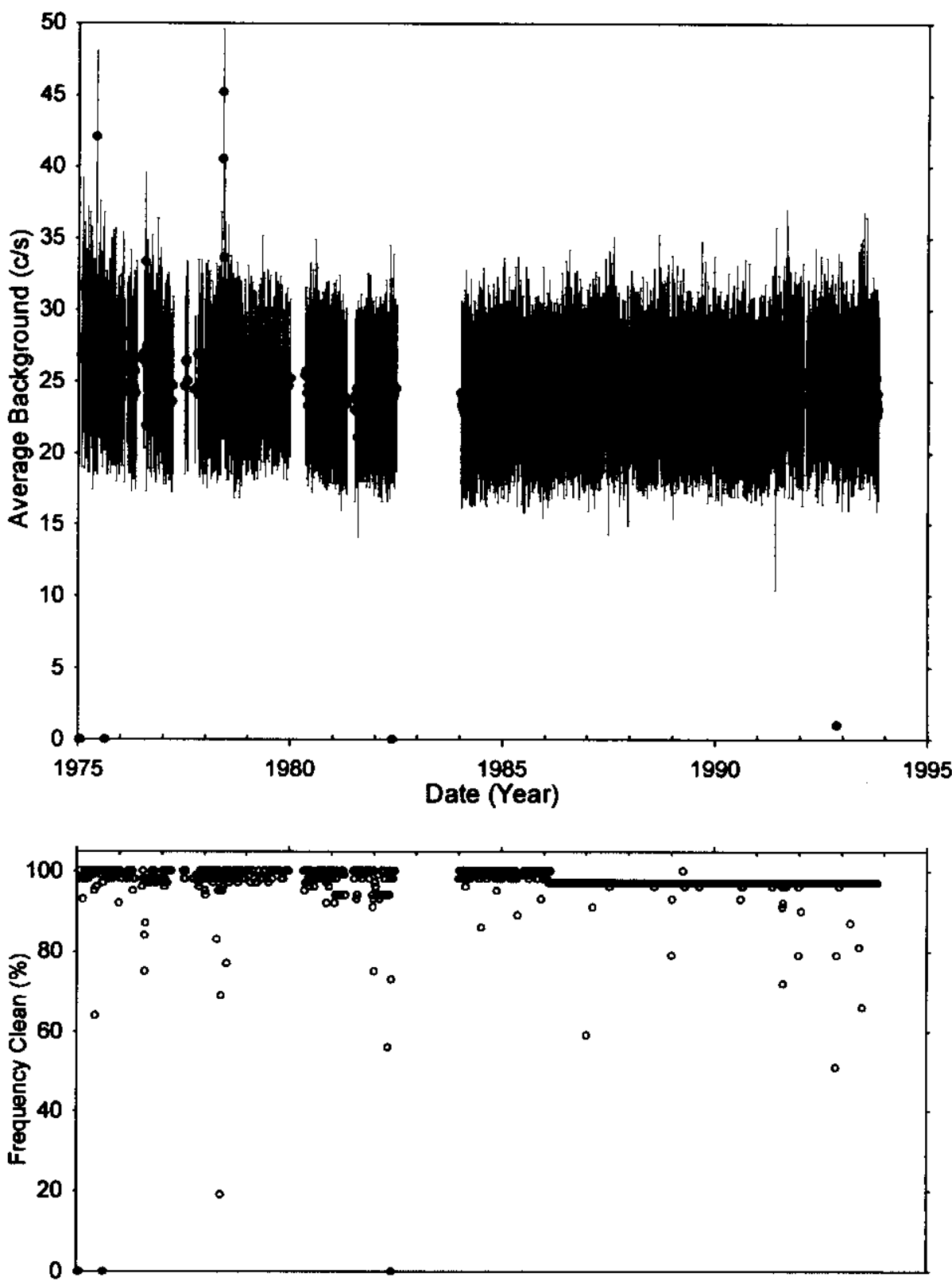

Anetyais by. Three Rivers Scientific 
HNF-4220, Rev. 0

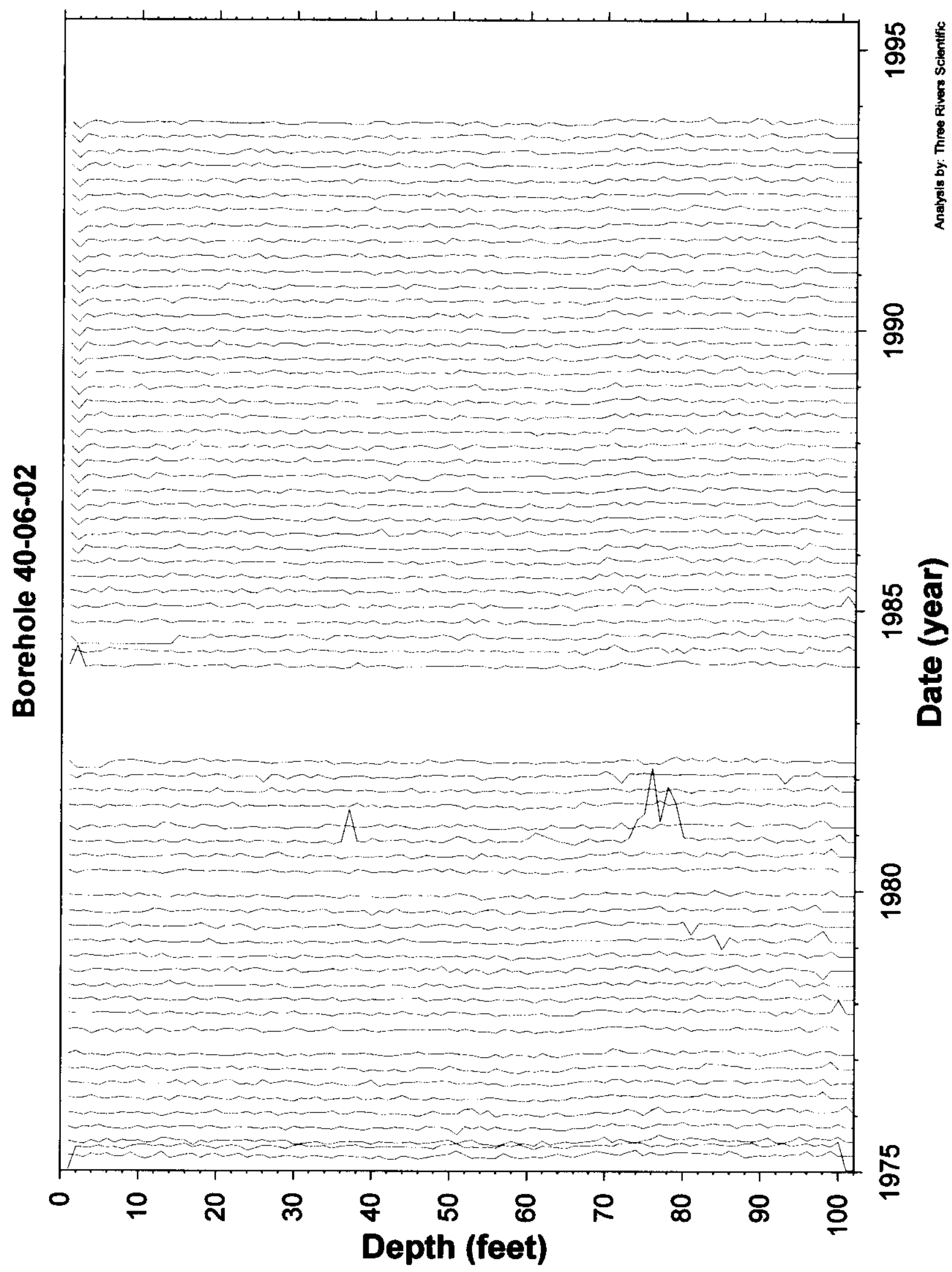

Tank S-106

Page 145 


\section{Borehole 40-06-04}

\section{No Gamma Ray Emitting Contamination was Identified.}

No significant levels of gamma ray contamination are present, based upon gross gamma data, above the survey probe detection threshold between 1978 and 1994 in the vadose zone from 2 to 125 feet. The HPGe logging system detected Cs-137 at less than $1 \mathrm{pCi} / \mathrm{g}$ from 2 to 5 feet.

Gross Gamma Survey Information

\begin{tabular}{|r|l|}
\hline Probe Type Processed: & $04: \mathrm{NaI}$ \\
\hline Other Probe Types : & $03:$ Neutron \\
\hline Survey Depth : & $125 \mathrm{ft}$ \\
\hline First Survey Date : & $10 / 06 / 1978$ \\
\hline Last Survey Date : & $11 / 01 / 1993$ \\
\hline Number Surveys Processed: & 707 \\
\hline
\end{tabular}

Analysis Notes

Method Used to Compute Background : $\quad$ Threshold $0<$ val $<50$

Depth(s) where Contamination was NONE

Identified in Gross Gamma Surveys :

Analyst Name: $\quad$ R. K. Price

Company Name : Three Rivers Scientific 


\section{Borehole 40-06-04}

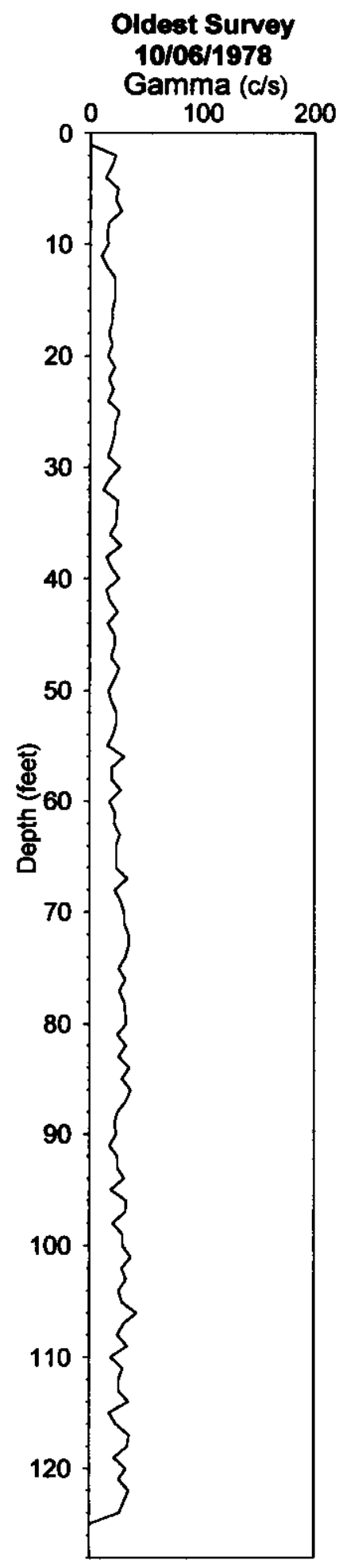

\section{No Gamma-Ray Emitting Contamination Above Survey Detection Threshold}
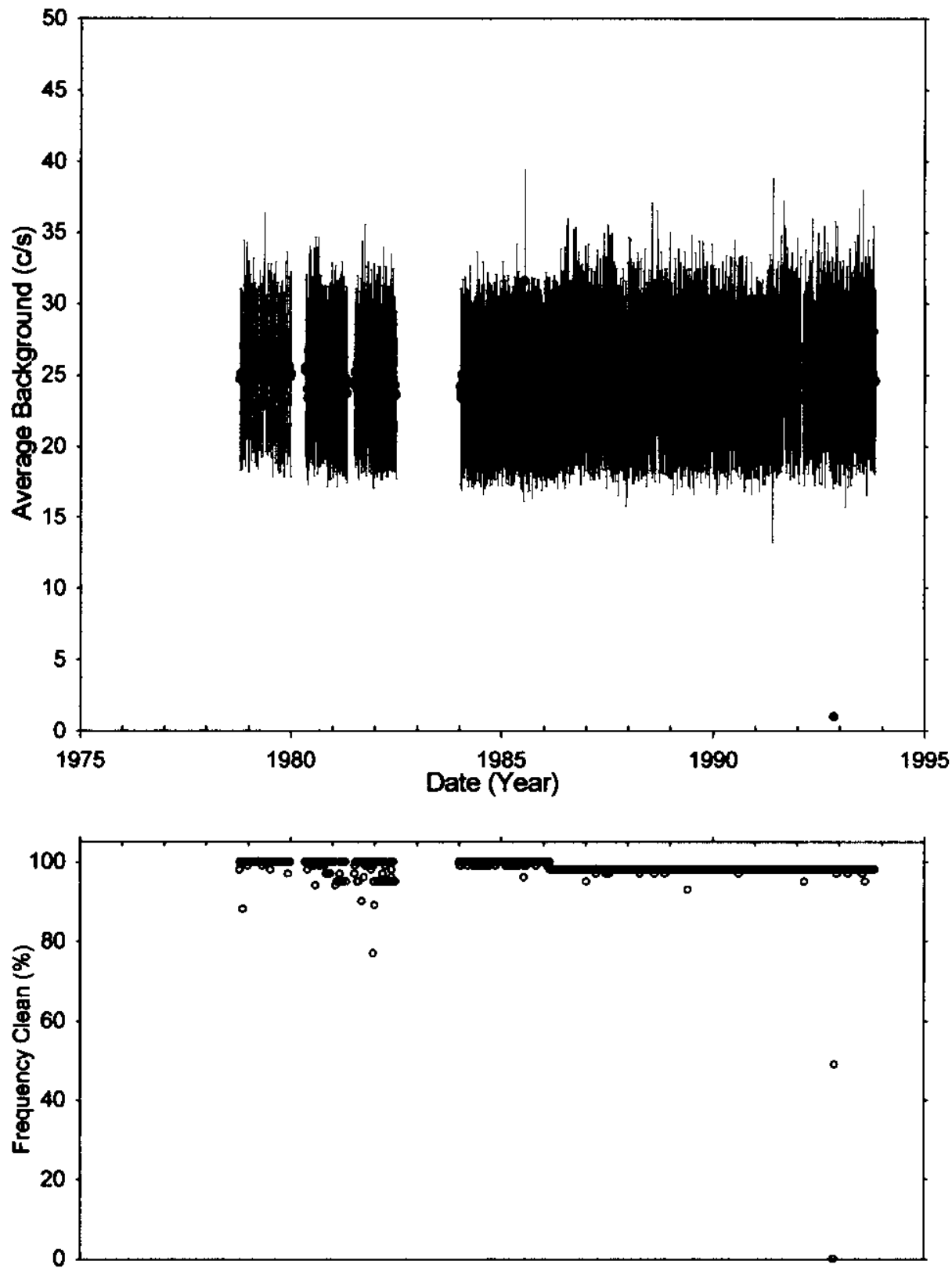

Antysis by: Three Rivers Scientific 
HNF-4220, Rev. 0

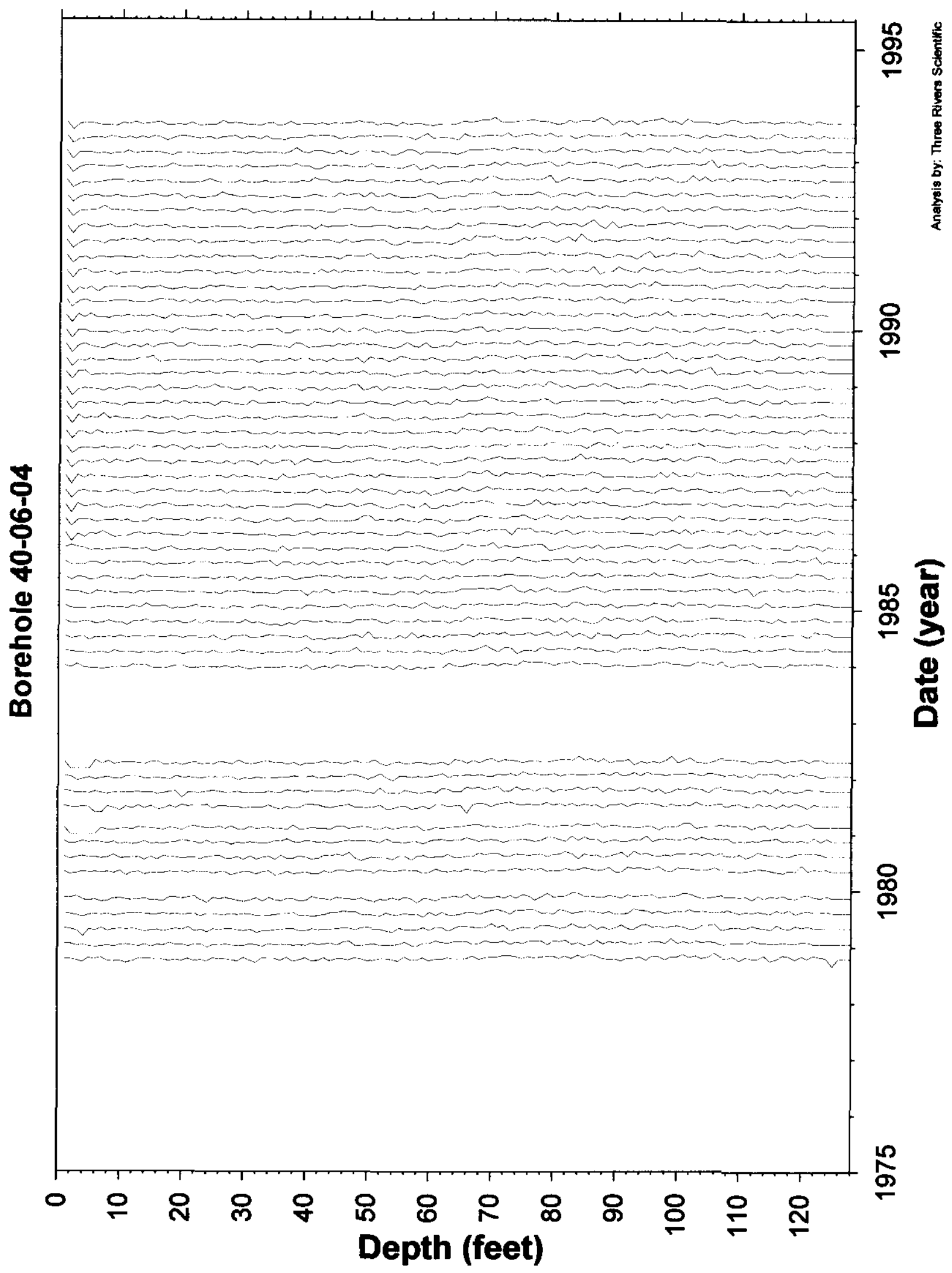

Tank S-106

Page 148 


\section{Borehole 40-06-05}

\section{No Gamma Ray Emitting Contamination was Identified.}

No significant levels of gamma ray contamination are present, based upon gross gamma data, above the survey probe detection threshold between 1975 and 1994 in the vadose zone from 2 to 140 feet. The HPGe logging system detected Cs-137 at less than 1 pCíg only at the ground surface.

Gross Gamma Survey Information

\begin{tabular}{|r|l|}
\hline Probe Type Processed: & $04:$ NaI \\
\hline Other Probe Types : & $03:$ Neutron \\
\hline Survey Depth : & $140 \mathrm{ft}$ \\
\hline First Survey Date : & $1 / 13 / 1975$ \\
\hline Last Survey Date : & $6 / 17 / 1993$ \\
\hline Number Surveys Processed: & 293 \\
\hline
\end{tabular}

Analysis Notes

Method Used to Compute Background : $\quad$ Threshold $0<$ val $<50$

Depth(s) where Contamination was NONE

Identified in Gross Gamma Surveys :

Analyst Name: $\quad$ R. K. Price

Company Name : Three Rivers Scientific 


\section{Borehole 40-06-05}

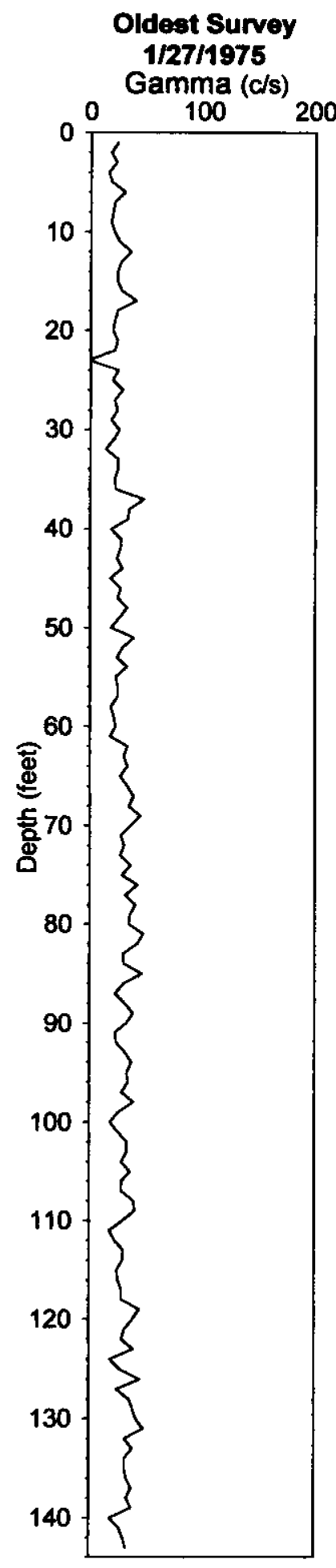

No Gamma-Ray Emitting Contamination
Above Survey Detection Threshold
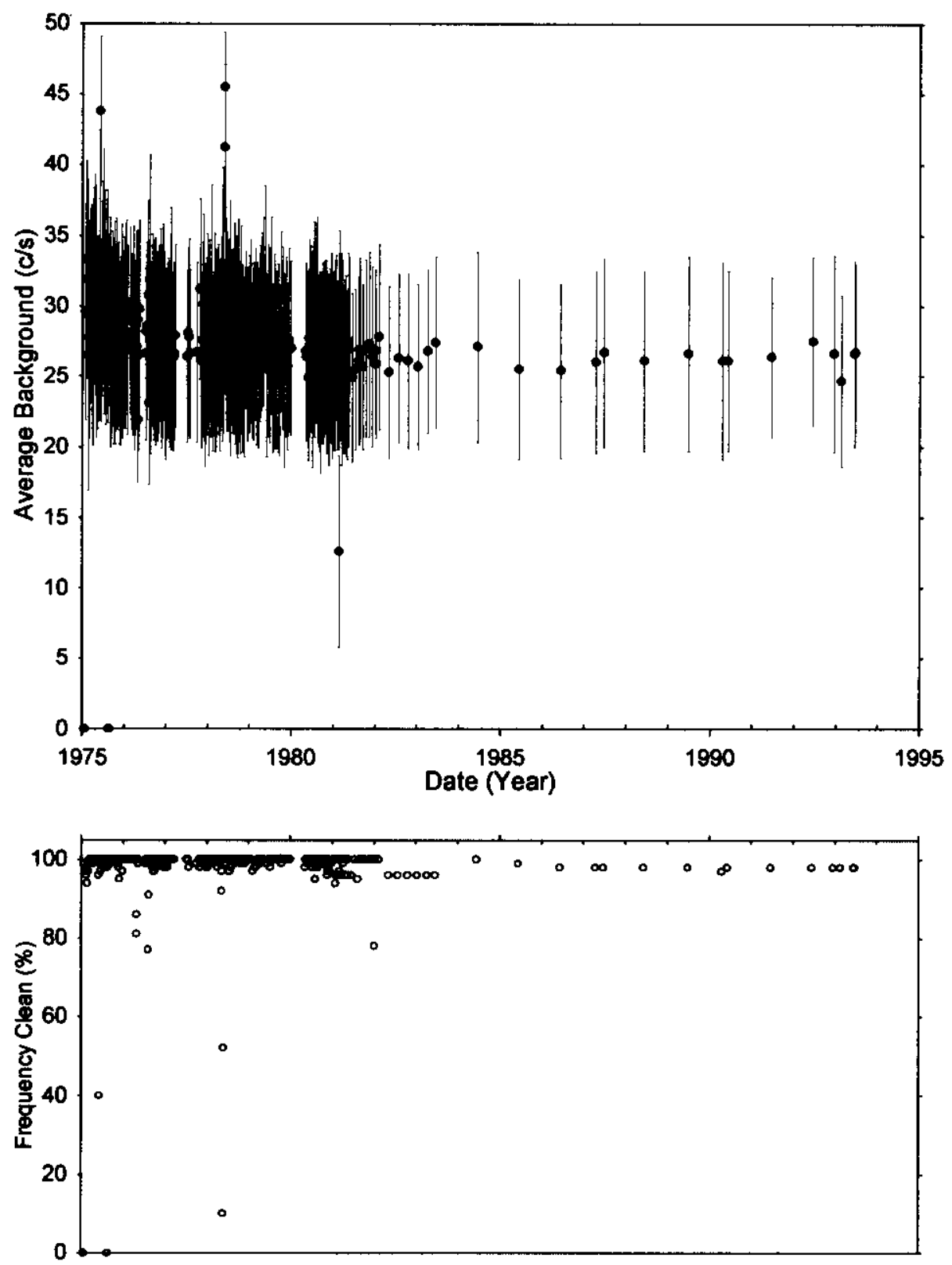

Analysis by. Three Rivers Sciontific 
HNF-4220, Rev. 0

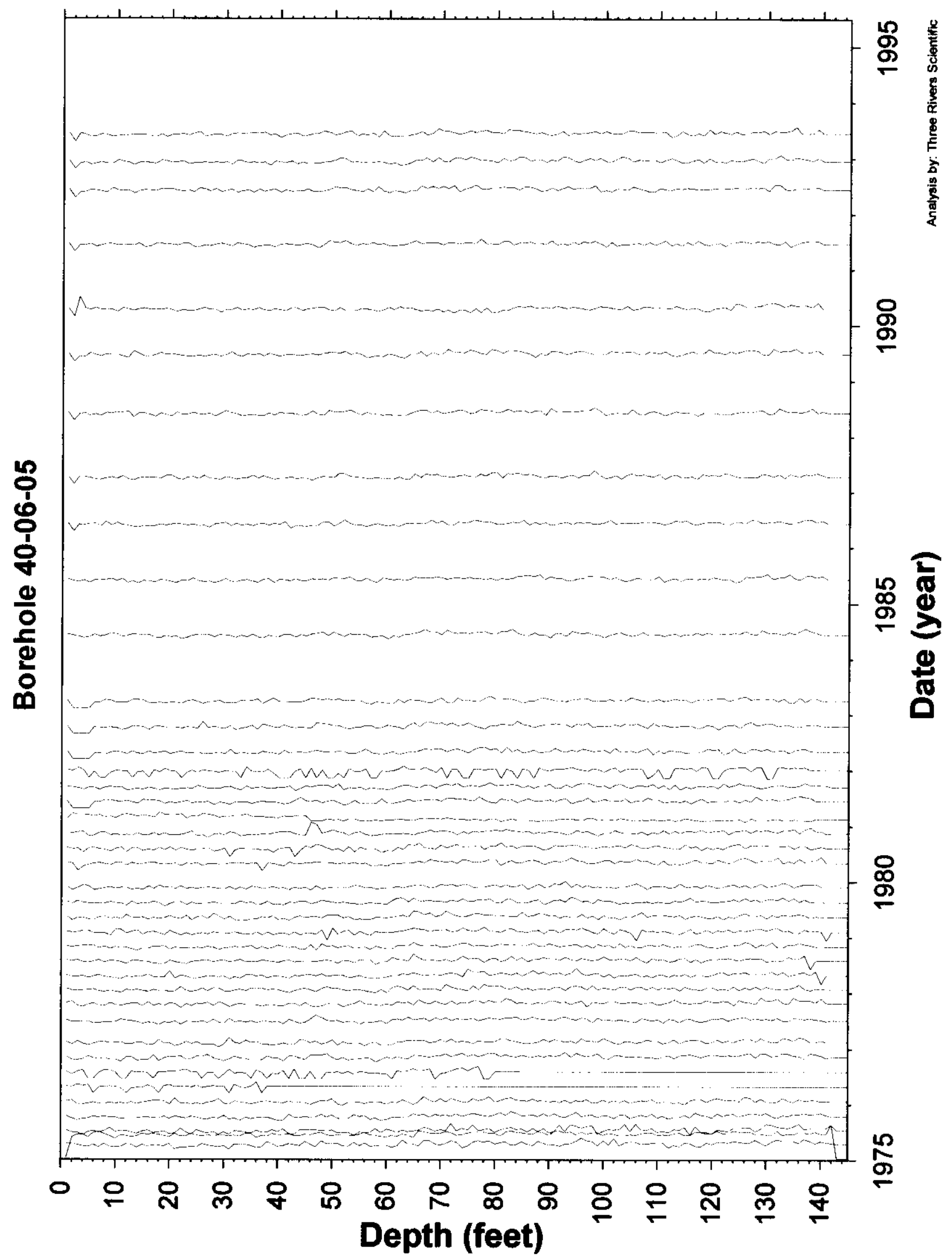

Tank S-106

Page 151 


\section{Borehole 40-06-06}

\section{No Gamma Ray Emitting Contamination was Identified.}

No significant levels of gamma ray contamination are present, based upon gross gamma data, above the survey probe detection threshold between 1975 and 1994 in the vadose zone from 2 to 97 feet. The HPGe logging system detected Cs-137 at less than $0.5 \mathrm{pCi} / \mathrm{g}$ in the borehole.

Gross Gamma Survey Information

\begin{tabular}{|r|l|}
\hline Probe Type Processed: & $04: \mathrm{NaI}$ \\
\hline Other Probe Types : & $03:$ Neutron \\
\hline Survey Depth : & $97 \mathrm{ft}$ \\
\hline First Survey Date : & $1 / 13 / 1975$ \\
\hline Last Survey Date : & $11 / 01 / 1993$ \\
\hline Number Surveys Processed: & 879 \\
\hline
\end{tabular}

Analysis Notes

Method Used to Compute Background : $\quad$ Threshold $0<$ val $<50$

Depth(s) where Contamination was NONE Identified in Gross Gamma Surveys :

Analyst Name: $\quad$ R. K. Price

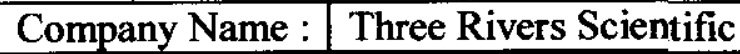




\section{Borehole 40-06-06}

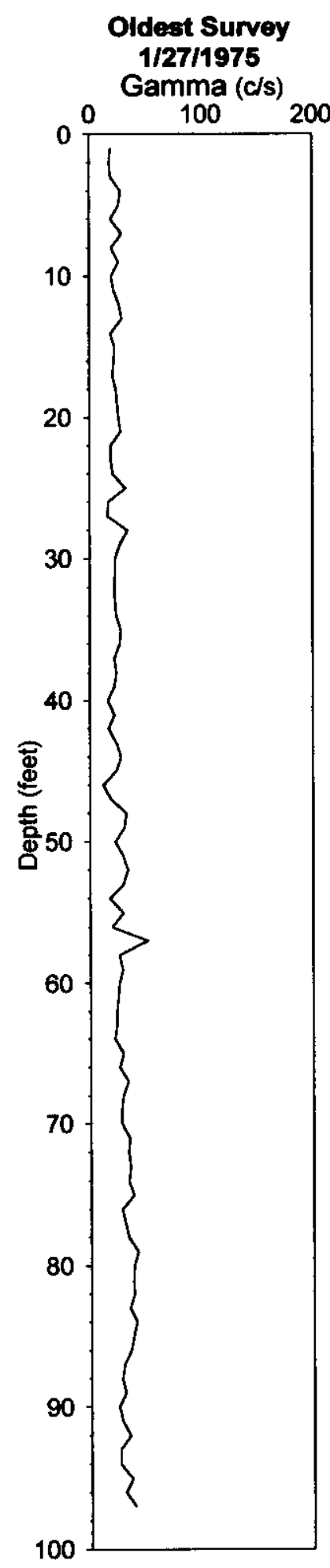
No Gamma-Ray Emitting Contamination
Above Survey Detection Threshold
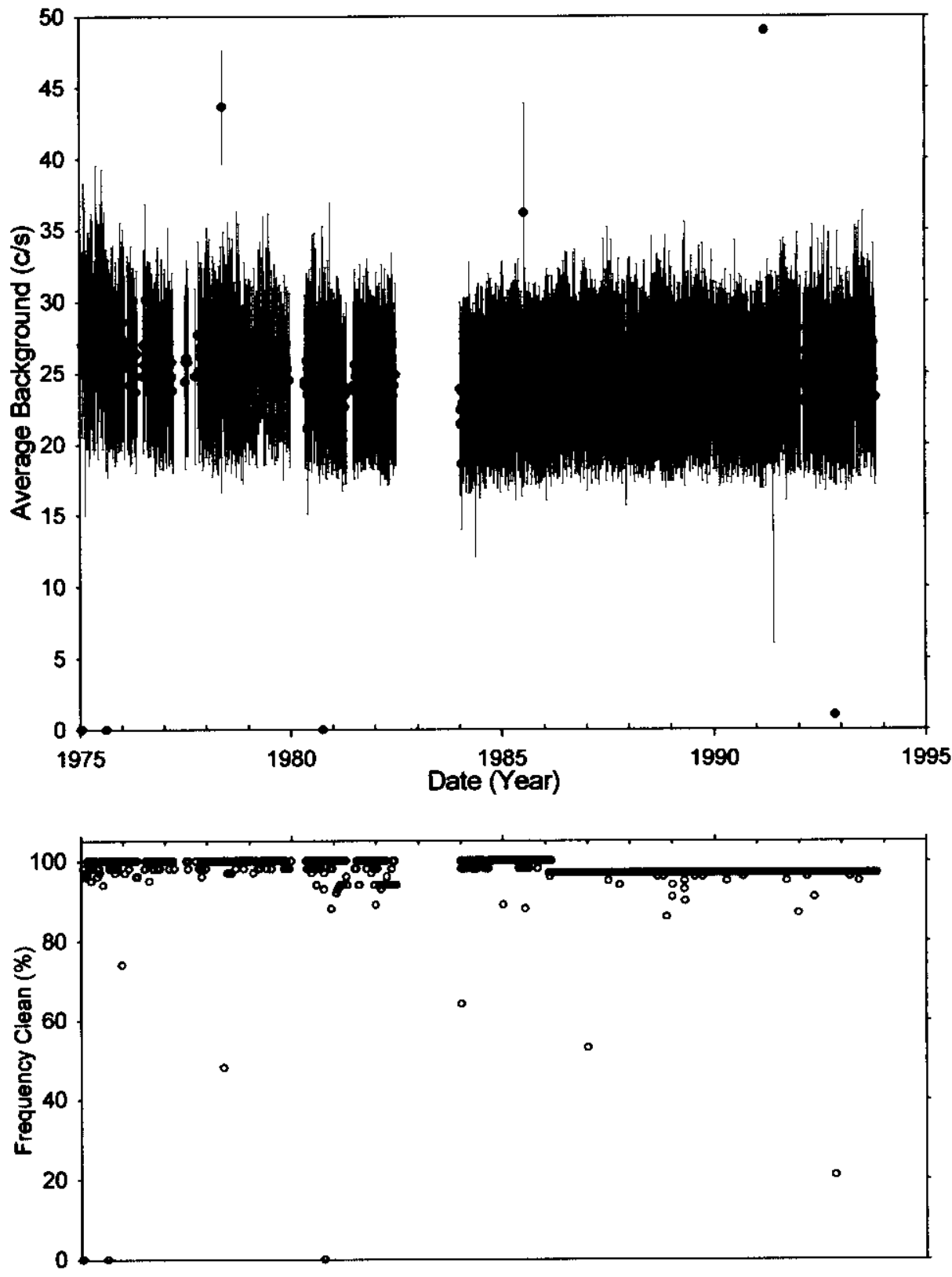

Analysis by: Throe Rivers Scientific 
HNF-4220, Rev. 0

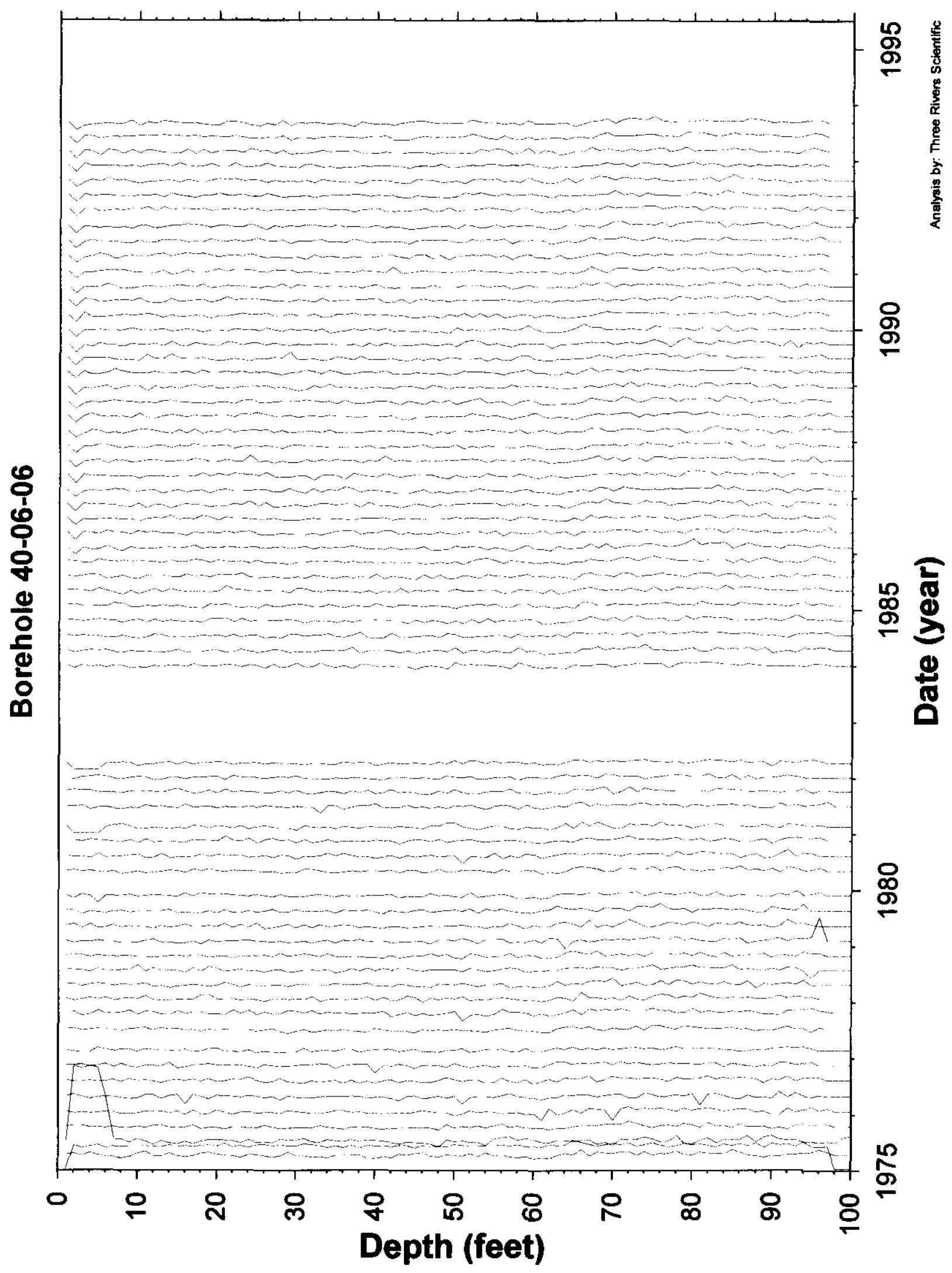

Tank S-106

Page 154 


\section{Borehole 40-06-08}

\section{No Gamma Ray Emitting Contamination was Identified.}

No significant levels of gamma ray contamination are present, based upon gross gamma data, above the survey probe detection threshold between 1976 and 1994 in the vadose zone from 2 to 97 feet. The HPGe logging system detected no man made radionuclides in the borehole. No Cs137 was detected.

Gross Gamma Survey Information

\begin{tabular}{|r|l|}
\hline Probe Type Processed: & $04:$ NaI \\
\hline Other Probe Types : & $03:$ Neutron \\
\hline Survey Depth : & $97 \mathrm{ft}$ \\
\hline First Survey Date : & $5 / 10 / 1976$ \\
\hline Last Survey Date : & $10 / 26 / 1993$ \\
\hline Number Surveys Processed: & 800 \\
\hline
\end{tabular}

Analysis Notes

Method Used to Compute Background : $\quad$ Threshold $0<$ val $<50$

Depth(s) where Contamination was NONE Identified in Gross Gamma Surveys :

Analyst Name : 1 R. K. Price

Company Name : $\quad$ Three Rivers Scientific 


\section{Borehole 40-06-08}

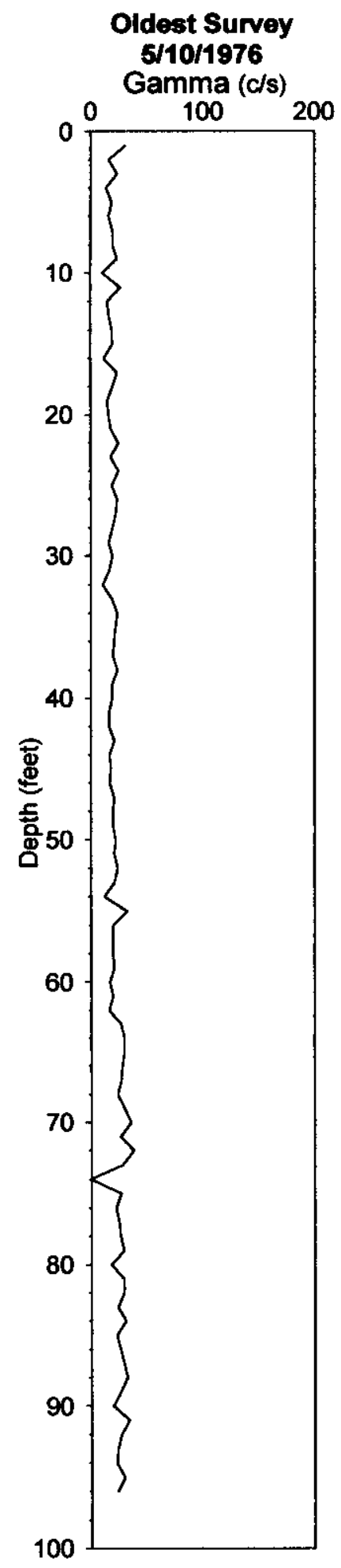

No Gamma-Ray Emitting Contamination Above Survey Detection Threshold
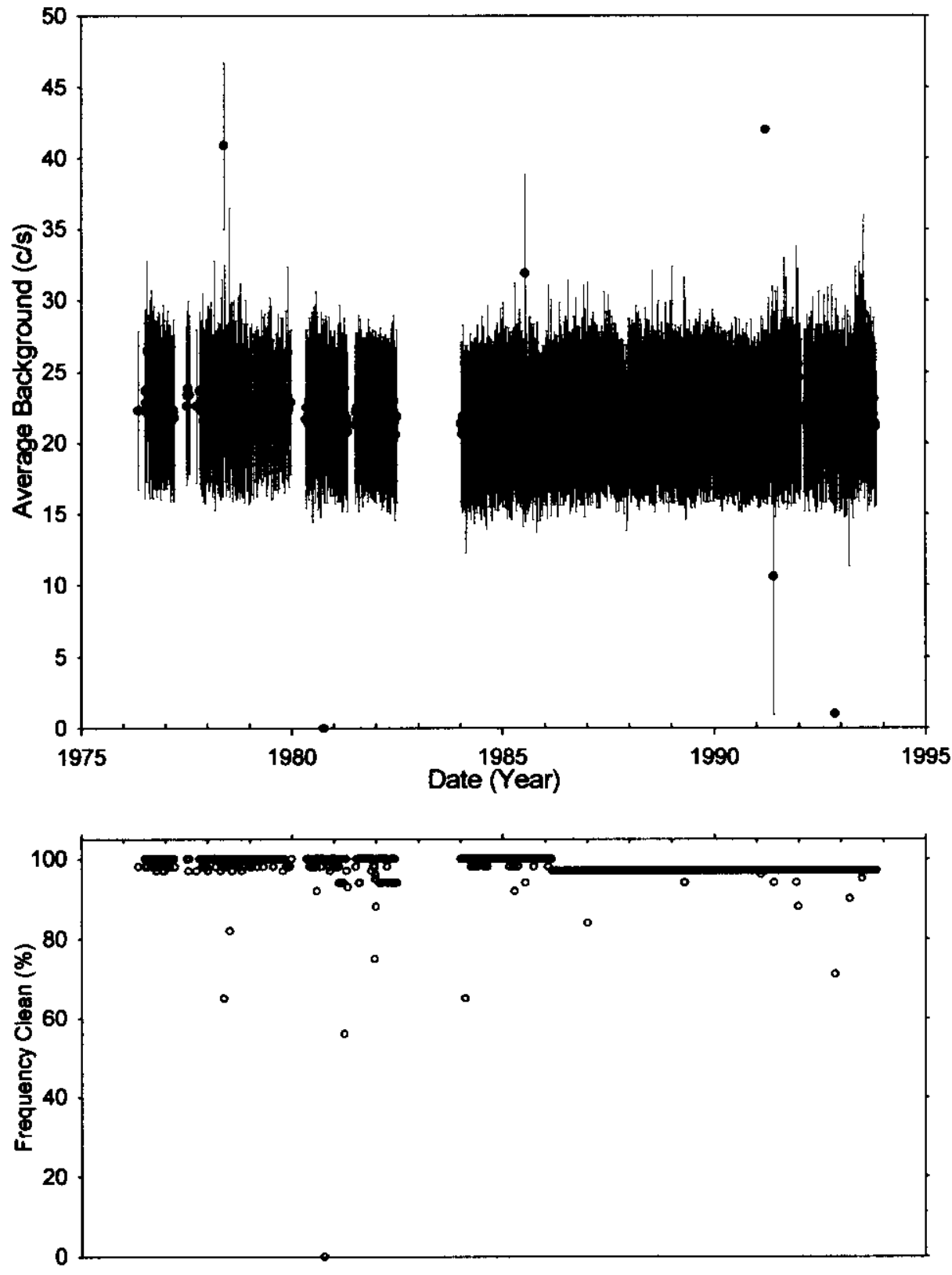

Analysis by: Throe Rivers Scientific 
HNF-4220, Rev. 0

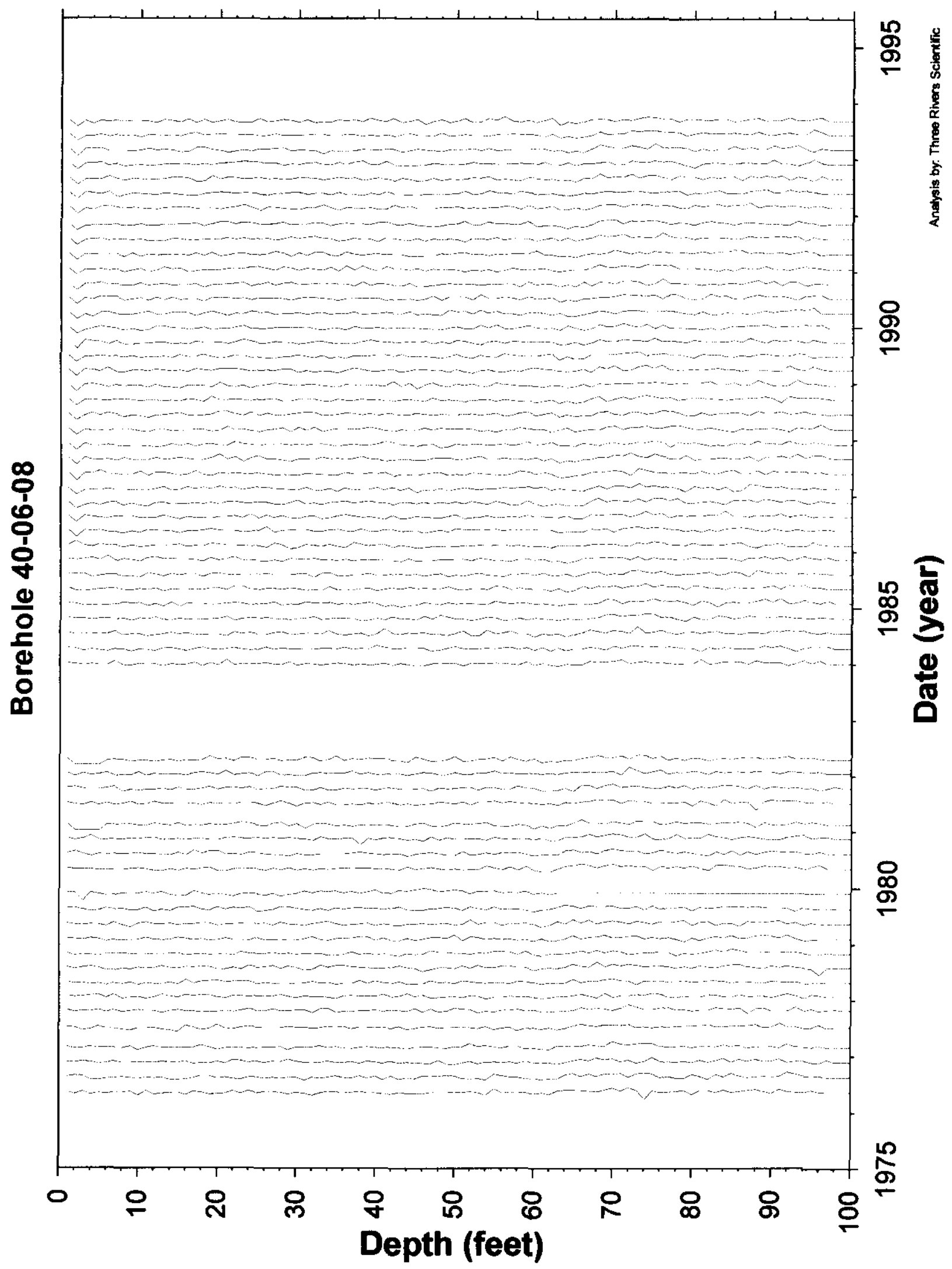

Tank S-106

Page 157 


\section{Borehole 40-06-09}

\section{No Gamma Ray Emitting Contamination was Identified.}

No significant levels of gamma ray contamination are present, based upon gross gamma data, above the survey probe detection threshold between 1975 and 1994 in the vadose zone from 2 to 100 feet. The HPGe logging system detected Cs- 137 at $2 \mathrm{pCi} / \mathrm{g}$ from 0 to 2 feet, but less than 1 $\mathrm{pCi} / \mathrm{g}$ for the rest of the borehole.

Gross Gamma Survey Information

\begin{tabular}{|r|l|}
\hline Probe Type Processed: & $04: \mathrm{NaI}$ \\
\hline Other Probe Types : & $03:$ Neutron \\
\hline Survey Depth : & $100 \mathrm{ft}$ \\
\hline First Survey Date : & $1 / 13 / 1975$ \\
\hline Last Survey Date : & $11 / 01 / 1993$ \\
\hline Number Surveys Processed: & 858 \\
\hline
\end{tabular}

Analysis Notes

Method Used to Compute Background : $\quad$ Threshold $0<$ val $<50$

Depth(s) where Contamination was NONE Identified in Gross Gamma Surveys :

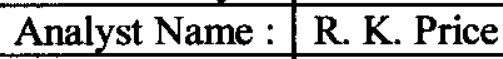

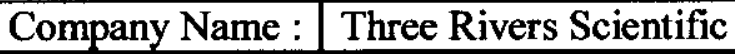




\section{Borehole 40-06-09}

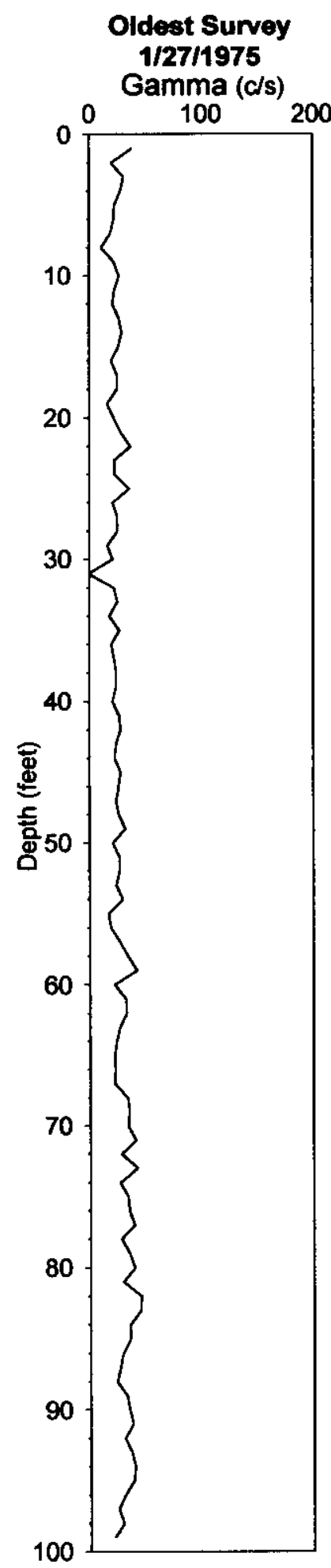

No Gamma-Ray Emitting Contamination
Above Survey Detection Threshold
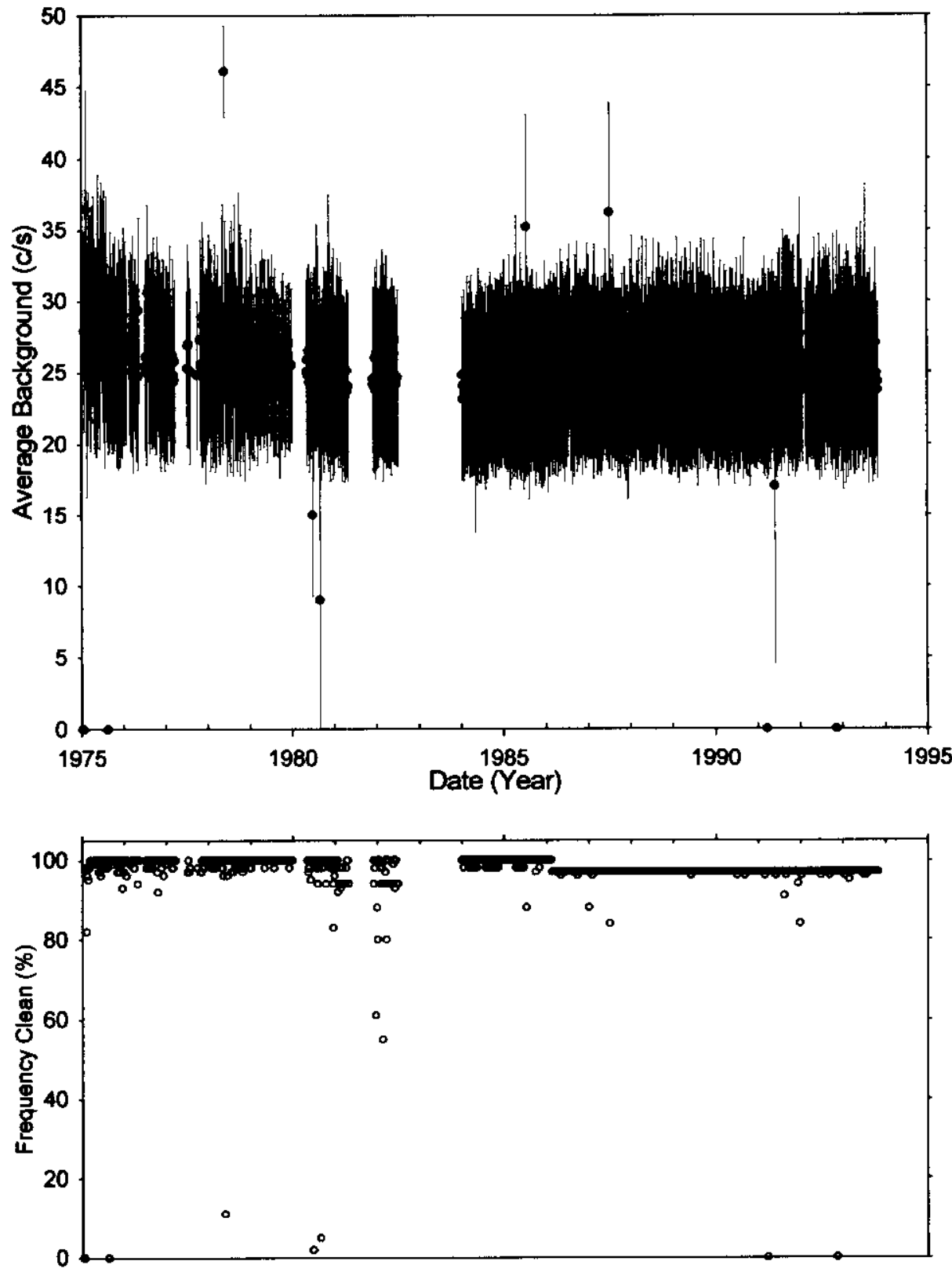

Anelysis by: Three Rivers Scientific 
HNF-4220, Rev. 0

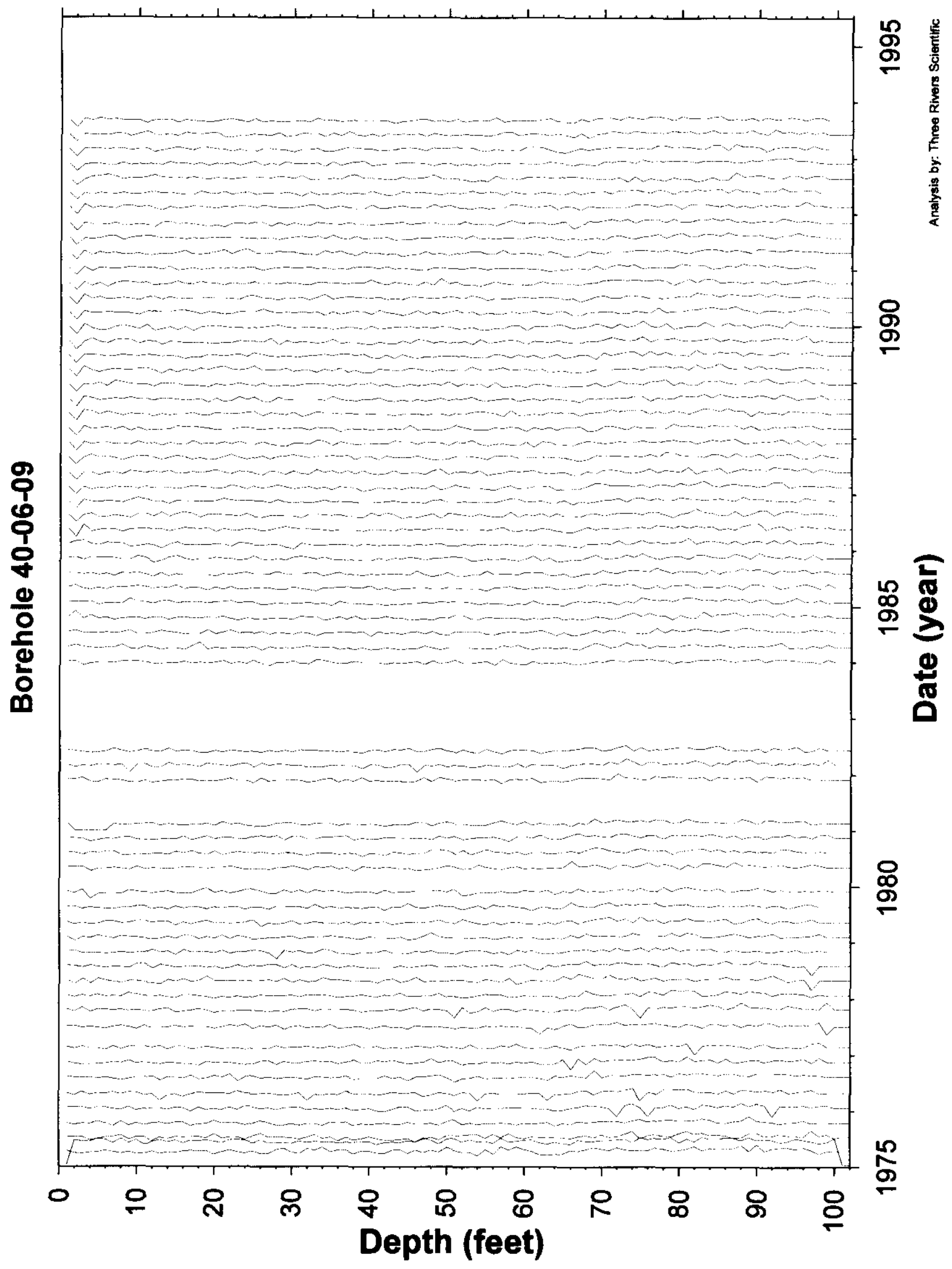


HNF-4220, Rev. 0

\section{S Tank 107 Wells}

Table of Contents

This section contains the analysis results for vadose zone boreholes (dry wells) associated with Tank 107 in the " $\mathrm{S}$ " Tank Farm.

Special Note: (none) 


\section{Borehole 40-07-01}

\section{No Gamma Ray Emitting Contamination was Identified.}

No significant levels of gamma ray contamination are present, based upon gross gamma data, above the survey probe detection threshold between 1975 and 1994 in the vadose zone from 2 to 100 feet. The HPGe logging system did not detect any man-made radionuclides above natural radionuclide concentrations. The first 7 surveys (1975) had elevated count rate activity at the surface and had additional data sample values resulting from manual operation of recording and winch controls. The high count rate activity at the surface was not recorded on the subsequent surveys when logging probe was not drawn above ground level.

Gross Gamma Survey Information

\begin{tabular}{|r|l|}
\hline Probe Type Processed: & $04: \mathrm{NaI}$ \\
\hline Other Probe Types : & $03:$ Neutron \\
\hline Survey Depth : & $100 \mathrm{ft}$ \\
\hline First Survey Date : & $1 / 14 / 1975$ \\
\hline Last Survey Date : & $6 / 09 / 1994$ \\
\hline Number Surveys Processed: & $04: 870$ \\
\hline
\end{tabular}

Analysis Notes

Method Used to Compute Background : $30-60 \mathrm{ft}$

Depth(s) where Contamination was NONE Identified in Gross Gamma Surveys :

Analyst Name : R. K. Price

Company Name : Three Rivers Scientific 


\section{Borehole 40-07-01}

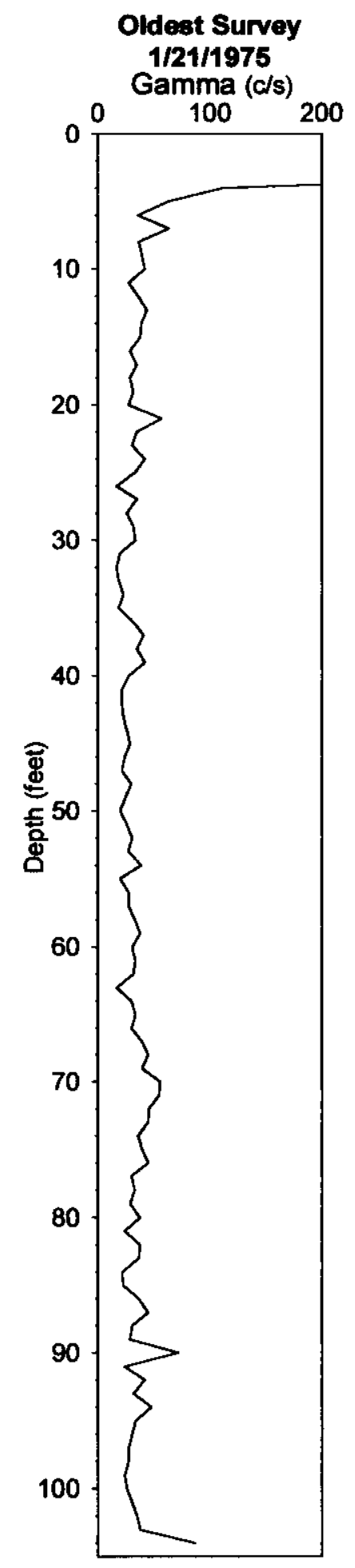
No Gamma-Ray Emitting Contamination Above Survey Detection Threshold
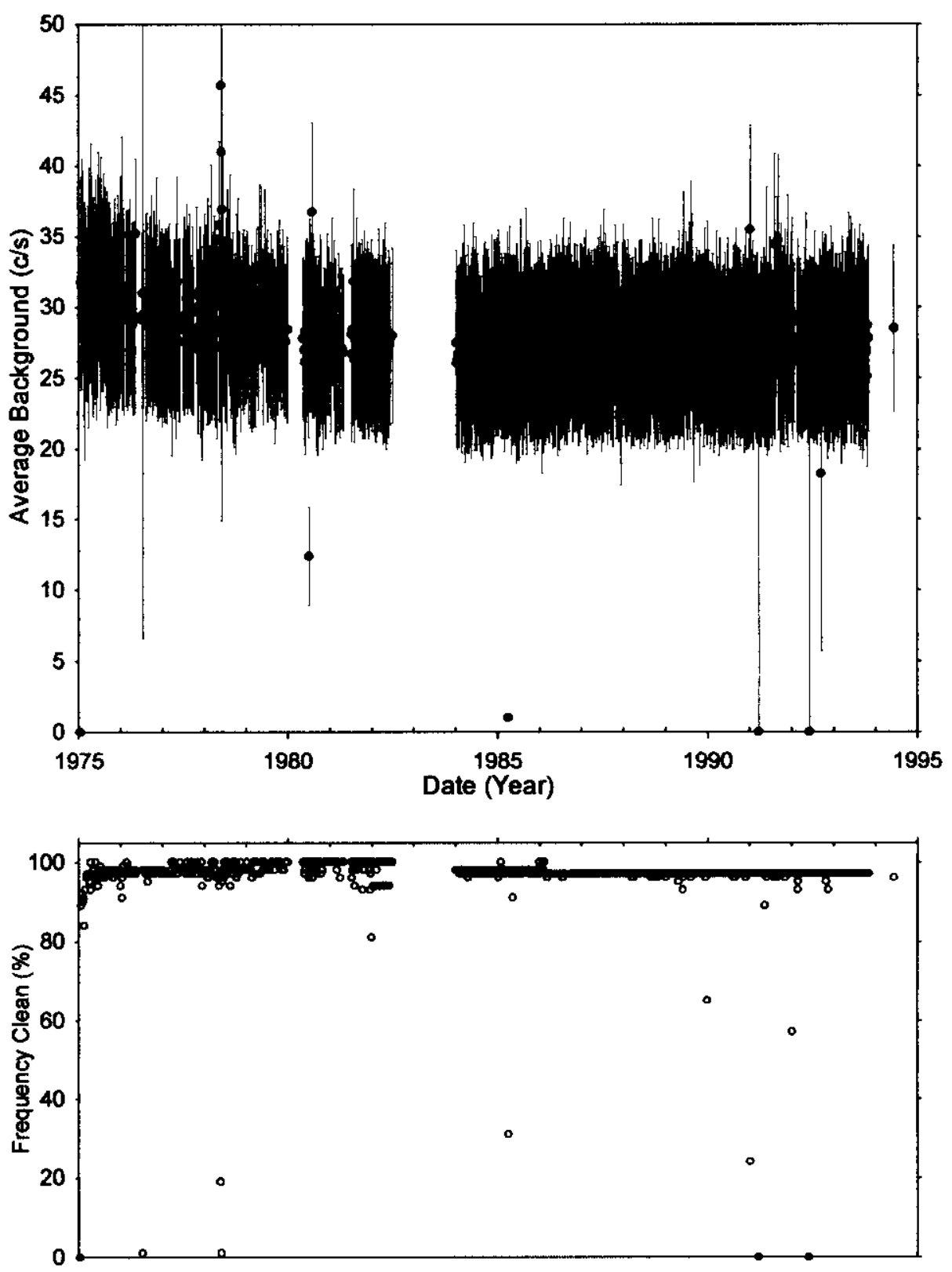

Anslysis by. Three Rivers Scientific 
HNF-4220, Rev. 0

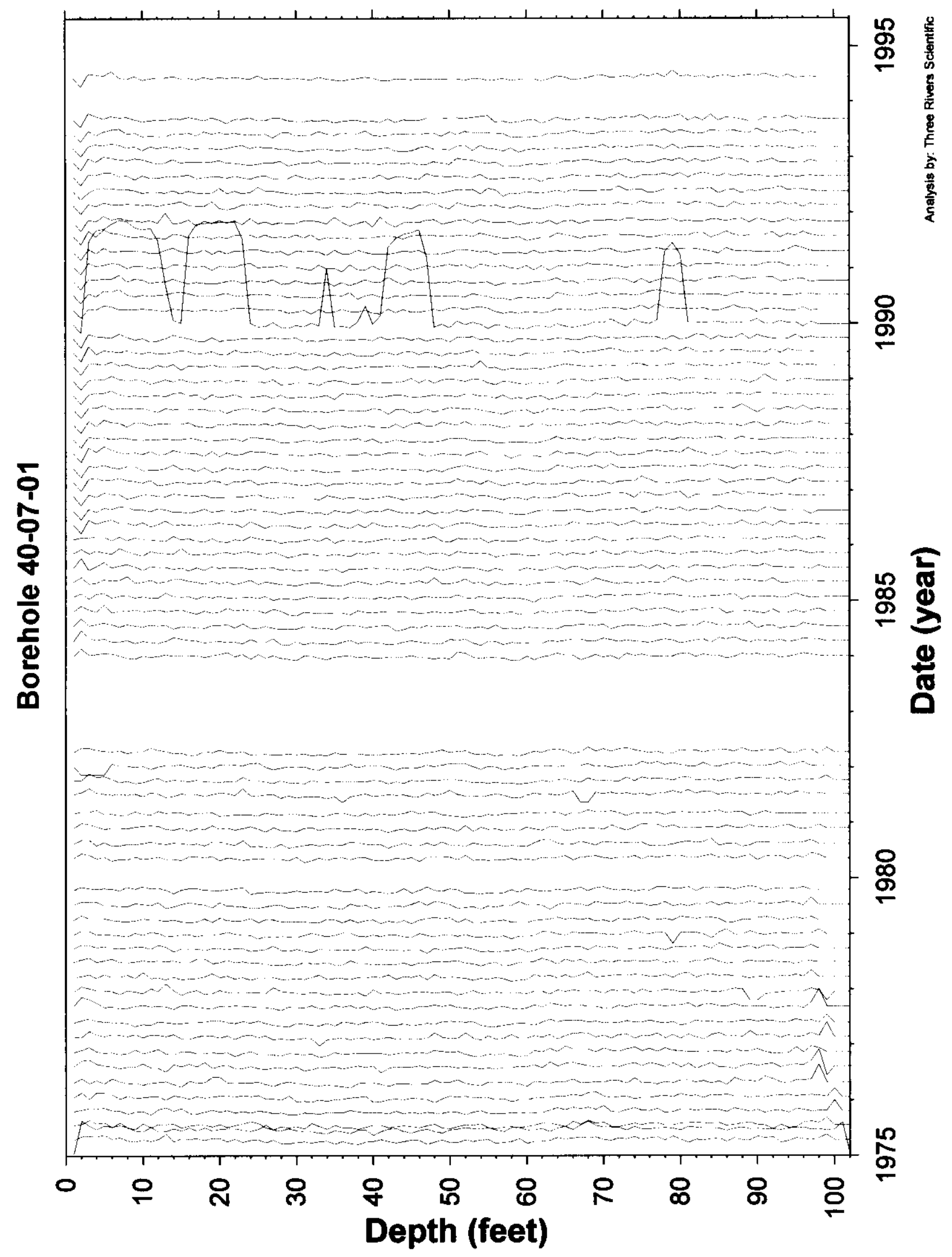

Tank S-107

Page 164 


\section{Borehole 40-07-04}

\section{No Gamma Ray Emitting Contamination was Identified.}

No significant levels of gamma ray contamination are present, based upon gross gamma data, above the survey probe detection threshold between 1975 and 1995 in the vadose zone from 2 to 102 feet. The HPGe logging system detected Cs-137 at less than $3 \mathrm{pCi} / \mathrm{g}$ from 1 to 3 feet.

Gross Gamma Survey Information

\begin{tabular}{|r|l|}
\hline Probe Type Processed: & $04:$ Nal \\
\hline Other Probe Types : & $03:$ Neutron \\
\hline Survey Depth : & $102 \mathrm{ft}$ \\
\hline First Survey Date : & $1 / 14 / 1975$ \\
\hline Last Survey Date : & $6 / 09 / 1994$ \\
\hline Number Surveys Processed: & 874 \\
\hline
\end{tabular}

Analysis Notes

\begin{tabular}{|r|l|}
\hline Method Used to Compute Background : & Threshold $0<$ val $<50$ \\
\hline $\begin{array}{r}\text { Depth(s) where Contamination was } \\
\text { Identified in Gross Gamma Surveys : }\end{array}$ & NONE \\
\hline Analyst Name : & R. K. Price \\
\hline Company Name : & Three Rivers Scientific \\
\hline
\end{tabular}




\section{Borehole 40-07-04}

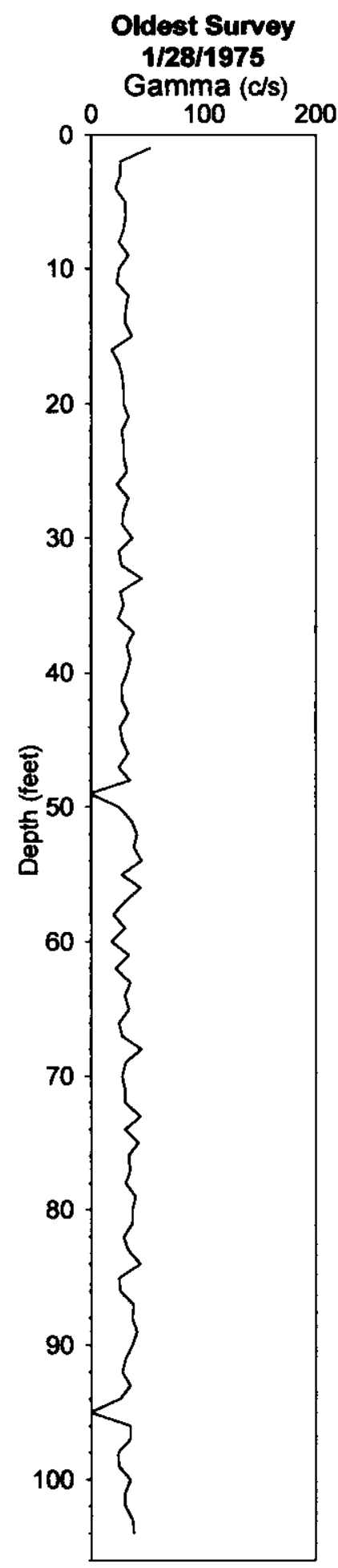

No Gamma-Ray Emitting Contamination Above Survey Detection Threshold
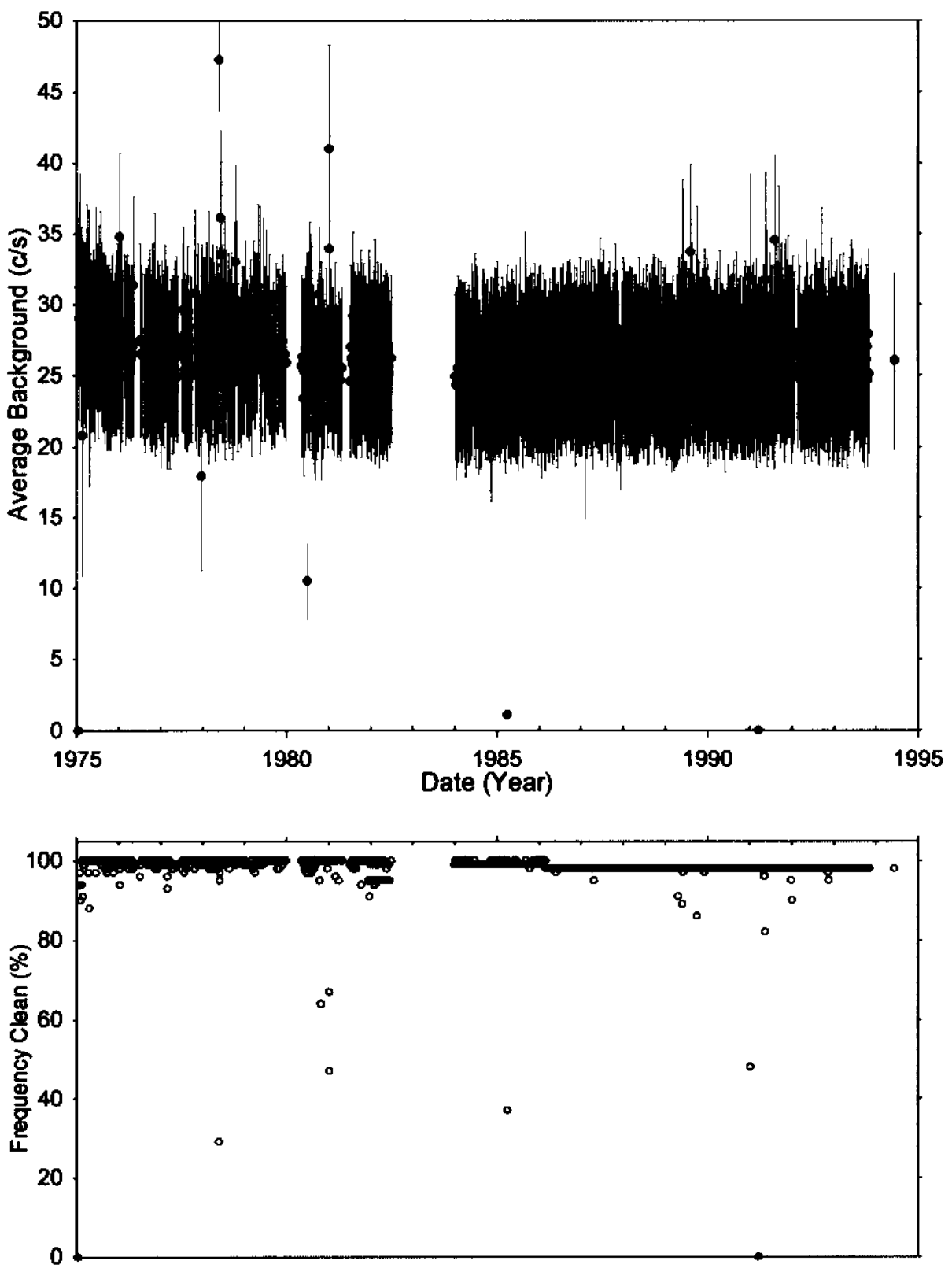

Analysis by: Throe Rivers Scientific 
HNF-4220, Rev. 0

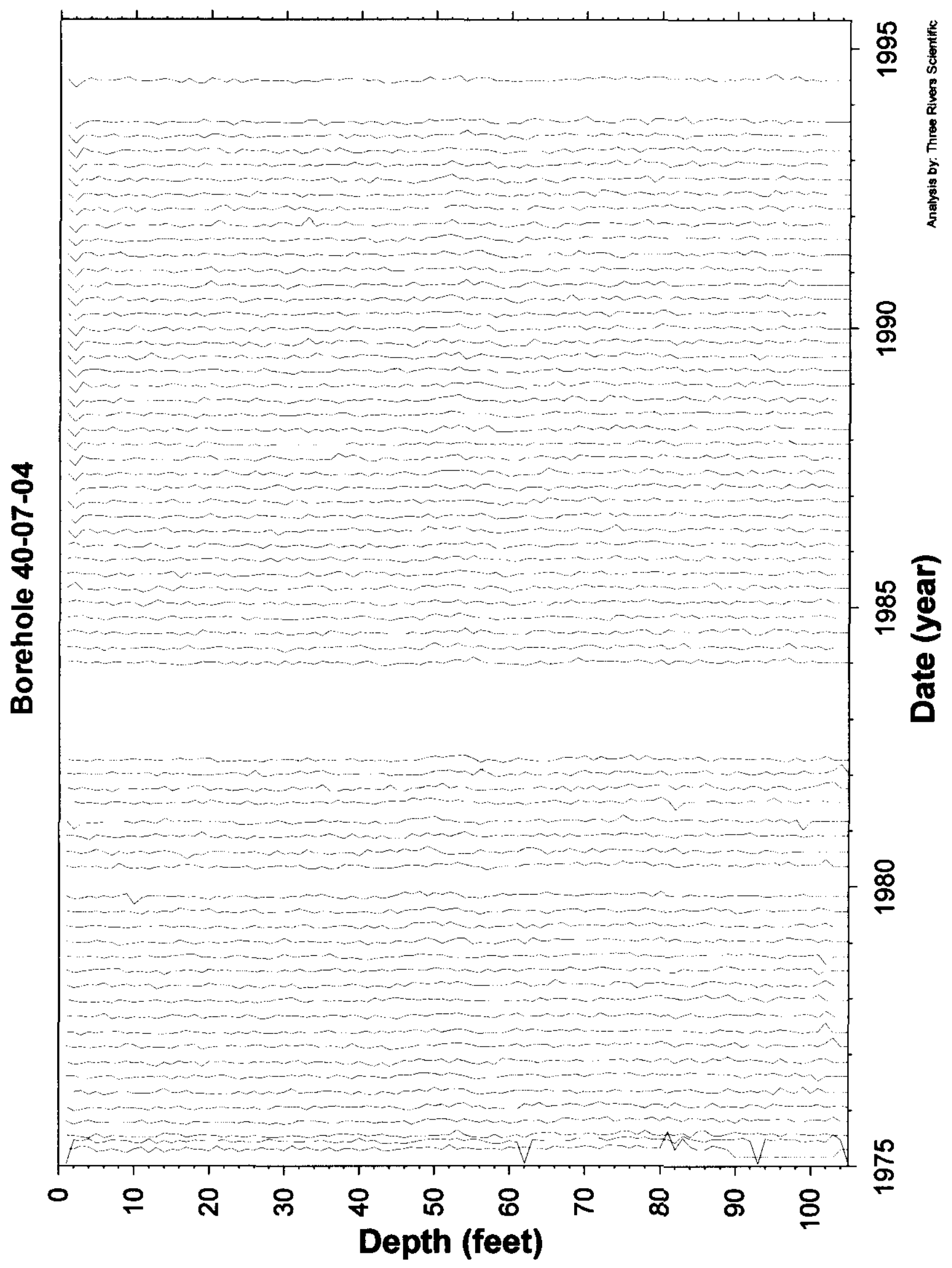




\section{Borehole 40-07-06}

\section{No Gamma Ray Emitting Contamination was Identified.}

No significant levels of gamma ray contamination are present, based upon gross gamma data, above the survey probe detection threshold between 1975 and 1995 in the vadose zone from 2 to 98 feet. The HPGe logging system detected Cs-137 at $20 \mathrm{pCi} / \mathrm{g}$ at 0 feet, but less than $1 \mathrm{pCi} / \mathrm{g}$ for the rest of the borehole.

Gross Gamma Survey Information

\begin{tabular}{|r|l|}
\hline Probe Type Processed: & $04:$ Nal \\
\hline Other Probe Types : & $03:$ Neutron \\
\hline Survey Depth : & $98 \mathrm{ft}$ \\
\hline First Survey Date : & $1 / 14 / 1975$ \\
\hline Last Survey Date : & $6 / 09 / 1994$ \\
\hline Number Surveys Processed: & 579 \\
\hline
\end{tabular}

Analysis Notes

Method Used to Compute Background : $\quad$ Threshold $0<\mathrm{val}<50$

Depth(s) where Contamination was NONE Identified in Gross Gamma Surveys :

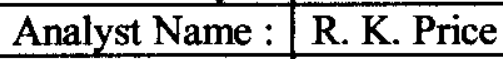

Company Name : Three Rivers Scientific 